الوحدة النفسية وفقا لمتتوى النرجسية لدى الاتفوقين دراسياً والعاديين هن طلاب كلية التزبية بماهمة الأزهر

\author{
إعـداد \\ د/ همدوع مصمود همطفى بدوي \\ مدرس الصمة النفسية \\ كلية التربية بالقاهرة - جامعة الأزهر
}


الوحدة النفسية وفقًا لمستوى النرجسية لاى المتفوقين دراسيًا والعاديين من طلاب كلية التربية بجامعة...

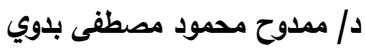

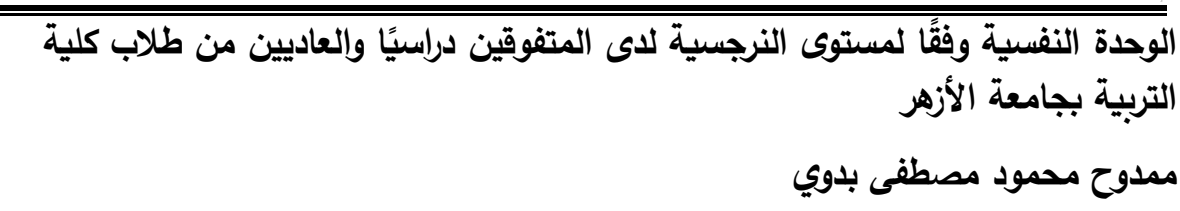
قسم الصحة النفسية، كلية التربية بالقاهرة، جامعة الأزهر ، مصر بدري mamdouhbadawy.197@azhar.edu.eg البريد الإكتروني:

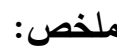

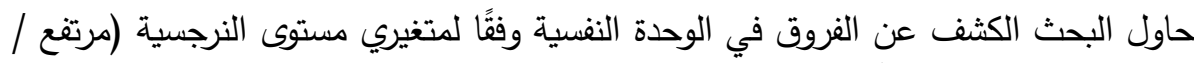

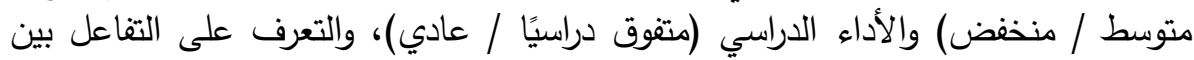

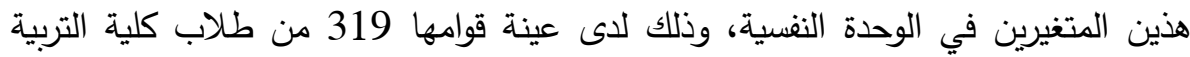

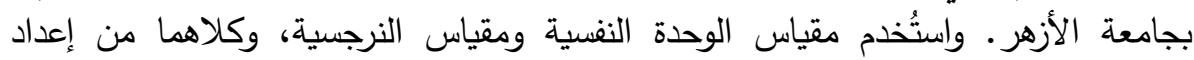

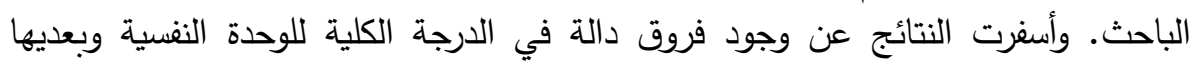

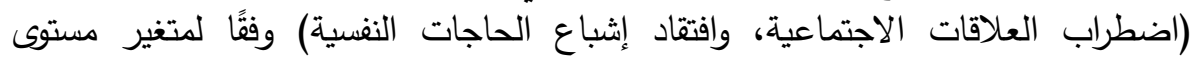

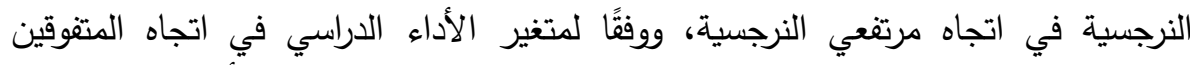

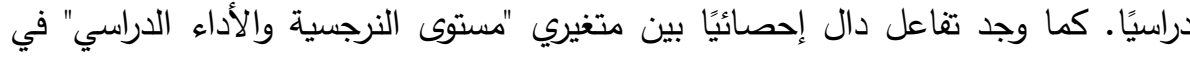

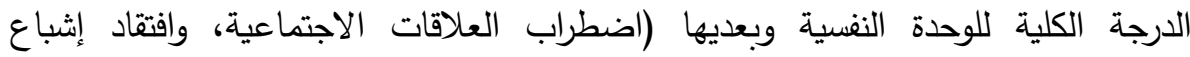

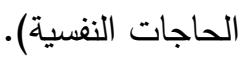

الكلمات المفتاحية: الوحدة النفسية، مستوى النرجسية، المتفوقون دراسيًا، العاديون، طلاب

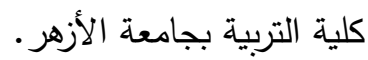


Psychological Loneliness According to Level of Narcissism among High achieving and Average Students at Faculty of Education Al-Azhar University

Mamdouh Mahmoud Mostafa Badawy

Department of Mental Health, Faculty of Education, Al-Azhar University, Eygpt.

Email: mamdouhbadawy.197@azhar.edu.eg

\begin{abstract}
:
This research attempted to identify differences in psychological loneliness according to level of narcissism (high / moderate / low) and academic performance (high achieving / average) as well as pointing out the interaction between both variables on psychological loneliness. The sample consisted of (319) students at the faculty of education Al-Azhar University. Both variables of psychological loneliness and narcissism (prepared by the researcher) were utilized. Results yielded statistically significant differences in total score and both dimensions (social relations disruption - lack of psychological needs satisfaction) of psychological loneliness according to level of narcissism (in favor of those with high levels of narcissism) and academic performance (in favor of the high achievers). Additionally, there was a statistically significant effect of interaction between both variables of level of narcissism and academic performance on total score and both dimensions (social relations disruption - lack of psychological needs satisfaction) of psychological loneliness.
\end{abstract}

Keywords: Psychological Loneliness, Level of Narcissism, High Achieving Students, Average Students, Students at Faculty of Education Al-Azhar University. 
يأتي الاهتمام بطلاب الجامعة من منطلق التأكيد على الاهتمام بالموارد البشرية

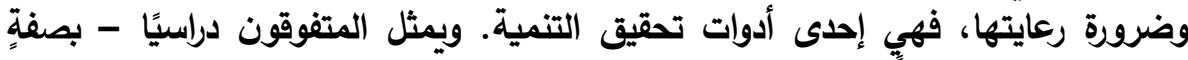

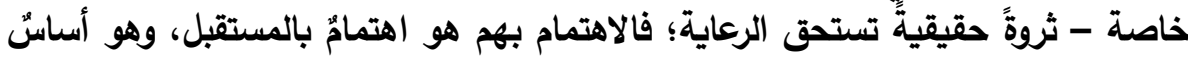

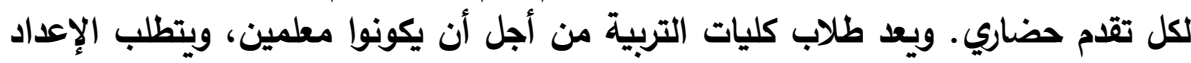

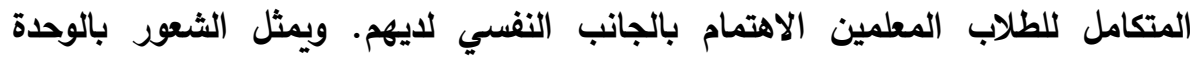

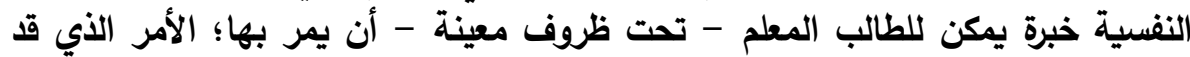
يؤثر سلبًا على جوانب شخصيته بصفة عامة لا سيما تحصيله الدراسي.

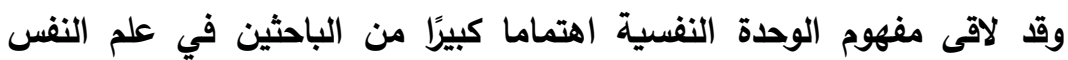

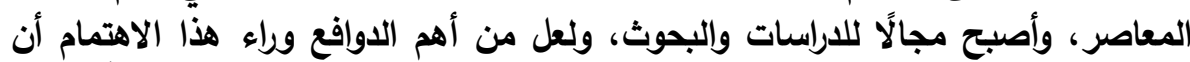

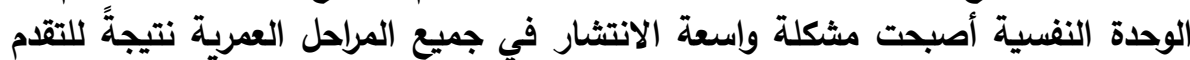

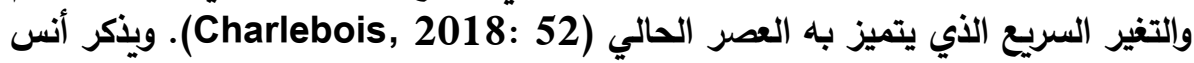

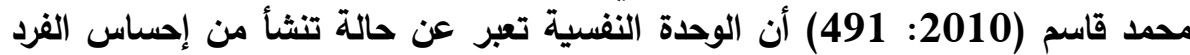

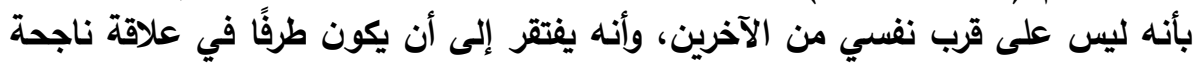

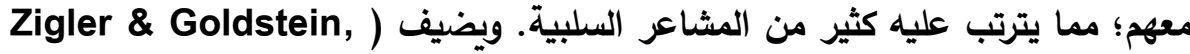

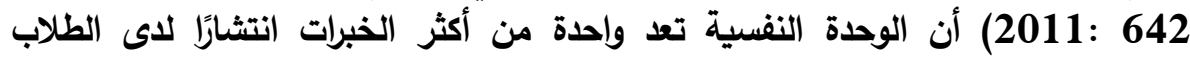

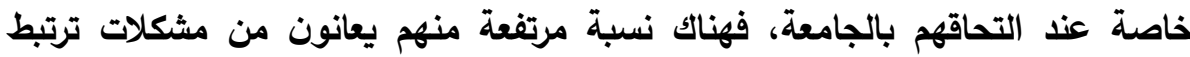

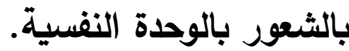

وقت يتعرض الطلاب الذين يخبرون الثعور بالوحدة النفسية لكثير من

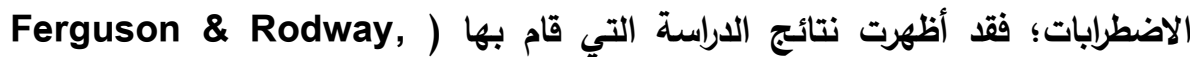

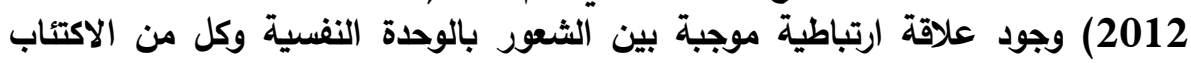

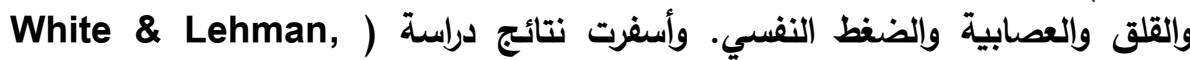
2013) عن وجود علاقة موجبة بين الثعور بالوحدة النفسية واضطرابات النوم لاى دوالى طلاب الجامعة. بينما توصلت دراسة (Robins; Beesley \& Mendozan, 2015) إلى وجود علاقة ارتباطية موجبة بين الثعور بالوحدة النفسية والأعراض السيكوسوماتية،

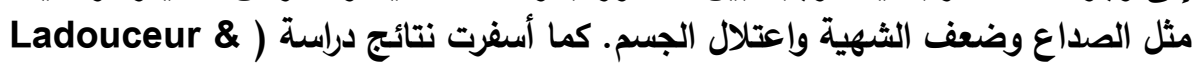

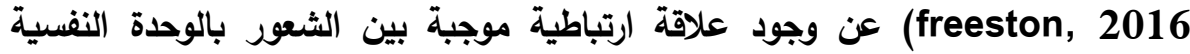
والسلوك غير السوي.

هذا بالإضافة إلى أن الثعور بالوحدة النفسية قد يؤدي إلى المشكلات الاراسية

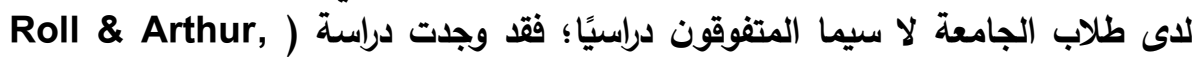


2019) علاقة ارتباطية موجبة بين الثعور بالوحدة النفسية والمشكلات الاراسية لاى طلاب الجامعة، وأثارت نتائج دراسة (Dunn \& Wayment, 2016) إلى أنى أن الوحدة الفيات

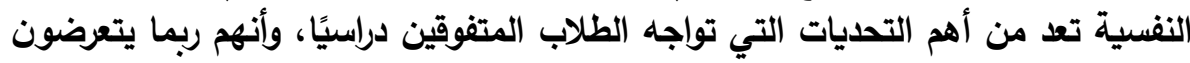

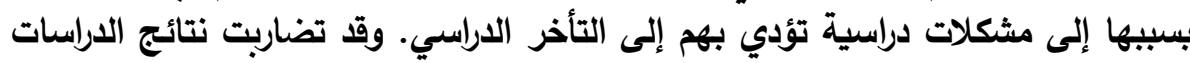

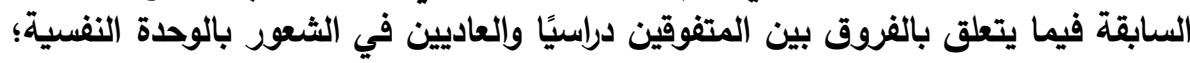

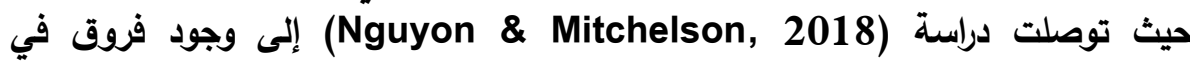
الثعور بالوحدة النفسية بين المتفوقين دراسيًا والعاديين في اتجاه المتفوقين دراسيًا. بينما

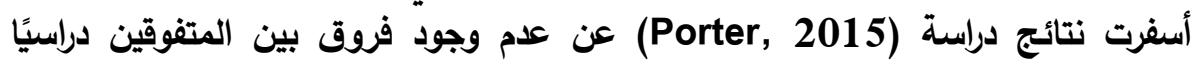
والعاديين في الثعور بالوحدة النفسية.

هذا، وتعد النرجسية واحدة من الأسباب التي قد تؤدي إلى الثعاب الثور بالوحدة

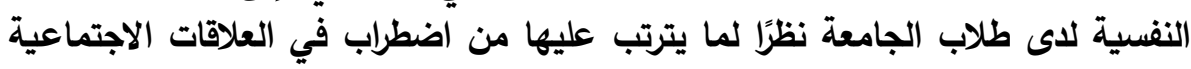

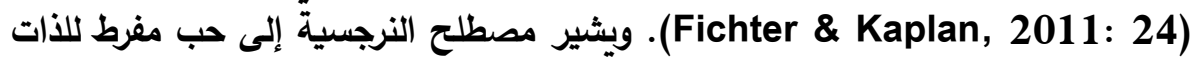

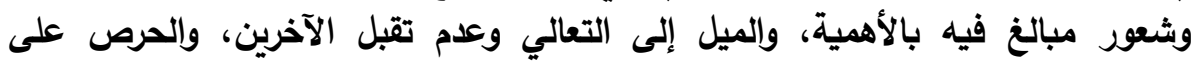

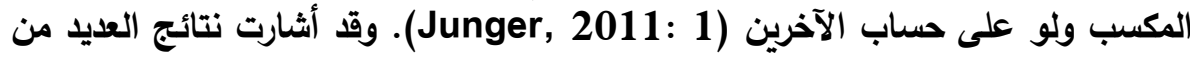

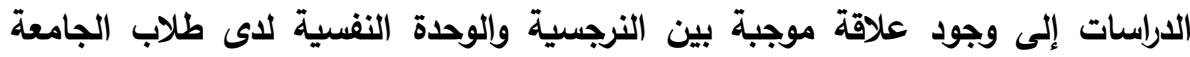
(Ames \& Pratt, 2017; Jacobs, 2019) بهاف التعرف على العلاقة بين النرجسية والوحدة الهية

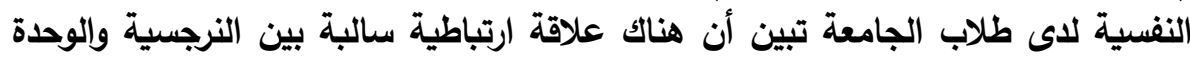

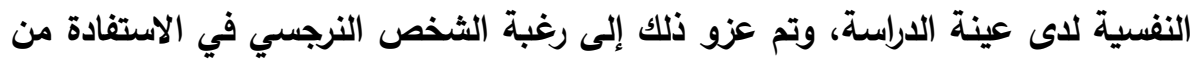

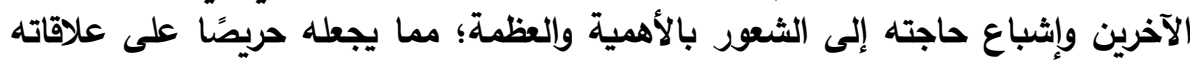

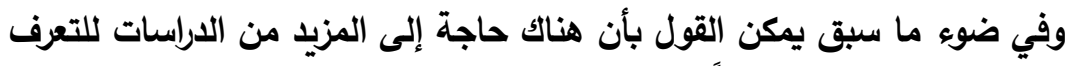

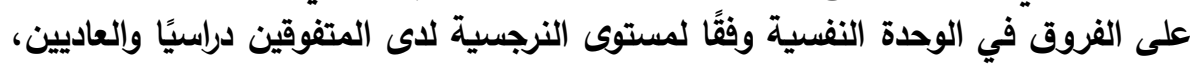
وهو ما يسعى البحث الحالي إلى استكثافه لاى طلاب كلية التربية بجامعة الأزهر .

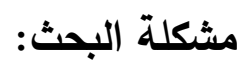

يعد الثعور بالوحدة النفسية إحدى المشكلات التي يواجهها العديد من طلاب

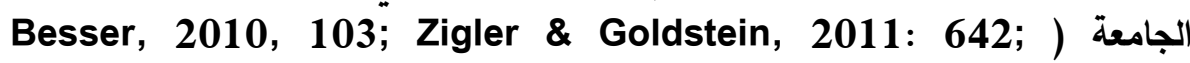
تومenneth \& Eric, 2015: 29 توصلت دراسة (Roll \& Arthur, 2019) إلى وجود علاقة موجبة بين الثعور بالوحدة

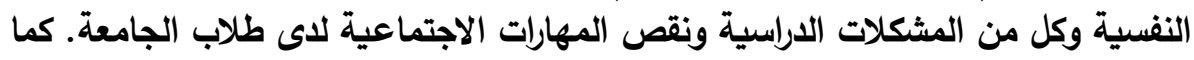


وجلت دراسة (Lakshmi, 2017: 335) أن الطلاب الذين يعانون من الوحدة النفسية

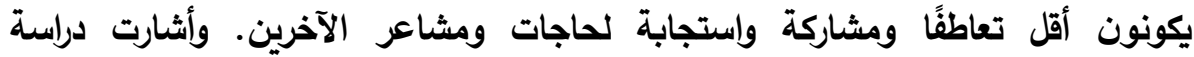
(Mansi \& Paulomi, 2016: 81)

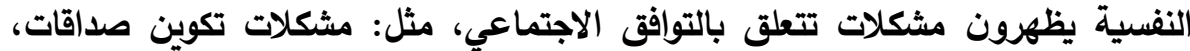

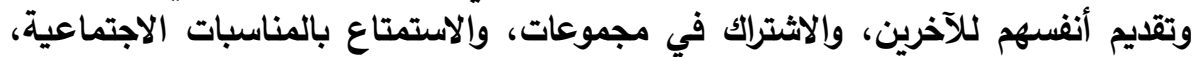

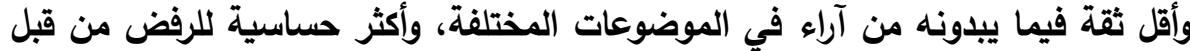
الآخرين.

ونظرًا لانتشار الشعور بالوحدة النفسية لاى طلاب الجامعة فقد اهتم الباحثون

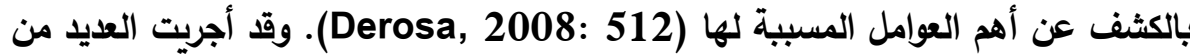
الاراسات للكثف عن العلاقة بين الوحدة النفسية والنرجسية لاى طلاب الجاب الجامعة انطلاقًا

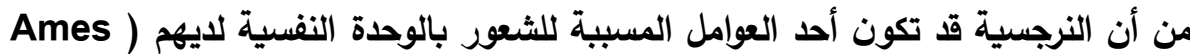
\& Pratt, 2017; Jacobs, 2019; Peeters \& Thisted, 2019

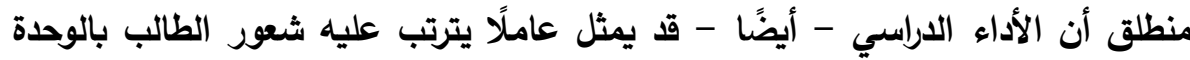

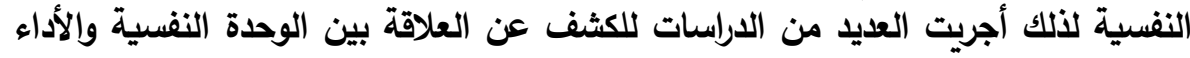
الاراسي لاى طلاب الجامعة (Porter, 2015; Nguyon \& Mitchelson, 2018). غير أنه بمراجعة العديد من هذه الدراسات تبين تضارب نتائجها على النحو الذي سبق النيق

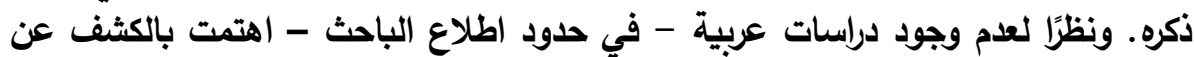

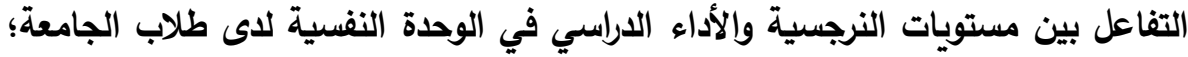

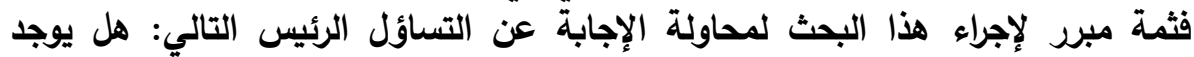

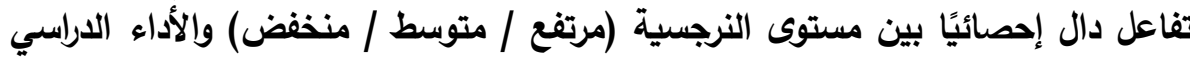
(متفوق دراسيًا / عادي) في الوحدة النفسية لاى طلاب كلية التربية بجامعة الأزهر؟ ويتفرع عن هذا التساؤل الرئيس التساؤلات الفرعية التالية:

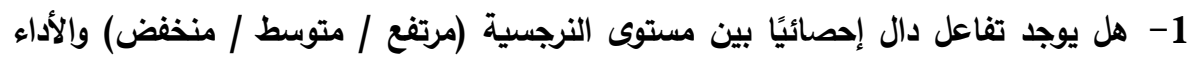

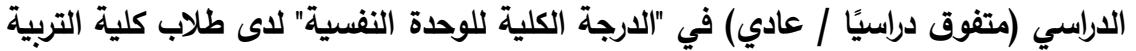
بجامعة الأزهر؟

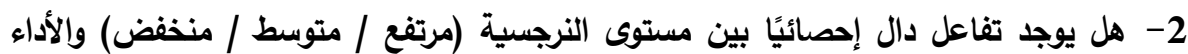

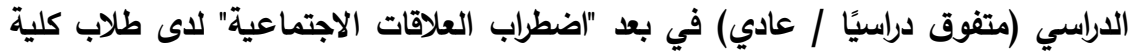

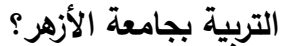
3- هل يوجد تفاعل دال إحصائيًا بين مستوى النرجسية (مرتفع / متوسط / منخفض) والأداء

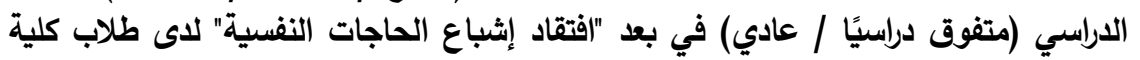
التربية بجامعة الأزهر؟ 
يهاف البحث الحالي إلى الكثف عن الفروق في الوحدة النفسية ببعديها (اضطراب

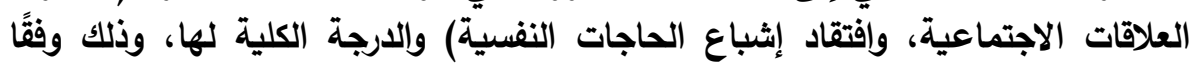

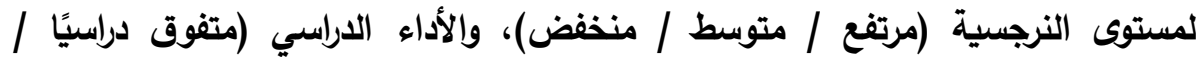

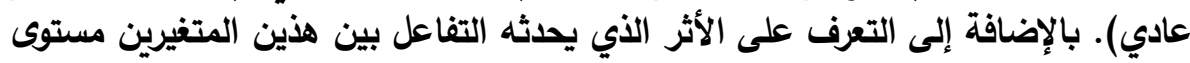

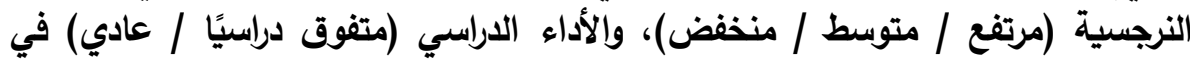

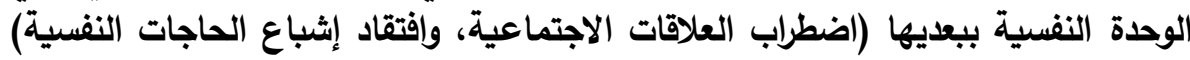
والدرجة الكلية لها لاى طلاب كلية التربية بجامعة الأزهر .

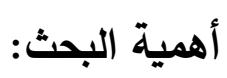

تكمن أهمية هذا البحث فيما يقدمه من إطار نظري لمتفيري "الوحدة النفسية"

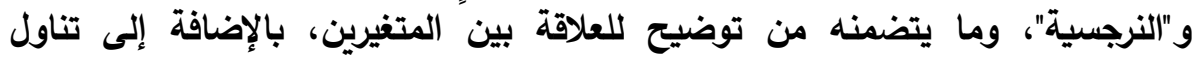

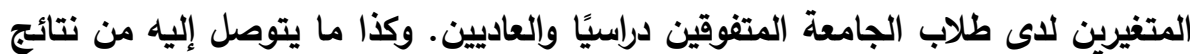

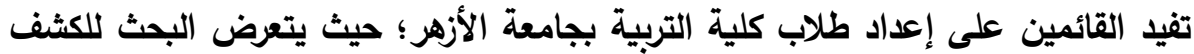

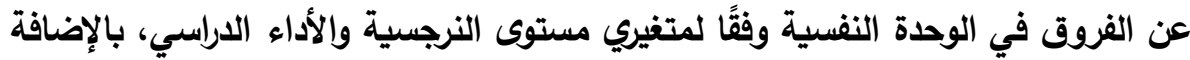

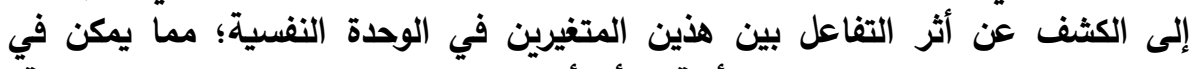

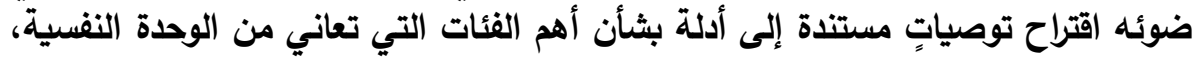
والتي ينبغي أن توجه إليها البرامج الإرشادية.

$$
\text { مصطاحات البحث: مصن }
$$

بناء على الإطار النظري يمكن عرض مصطات البحث كما يلي: • الوحدة النفسية: حالة يثعر فيها الفرد بضعف القدرة على الاندماج مع الآخرين،

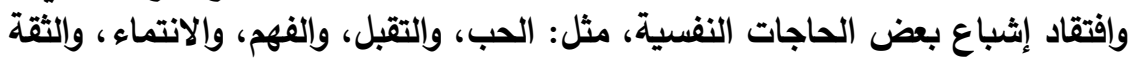

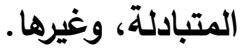

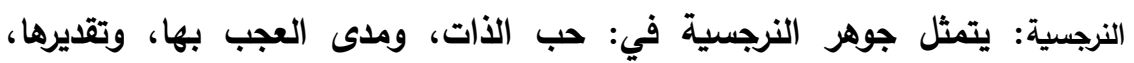
والثعور بأهميتها، والحساسية لنقا الآخرين. وهي ذات ثلاثلة مستويات: 
الوحدة النفسية وفقًا لمستوى النرجسية لاى المتفوقين دراسيًا والعاديين من طلاب كلية التربية بجامعة...

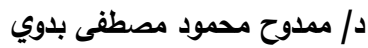

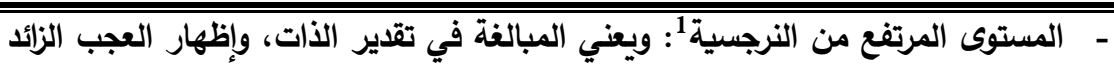

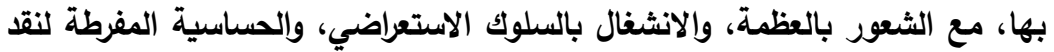

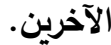

- المستوى المتوسط من النرجسية: ويقصد به تقبل الأات، والتقدير المعتدل لها، وعدم المبام

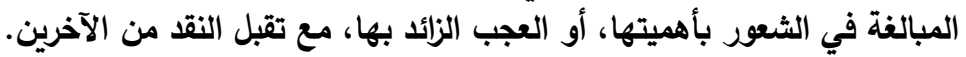

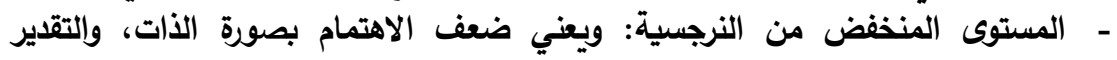
المنذفض لها، الذي قد يصل إلى عدم الرضا عنها، بالإضافة إلى اللامبالاة بنقد الآخرين.

الطلاب المتفوقون دراسيًا: وهم الطلاب مرتفعو التحصيل الدراسي، وقد تم تحديدهم

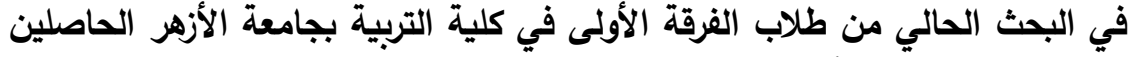

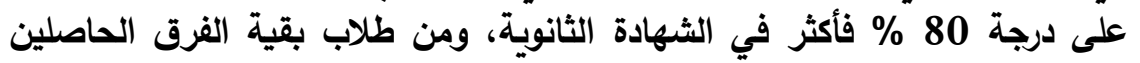

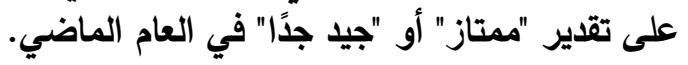

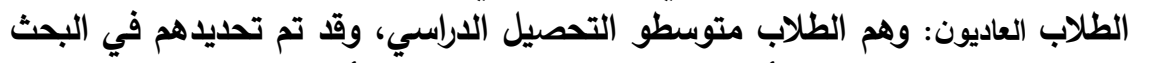

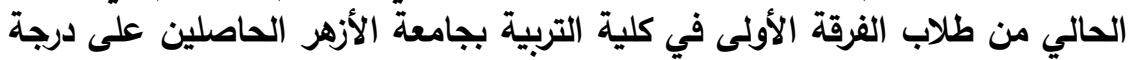

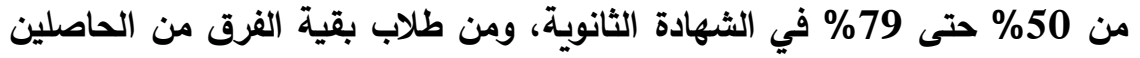
على تقدير "جيد" أو "مقبول" في العام الماضي.

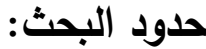

• حدود بثرية: تتحدد في المشاركين في البحث من طلاب كلية التربية بالقاهرة - جامعة

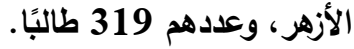

حدود مكانية: تتحدد في المكان الذي تم تمالبًان تطبيق أدوات البحث فيه، وهو قاعات كلية التربية بالقاهرة - جامعة الأزهر.

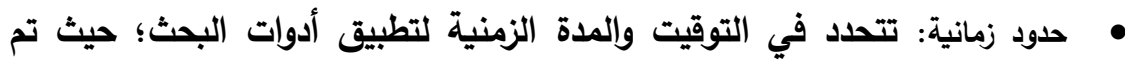

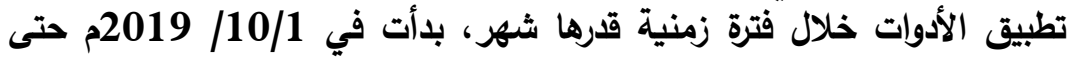
2019/10/30

1 عندما يرد ذكر مصطلح "النرجسي" أو النرجسيين" مطلقًا دون الثقييد بوصف فإنه يكون المر اد به ذوي المسنوى المرتفع من النرجسية. 
تعددت وجهات نظرت الباحثين حول مفهوم الوحدة النفسية نظرًا للحداثة النسبية

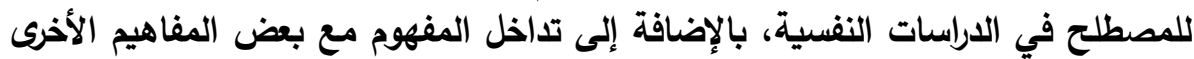

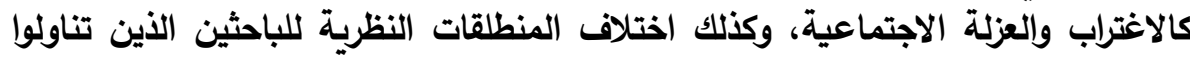

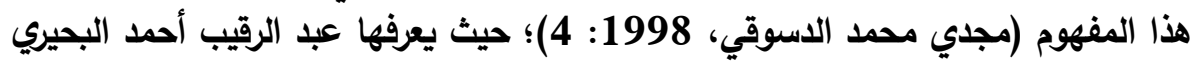

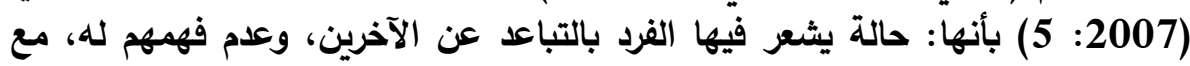

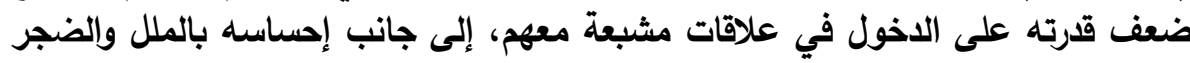

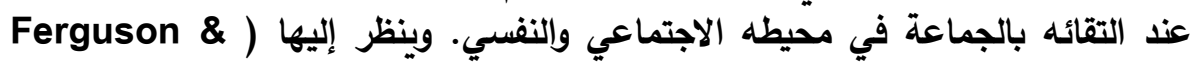
(Rodway, 2012: 158

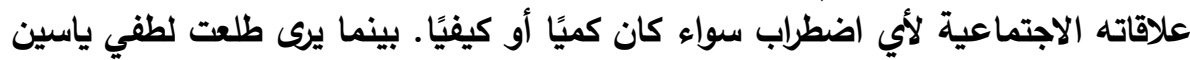

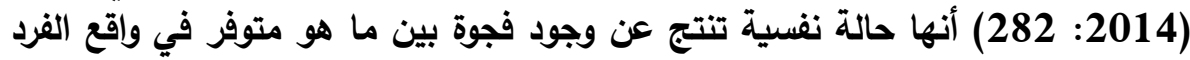

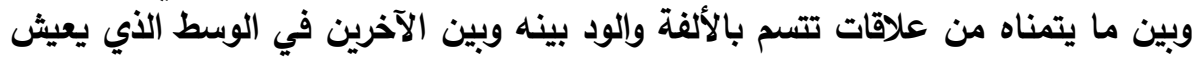

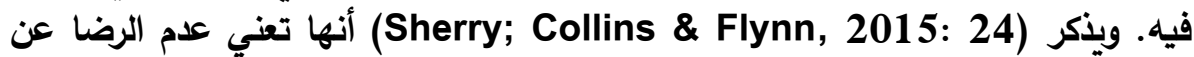

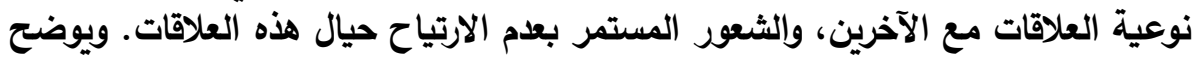

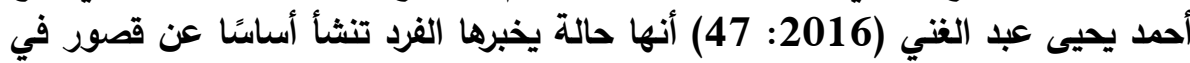

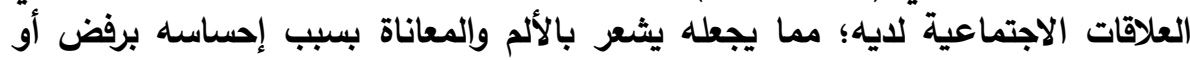

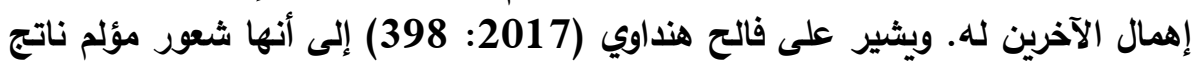

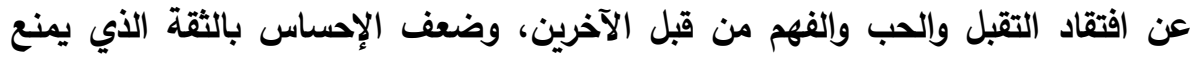

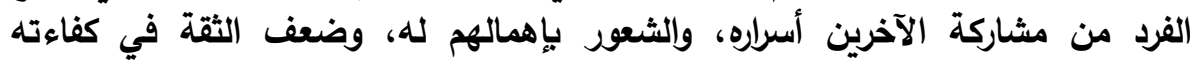

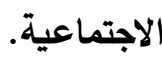
وهناك العديد من المفاهيم المرتبطة بالوحدة النفسية، مثل العزلة الاجتماعية،

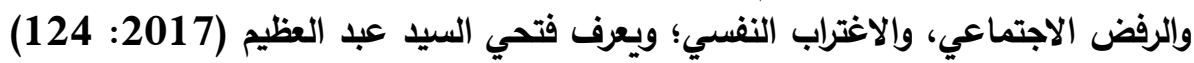

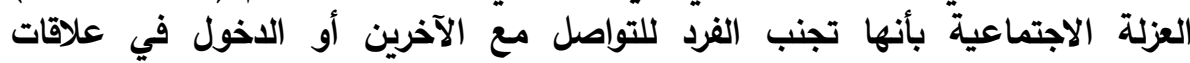

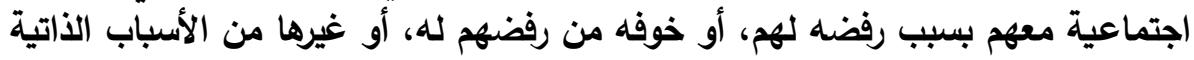

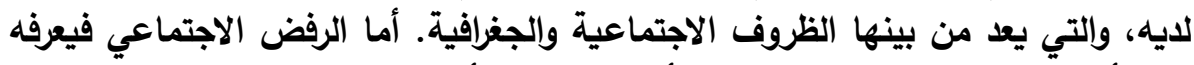

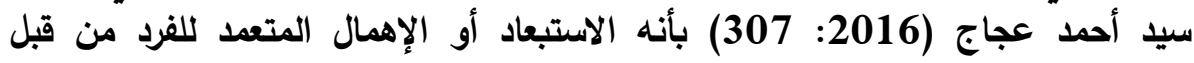

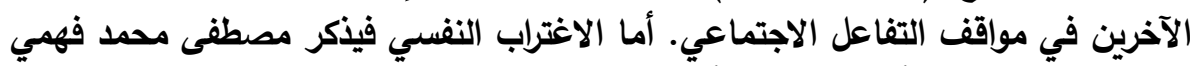

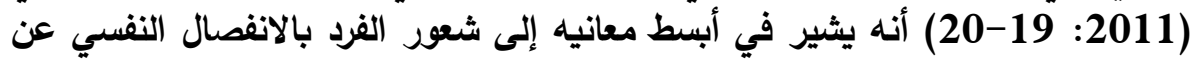

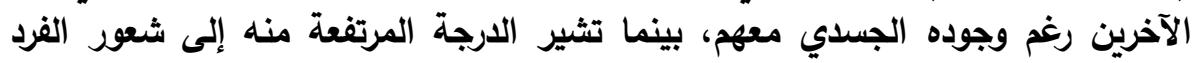


الوحدة النفسية وفقًا لمستوى النرجسية لاى المتفوقين دراسيًا والعاديين من طلاب كلية التربية بجامعة...

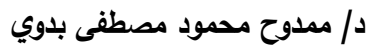

بانفصال ذاته عن هويتها أو عن واقع المجتمع الذي يعيش فيه، ومن مظاهره السخط براي وكراهية الآخرين واحتقار الأات. وفي ضوء ما سبق يمكن استخلاص ما يلي:

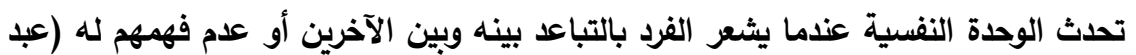

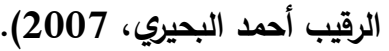

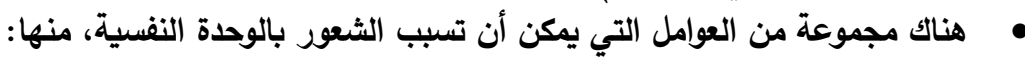

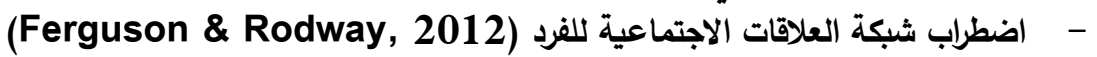
- - مجود فجوة بين ما هو متوفر في واقع الفرد وبين ما يتمناه من علاقات (طلعت لطفي

$$
\text { ياسين، 2014). }
$$

- - القصور في العلاقات الاجتماعية للفرد (أحمد يحيى عبد الغني، 2014) - 2016).

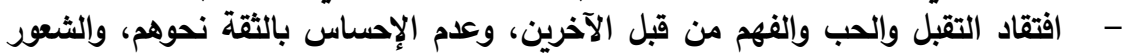

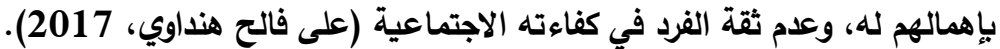

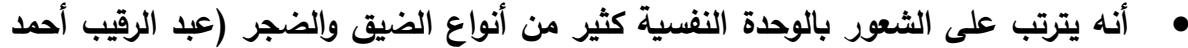
البحيري، 2007)، والثشعور بالألم والمعاناة (أحمد يحيى عبد الغني، 2016).

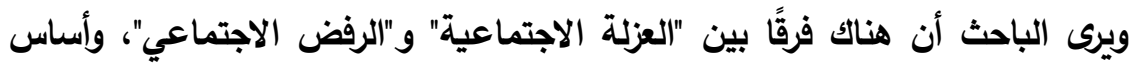

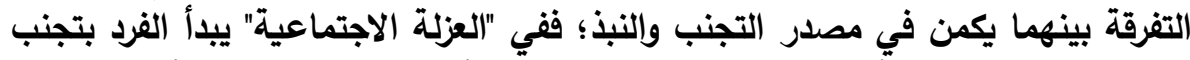

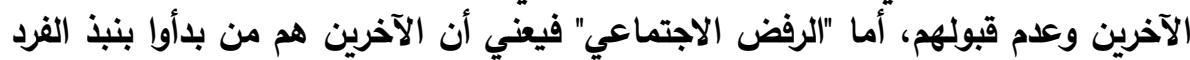

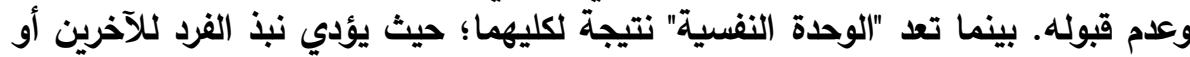

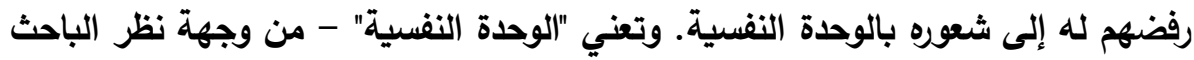

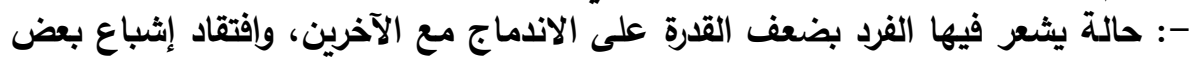

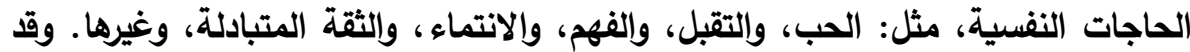

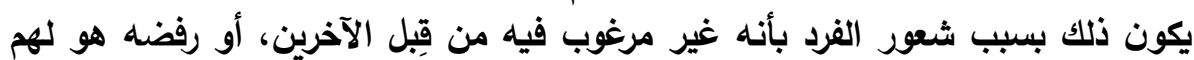

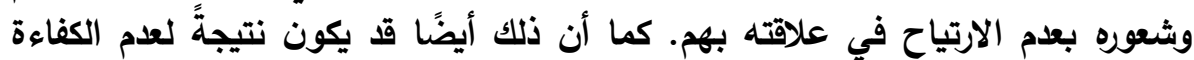

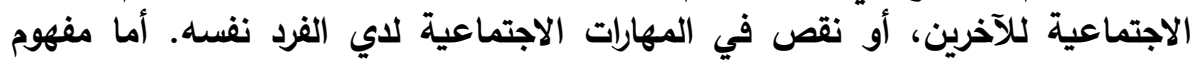

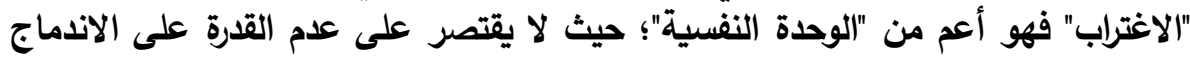

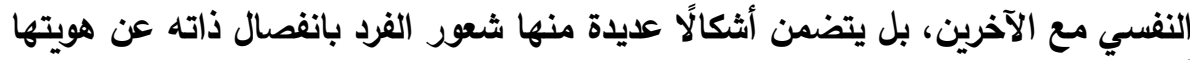
أو عن واقع المجتمع الذي يعيش فيه.

وقد تعدت وجهات النظر المفسرة للوحدة النفسية؛ حيث يرى سيجموند فرويد

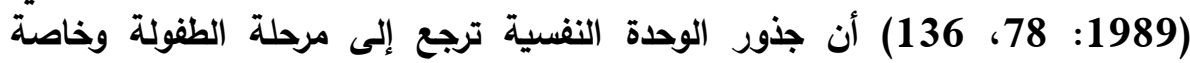

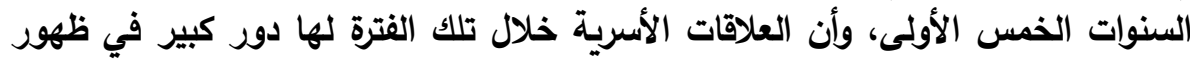

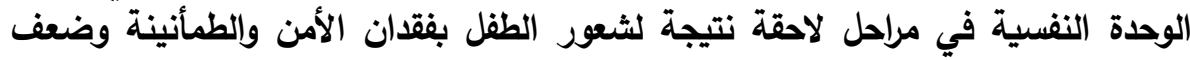
العلاقات، كما أن الثعور بالوحدة النفسية يكون نتيجة للقلق العصابي الطفولي الناتج 


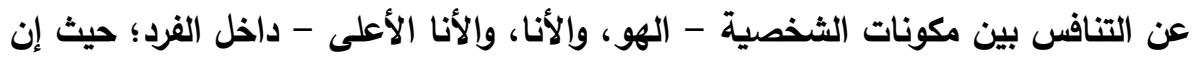

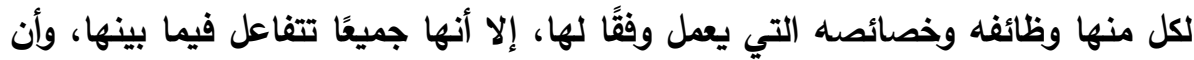

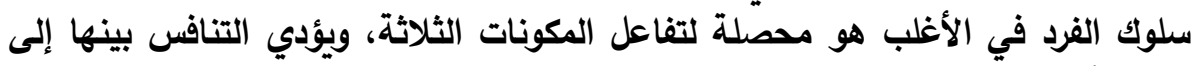

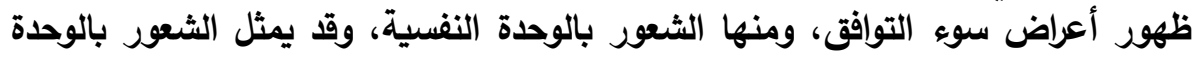

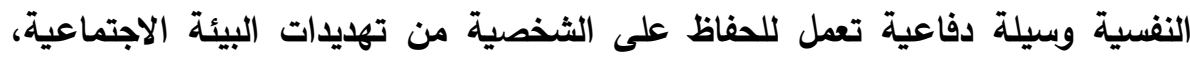

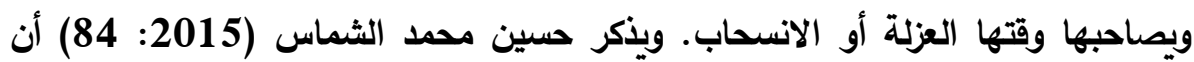

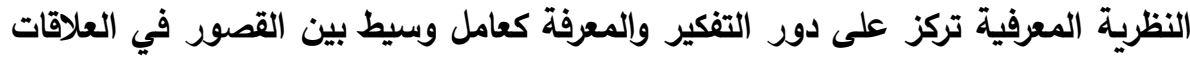

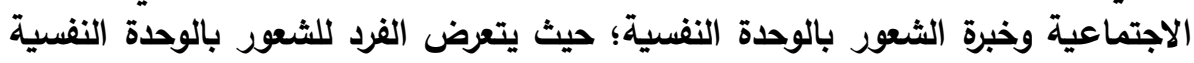

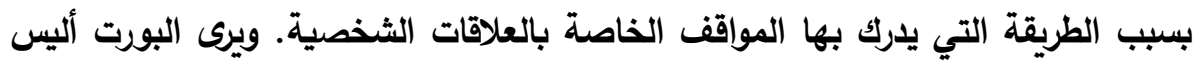

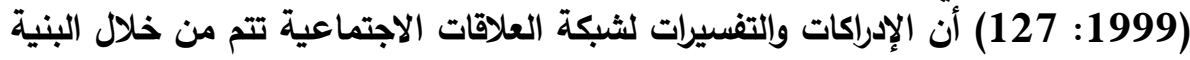

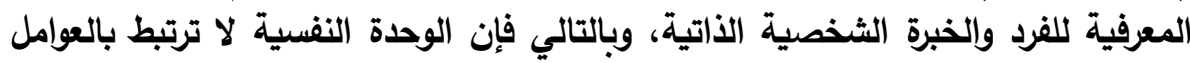

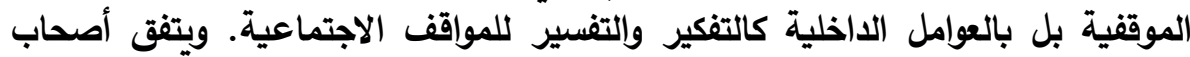

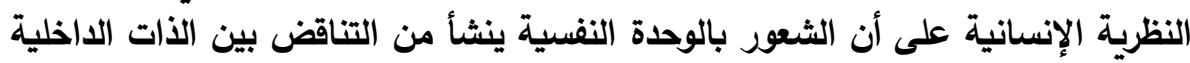

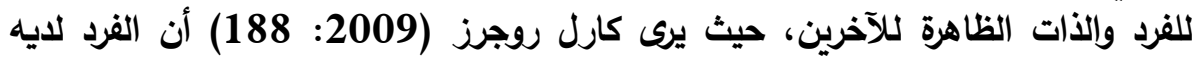

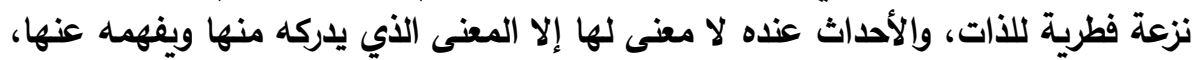

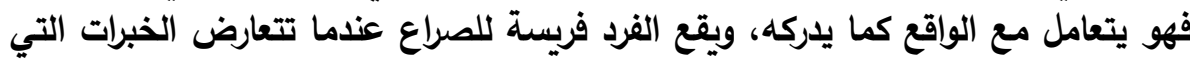

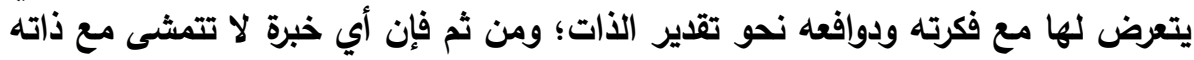

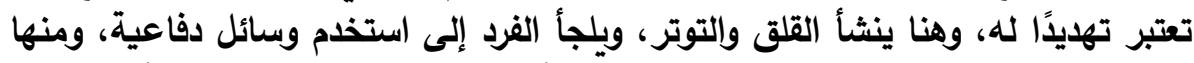

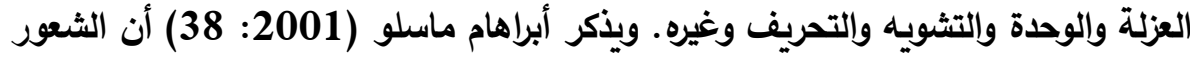

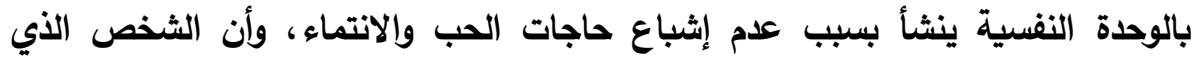

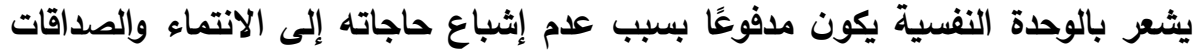

وفي ضوء ما سبق يمكن القول إن التوجهات النظرية السابقة تتكامل في

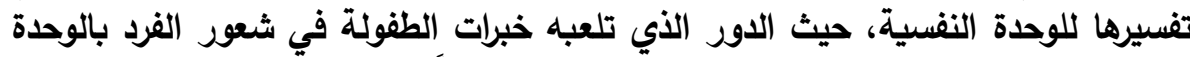

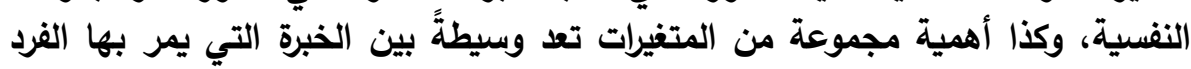

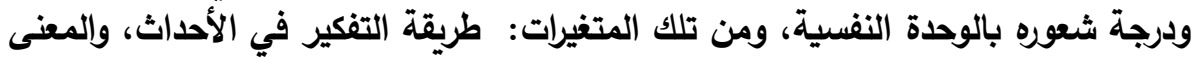

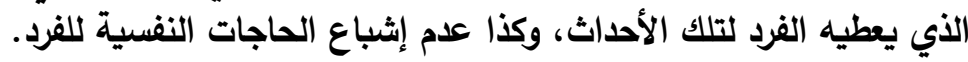

الوحدة النفسية لاى طلاب الجامعة المتفوقين دراسيًا والعاديين:

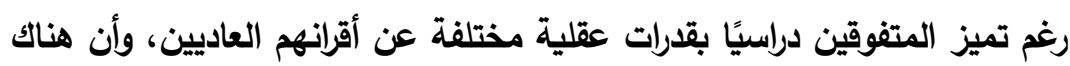

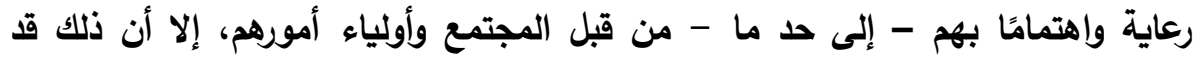

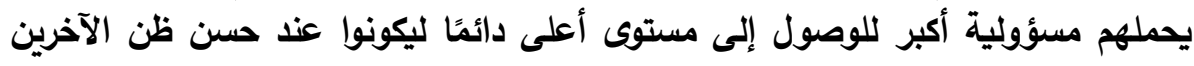




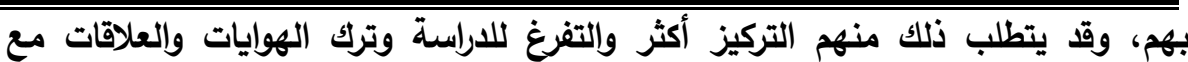

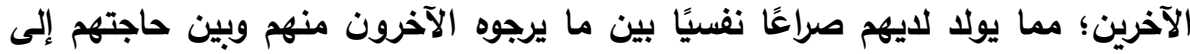

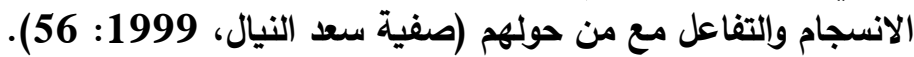

وقد توصلت نتائج دراسة (Nguyon \& Mitchelson, 2018) إلى وجود

فروق ببين المتفوقين دراسيًا وإلعاديين في الوحد النفية في اتجاه التهاه المتفوقين دراسيًا. كما

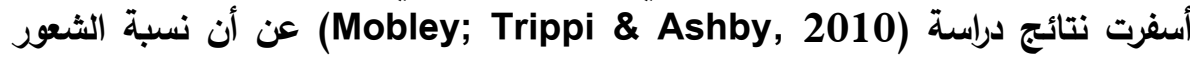

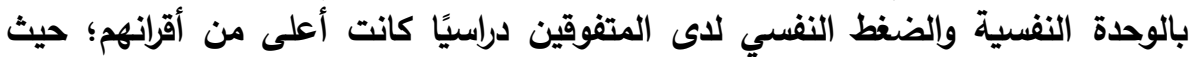

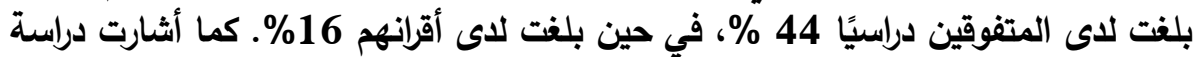
(Dunn \& Wayment, 2016)

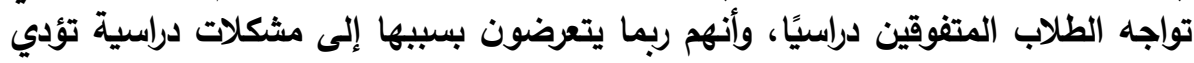

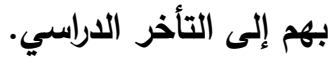

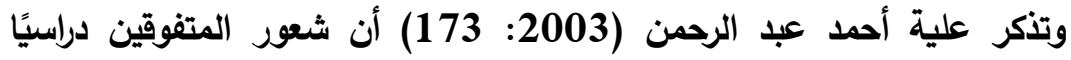

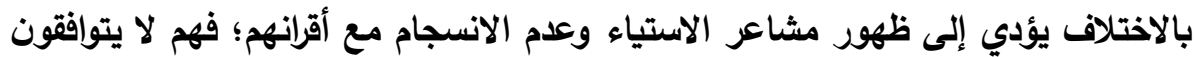

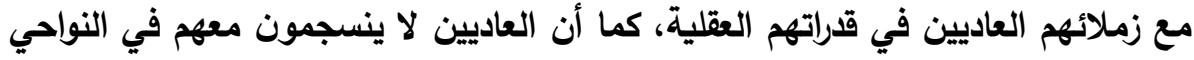

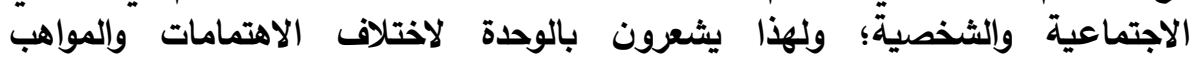

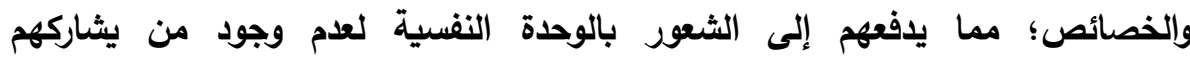

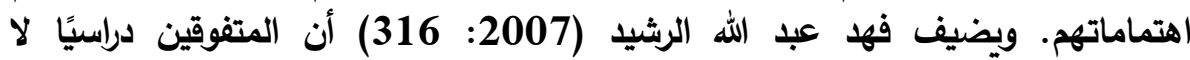

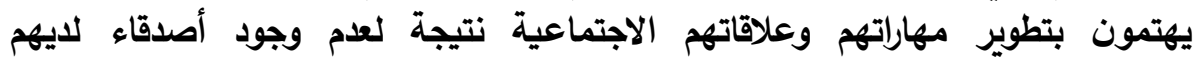

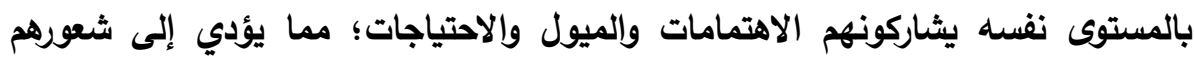
بالوحدة النفسية.

وكلما زاد العمر العقلي ومستوى الذكاء لاى المتفوقين دراسيًا اتسعت الهوة بينهم

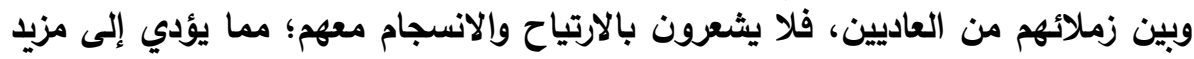

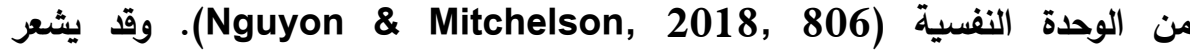
المتفوقون دراسيا بالاضطراب النفسي نتيجة للمسميات التي يتم إلصاقها بهم؛ فقفد أشارت

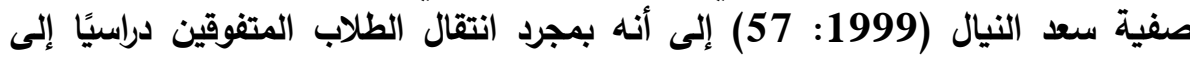

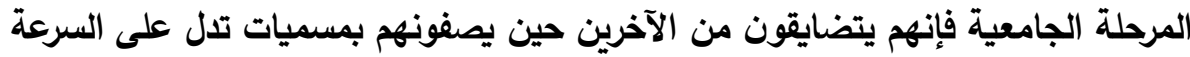

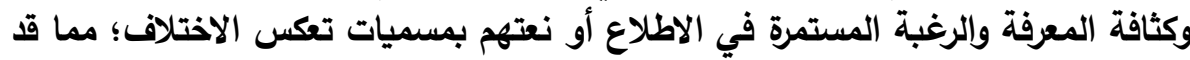

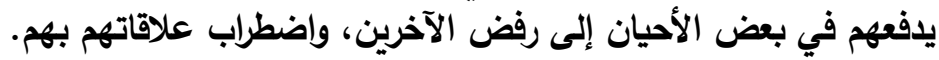

كما يرجع الثعور بالوحدة النفسية لاى المتفوقين دراسيًا إلى الاضطراب العاطفي

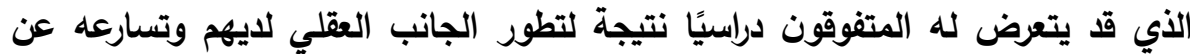


الجانب العاطفي؛ وبالتالي عدم وجود توازن بين النمو العقلي والنمو العاطفي (فهر عبد النائ الله الرشيد، 2007: 318). وقد تظهر مثاعر الاستياء والغضب لانى المتفوقين دراسيًا

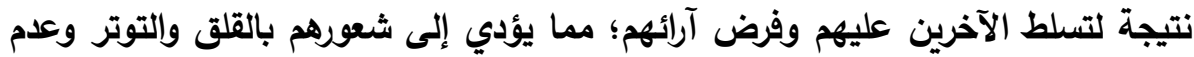

الرضا عن علاقاتهم بالآخرين (Mobley et al, 2010: 51)

ورغم أن العديد من الدراسات - التي سبقت الإثارة إليها - أثشارت إلى وجود

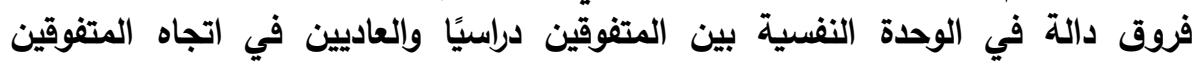

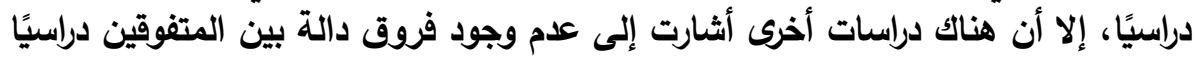

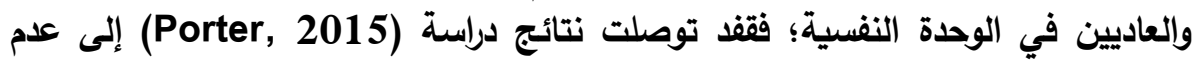

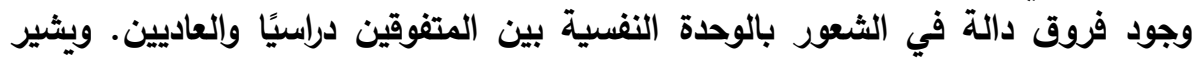
(Derosa, 2008: 534) على عامل الأداء الاراسي فقط.

ومن ناحية أخرى يذكر ماهر صالح العرجان (2015: 24) أن أن المتفوقين دراسيًا

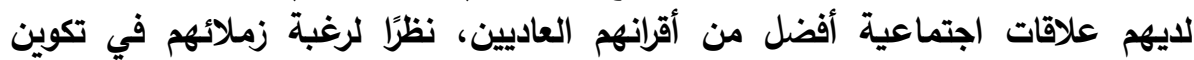

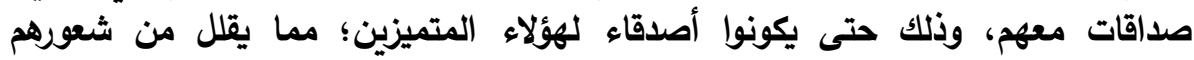

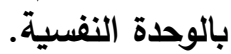

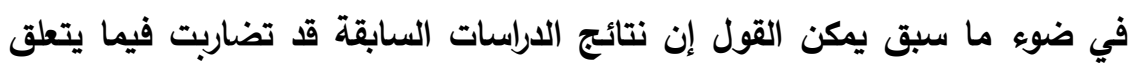
بالفروق في الوحدة النفسية بين المتفوقين دراسيًا والعاديين على النحو التالي:

- أن المتفوقين دراسيًا أكثر عرضة للشعور بالوحدة النفسية من زملائهم العاديين Mobley et al, 2010; Nguyon \& Mitchelson, 2018) لأسباب عديدة، منها: اضطراب علاقاتهم الاجتماعية نتيجة للمسميات التي يتم إلصاقها

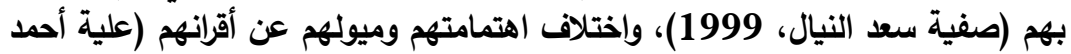

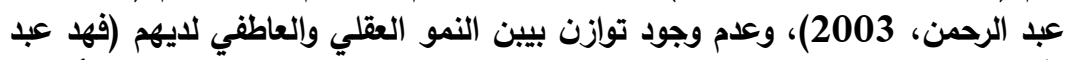

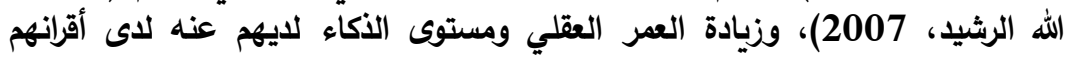
.(Nguyon \& Mitchelson, 2018) (Porter, 2015)؛ وذلك لأن الوحدة النفسية تتعدد مسبباتها، ولا يمكن اقتصارها على الأداء الدارسي (Derosa, 2008). أن المتفوقين دراسيًا أقل شعولًا بالوحدة النفسية من زملائهم العاديين؛ لما لايهم من

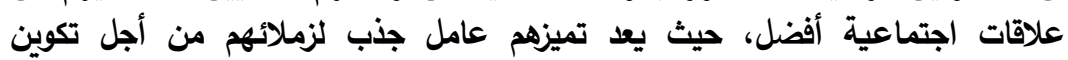
صداقات معهم (ماهر صالح العرجان، 2015). 
وتجدر الإثارة إلى أن تضارب آراء الباحثين حول الفروق في الوحدة النفسية بين

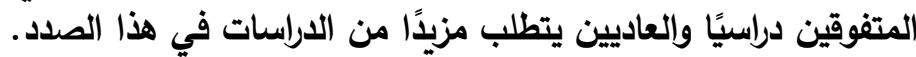

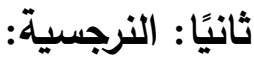

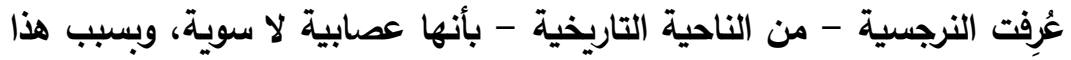

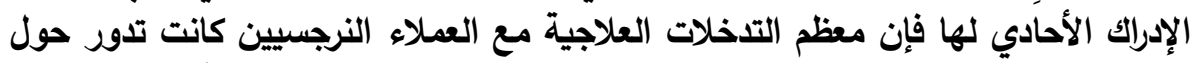

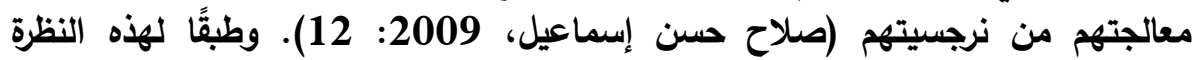

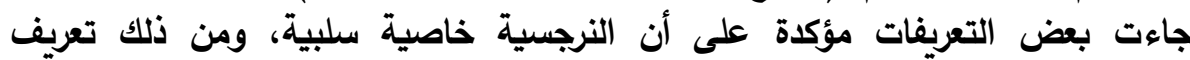
(Danese \& Caspi, 1999:7)

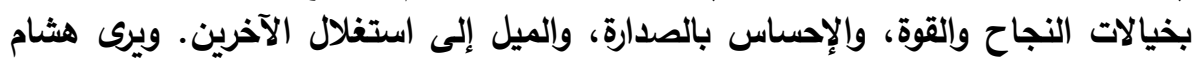

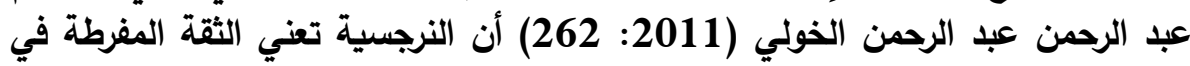

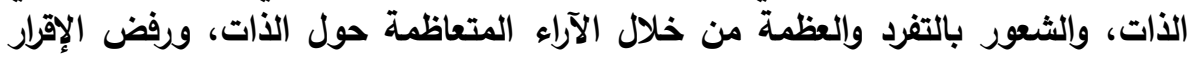

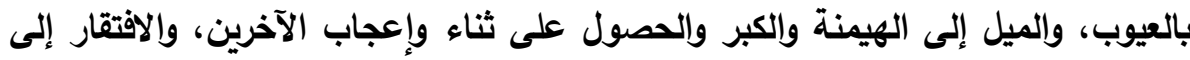

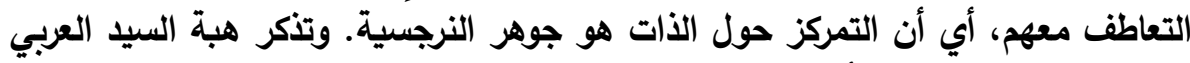

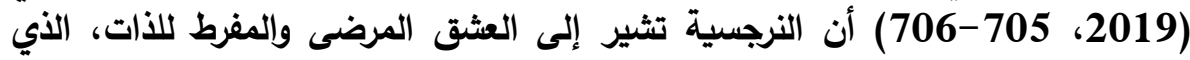

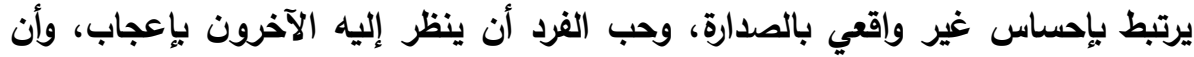

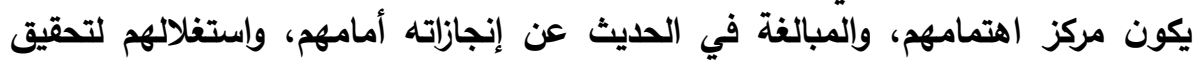
مآربه الشخصية.

واهتم بعض الباحثين بموضوع النرجسية، وواصلوا البحث حول ماهيتها

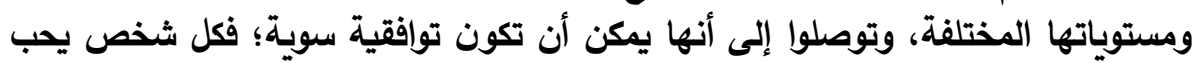

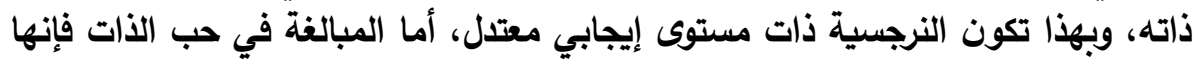

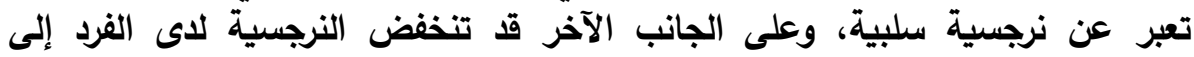

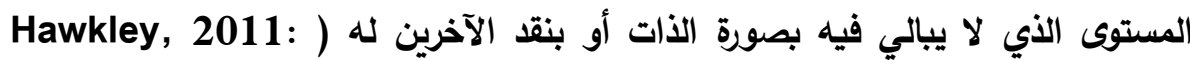

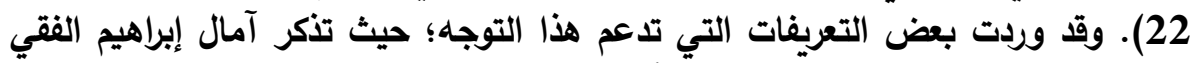

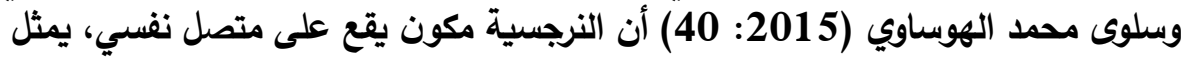

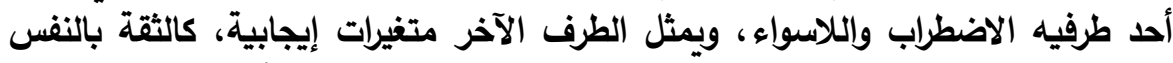

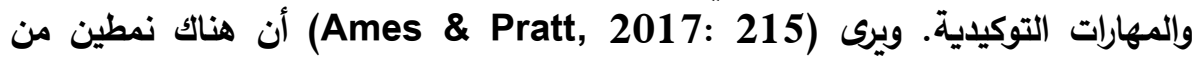

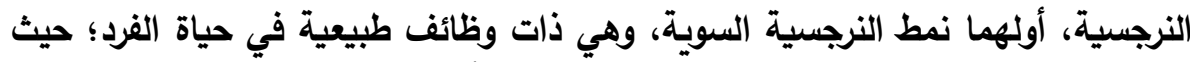

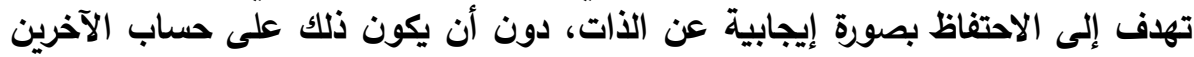

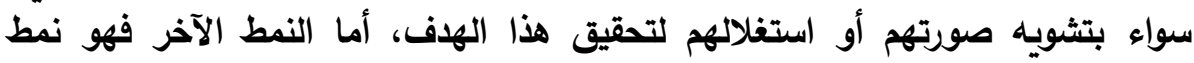

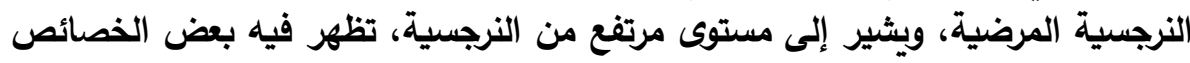

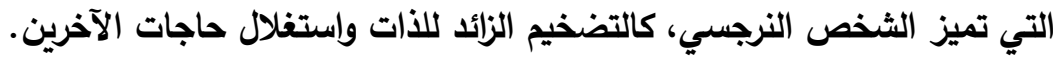


وقارن (-84-83) بين النرجسية السوية والنرجسية

$$
\text { المرضية في ضوء مجموعة من المعايير، منها: }
$$

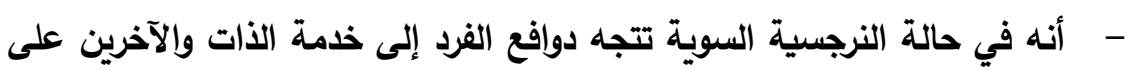

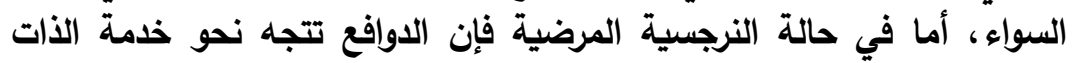

$$
\text { فقط. }
$$

- - أن النرجسيين الأسوياء يرتبط تقييمه لذواتهم بالواقع والقدرات الثخصية

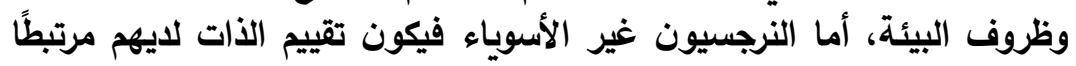

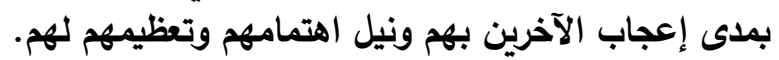

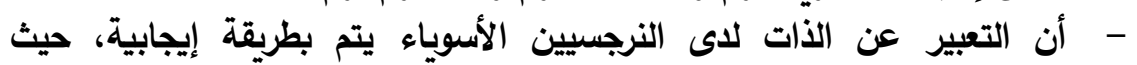

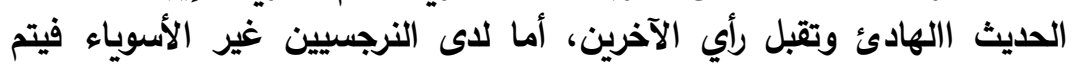

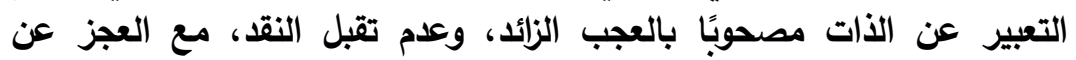

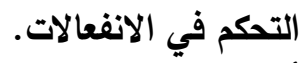
- أنه تنتشر لاى النرجسيين الأسوياء المشاعر الإيجابية مثل حب الآخرين

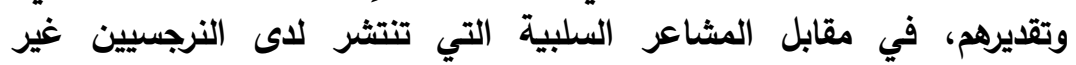

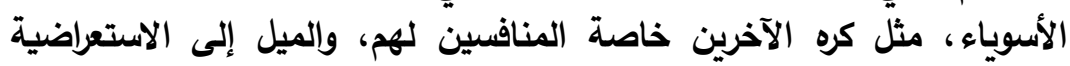

$$
\text { والاستغلالية. }
$$

بينما يذكر (Wintre, 2013: 526) أن مصطلح "النرجسية" عندما يطلق فإنه يراد

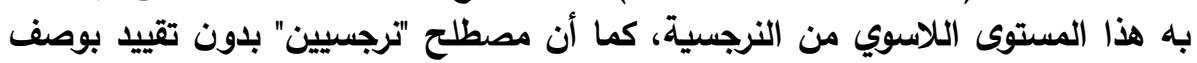

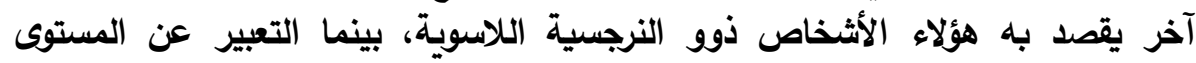

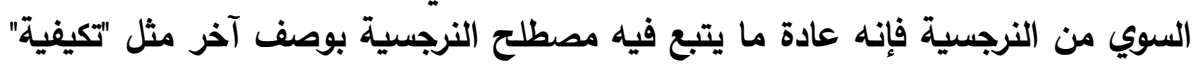

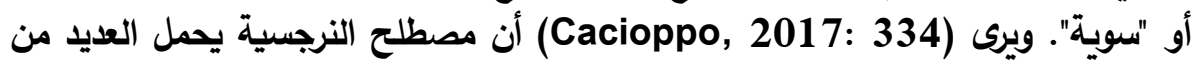

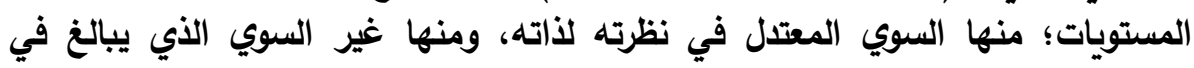

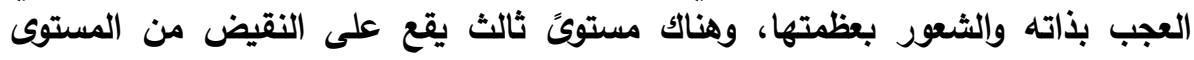

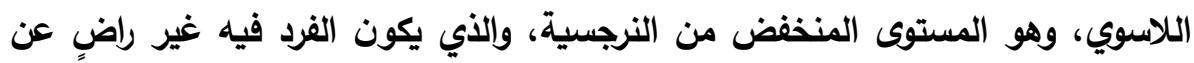

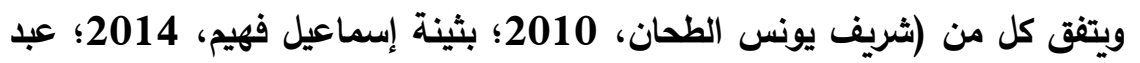

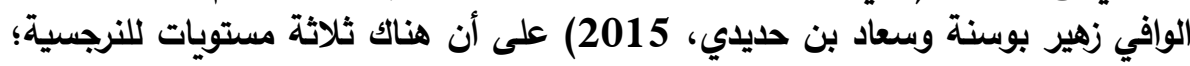

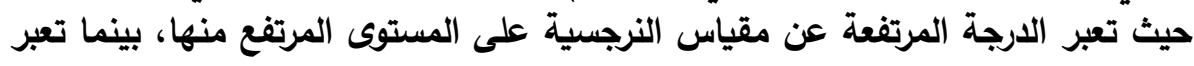

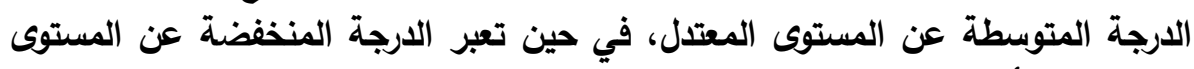

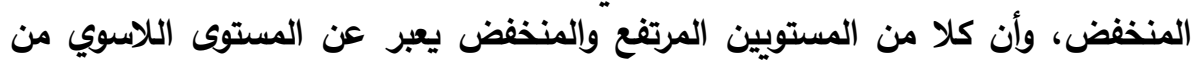


الوحدة النفسية وفقًا لمستوى النرجسية لاى المتفوقين دراسيًا والعاديين من طلاب كلية التربية بجامعة...

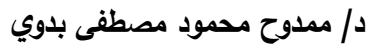

النرجسية.

وهناك عدة خصائص لذوي النرجسية اللاسوية (مرتفعي النرجسية) منها:

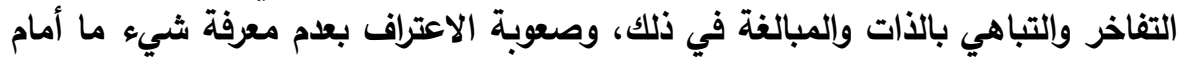

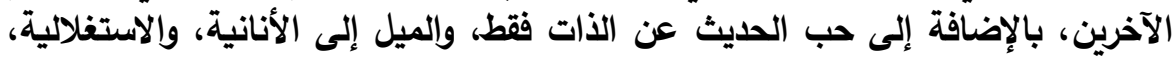

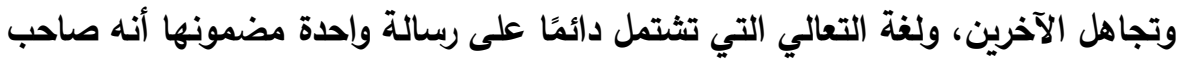

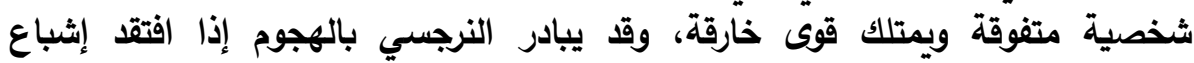
Bushman; Bonacci \& Baumeister, 2003: ) الحاجات النرجسية ممن حولية ولئل عالمي فائ 756

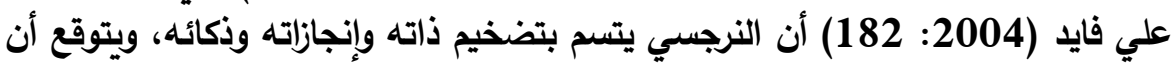

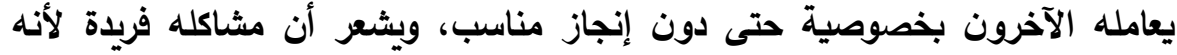

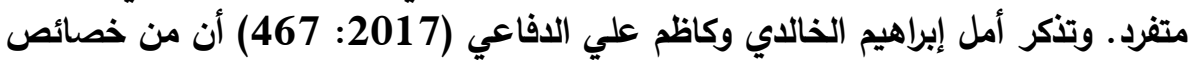

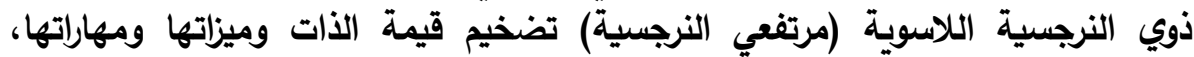

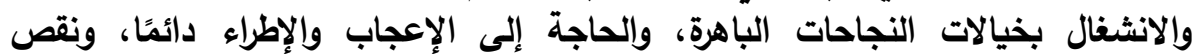

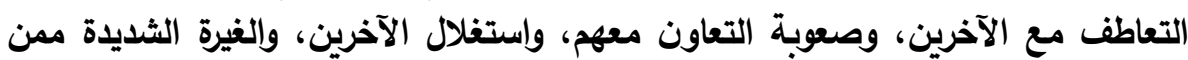
يتنافسون معه، وإعتقاد أن الآخرين يغارون منه، وعدم تقبل النقد.

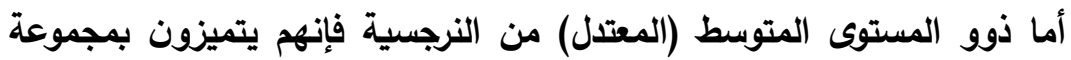

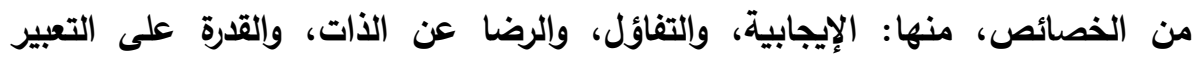

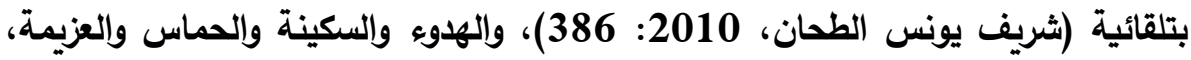

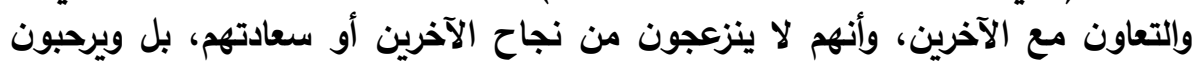

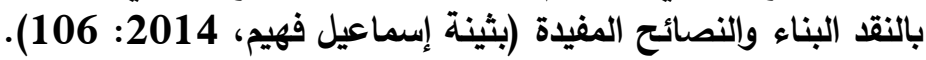

بينما يتسم ذوو المستوى المنخفض من النرجسية بمجموعة من الخصائص،

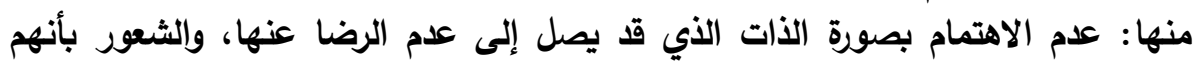

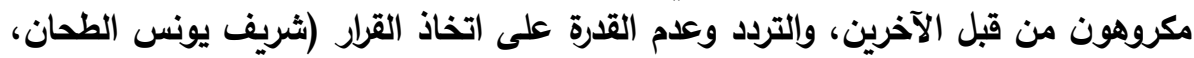

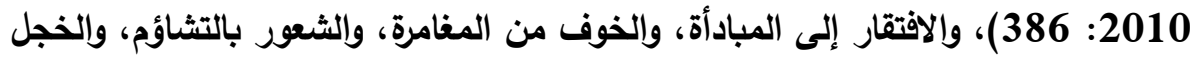

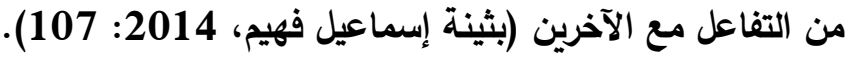
مما سبق يمكن استخلاص ما يلي: أن النرجسية مفهوم يقع على متصل نفسي، يمثل أحد طرفيه اللاسواء، ويمثل الطرف

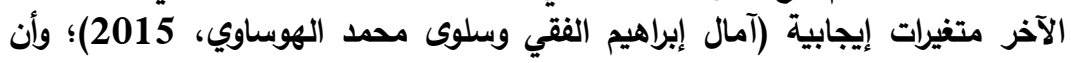

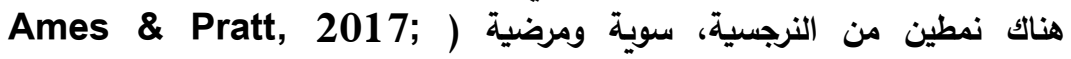


Goldstein, 2017 )، بينما يرى آخرون أن هناك ثلاثة مستويات من النرجسية،

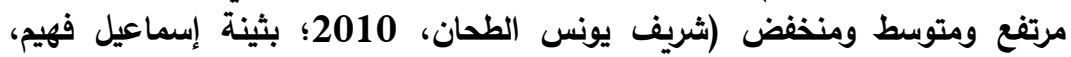

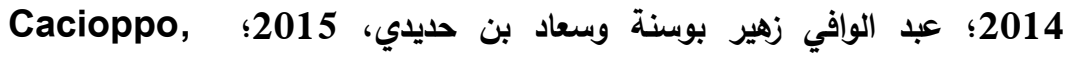

أن اهتمام الباحثين بالمستوى المرتفع من النرجسية كان مبكرًا عن اهتمامهم بالمستويين الآخرين (صلاح حسن إنمانين النماعيل، 2009).

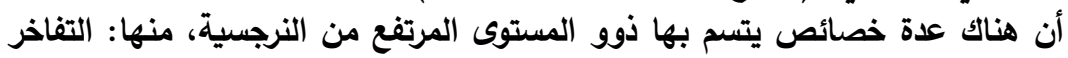

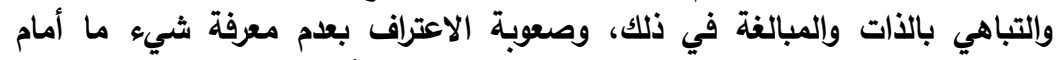
الآخرين، وحب الحديث عن الذات فقط، والميل إلى الأنانية، والاستغلالية، وتجاهل الآخرين (Bushman et al, 2003; Bettencourt et al, 2006). بينما يتميز ذوو المستوى المتوسط من النرجسية بعدة خصائص، منها: الهاوء والسكينة

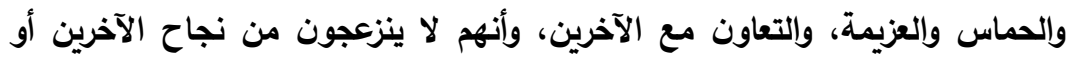

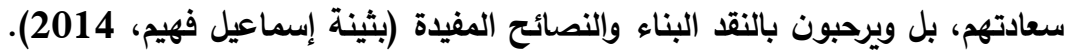

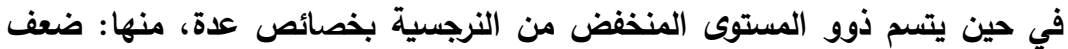

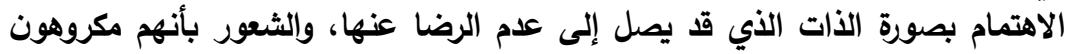
من قبل الآخرين، والتردد وعلدم القدرة على التخاذ القرار (شريف يونس الطعان الطعان،

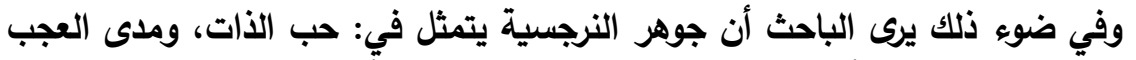
بها، وتقديرها، والثعور بأهميتها، وإلحساسية لنقد الآخرين. وأنتها ذات ثلاثة مستويات

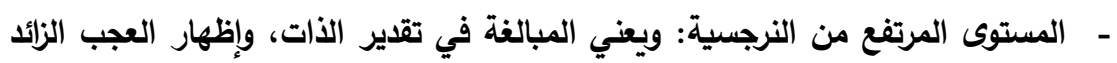

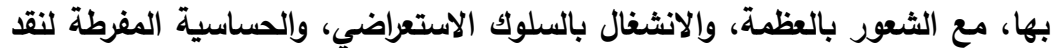

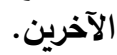

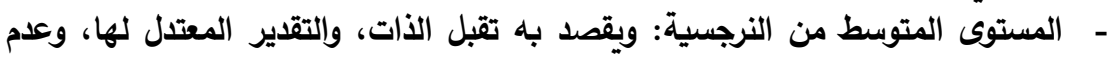

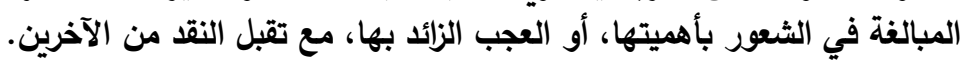

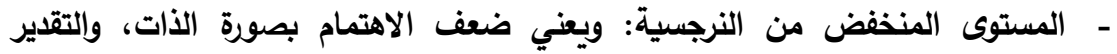
المنففض لها، الذي قد يصل إلى عدم الرضا عنها، بالإضافة إلى اللامبالاة بنقد الآخرين.

هذا، وقد تعددت وجهات النظر المفسرة للنرجسية؛ فقد استخدم فروبد النيا

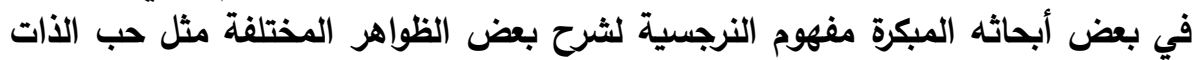

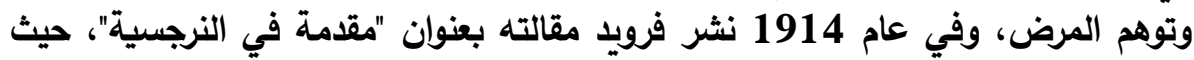

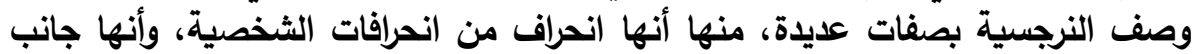
لحب الذات يظهر من خلال تصرفات الفرد مع الآخرين (بيلا غرانبرغز ، أنساف 2000: 11- 
12). ويرتبط مفهوم النرجسية عند سيجموند فرويد (دت: 91) بما يسمى "الليبيدو

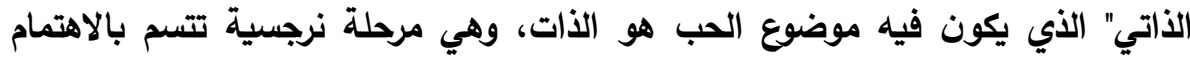
المفرط بالذات ونقص الاهتمام بالآخرين، ثم تنبعث بعد ذلك الثرن الثحنات الليبيدية من الذات

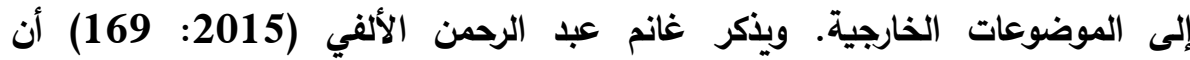

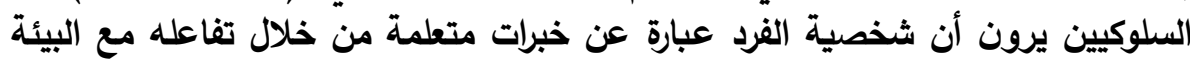

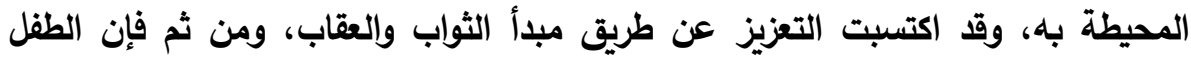

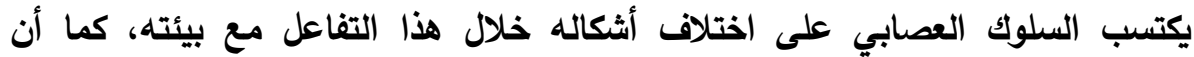
التقص يسمح للطفل بتقليد السلوك الذي تعلمه من الأخرين، فمن خلال التنشئة

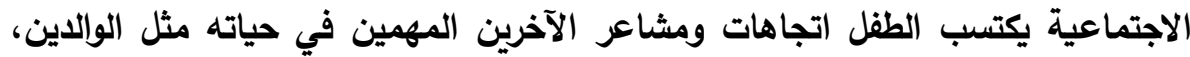

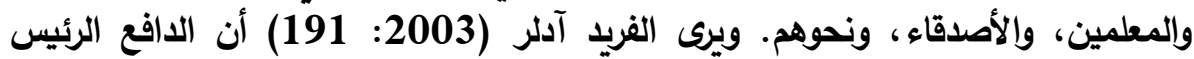
لنمو الثخصية هو الكفاح من أجل التغلب على الثعور بالاونية التي تنبع من خلادل

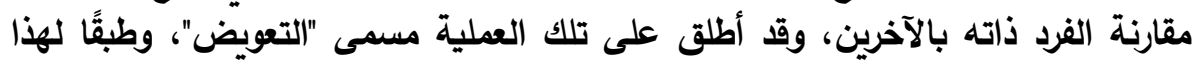

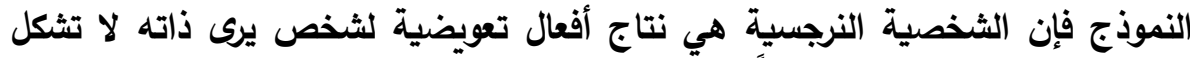

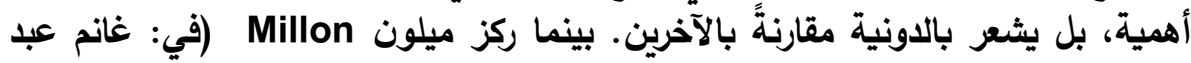

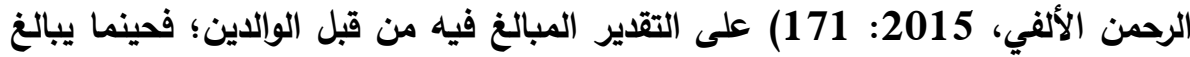

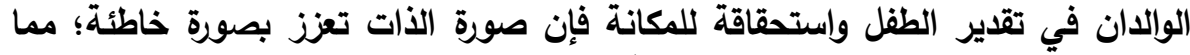

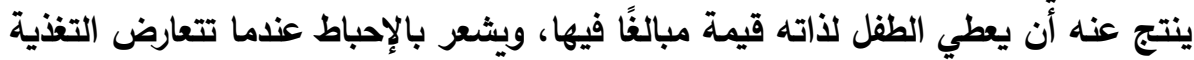
الراجعة من الأصدقاء أو المعلمين مع تلك القيمة.

وفي ضوء ما سبق يرى الباحث أن التوجهات النظرية التي حاولت تفسير

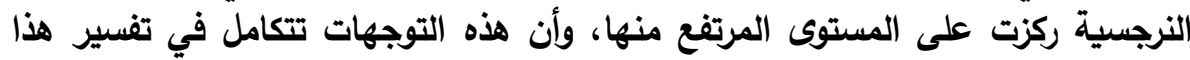

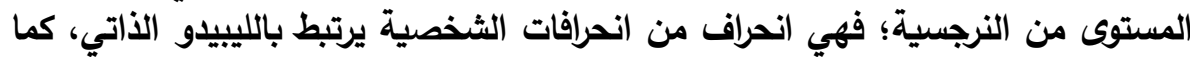

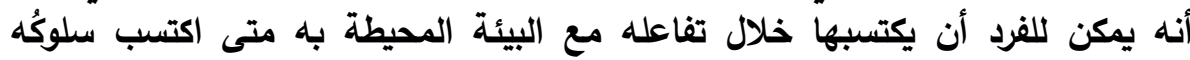

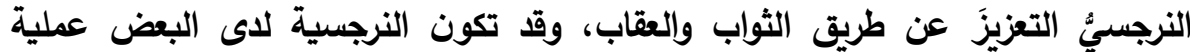
تعويضية من أجل التغلب على شعنى شعورهم بالدونية. النرجسية لاى طلاب الجامعة المتفوقين دراسيًا والعاديين:

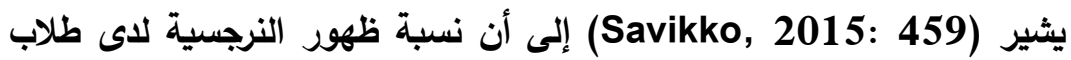
الجامعة تزداد بوجود عوامل لايهم تميزهم عن أقرانهم، مثل قدراتهم العقلية العالية، أو أو

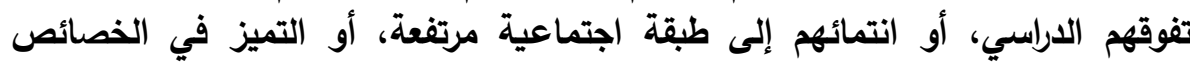

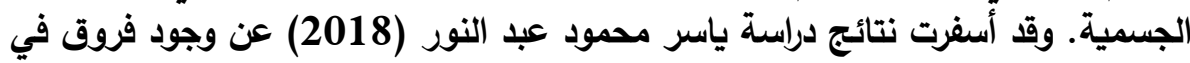

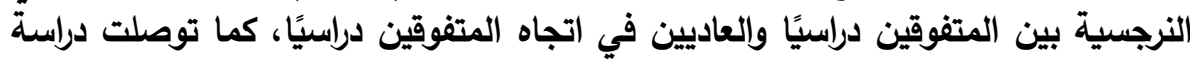
(Talepasand \& Rezaei, 2014) 
وانتشار النرجسية لاى طلاب الجامعة؛ فكلما زاد التحصيل الأكاديمي لايهم زادت احتمالية

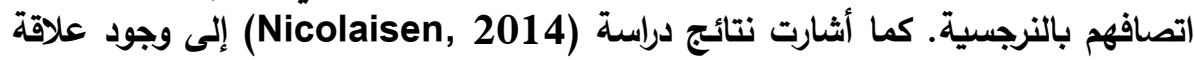

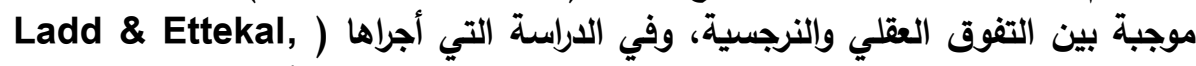

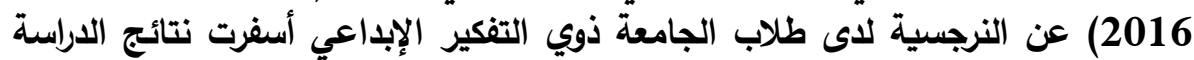
عن انتشار النرجسية لاى 37 \% من عينة الدراسة من طلاب الجامعة ذوي التابعة التفكير الإبداعي.

ويذكر (Kroenke \& Spitzer, 2018: 715) أن السعي وراء التفوق قـ

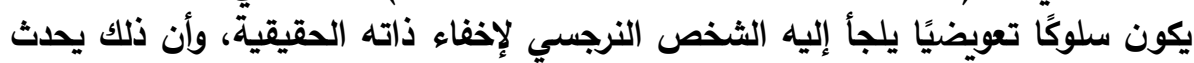

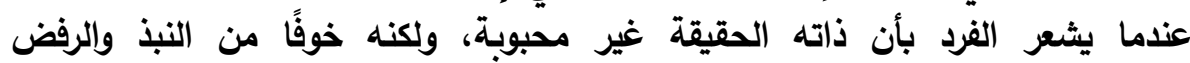

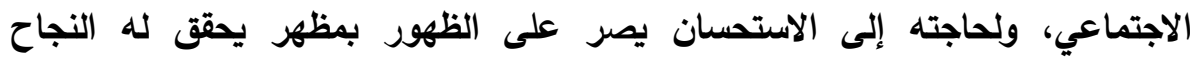

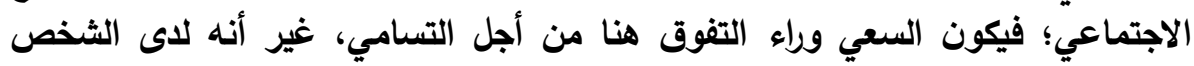
النرجسي يكون في خدمة الاستعراض، وني ومن ثم فهو استعلاء زائف. ويرى (Girgin, 2011 ( 1 (أن التفوق الدراسي يعد عاملًا مساعدًا لظهور

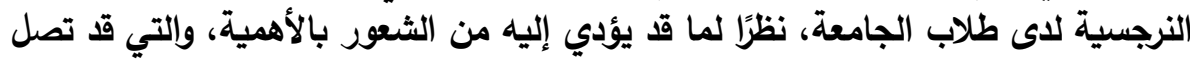

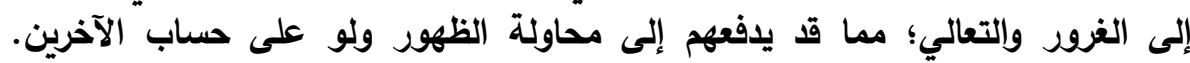
ويضيف (Stephan, 2016: 294) أن من أهم مسببات النرجسية لاى المتئية

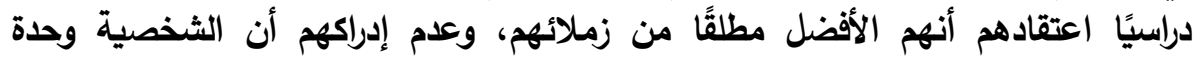

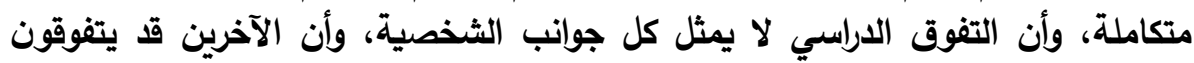

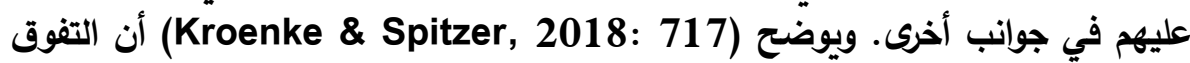
الدراسي يصبح عاملًا لظهور النرجسية لدى طوات طلاب الجامعة عندما يبالغون في استعراض

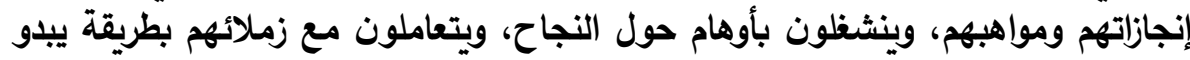
عليها الغرور والتعالي.

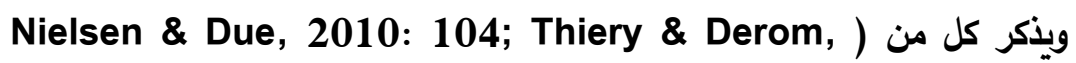

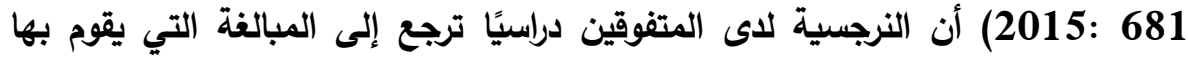

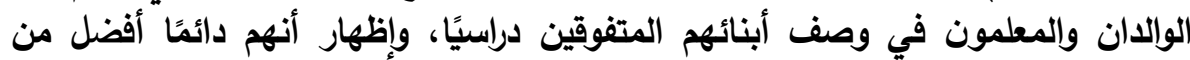

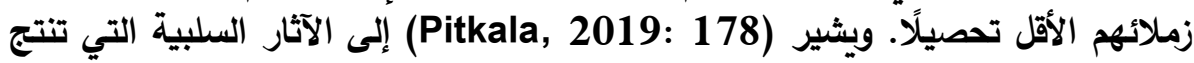

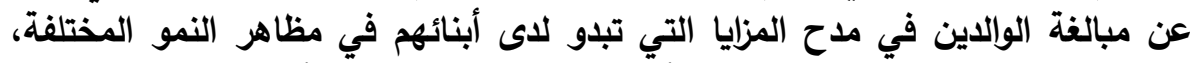

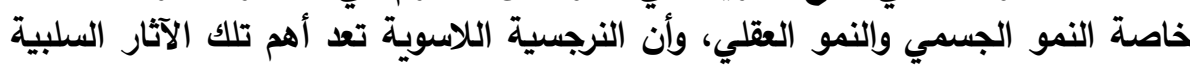
التي تنتج عن ذلك. 
- أن التفوق الداسي يعد عاملً مساعدًا لظهور النرجسية لاى طلاب الجامعة

(Girgin, 2011)

- أن هناك فروقًا في النرجسية بين المتفوقين دراسيًا وإلعاديين في اتجاه المتفوقين

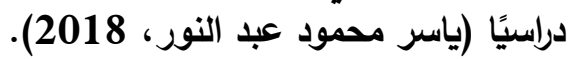

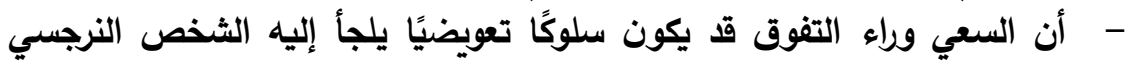

لإخفاء ذاته الحقيقية (Kroenke \& Spitzer, 2018).

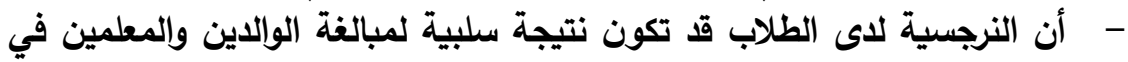

Nielsen \& Due, 2010; Thiery \& ) مدح الأبناء المتفوقين دراسيًا

.(Derom, 2015; Pitkala, 2019

ثالثًا : الوحدة النفسية والنرجسية لاى طلاب الجامعة:

يذكر غانم عبد الرحمن الألفي (2015: 143) أن النرجسية تعد واحدة من

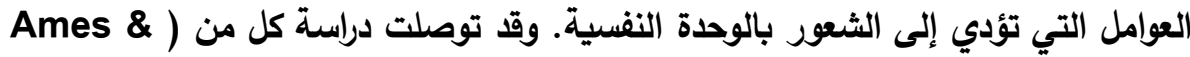
(Pratt, 2017; Jacobs, 2019

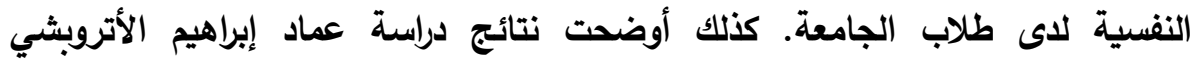

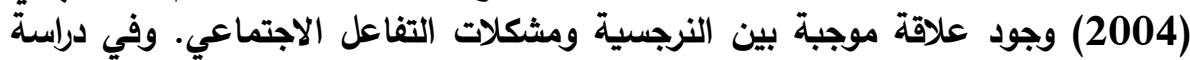

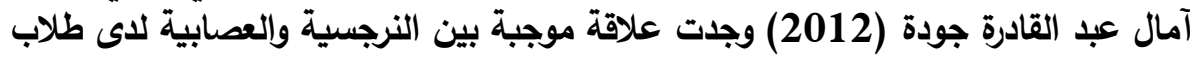

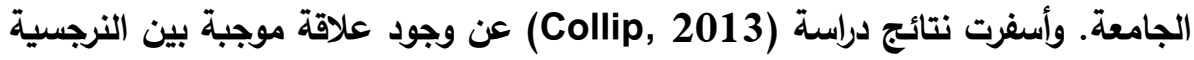

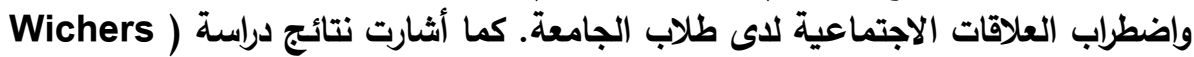

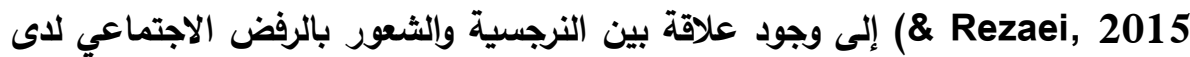
طلاب المدارس الثانوية.

وتؤدي النرجسية لاى طلاب الجامعة المتفوقين دراسيًا إلى مشكلات عديدة في

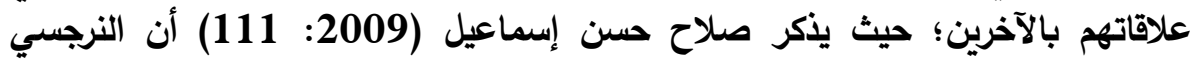

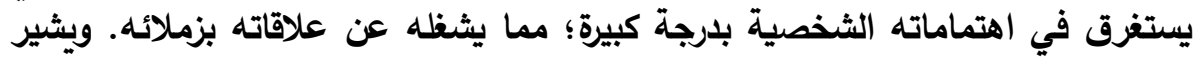
(Stephan, 2016: 296)

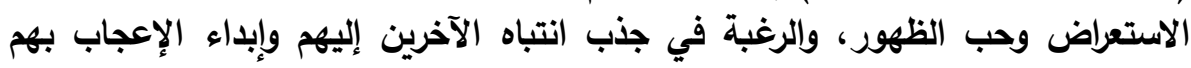
بصفة مستمرة، وعندما يفشل زملاؤهم في إقرار تلك المنزلة لهم فإنهم يميلون إلى إلى اعتى اعتبار

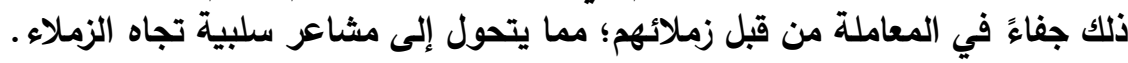
ويذكر محمد سعيد أبو ضيف (2013: 267) أن النرجسية تقترن لاى الطلاب الني المتفوقين دراسيًا بحب الذات؛ فيسعى النرجسي إلى الحصول على التفوق؛ ولتحقيق هذا 
الهدف يمكنه استغلال زملائه بالحصول منهح على ما يتعلق بالمواد الاراسية، دون أن الن النوال

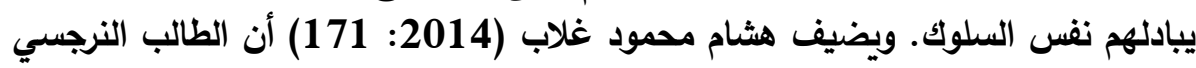

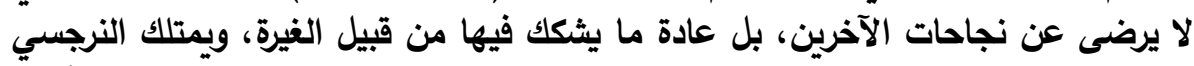

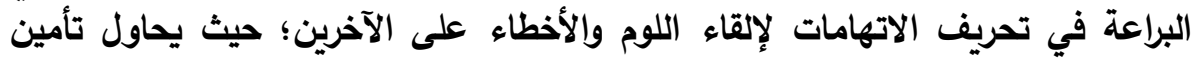
شعوره بالتفوق - في مواجهة قدرات شخص آخر متفوق - باستخدام الازدراء للتقليل من الأن

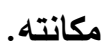

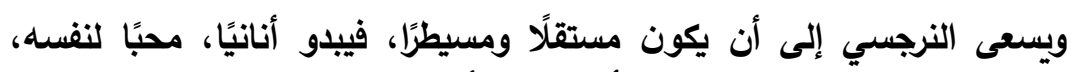

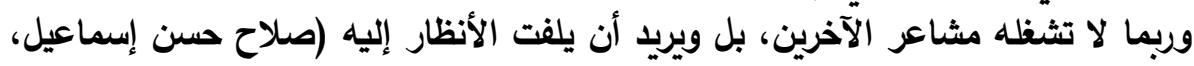

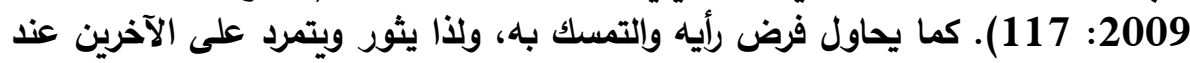

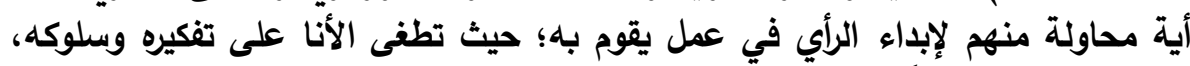

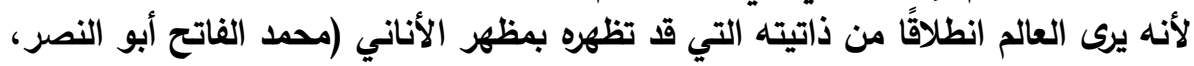
(386:2010

ويشير (Girgin, 2011 : 91 إلى أن النتيجة المترتبة على اضطراب العلاقات

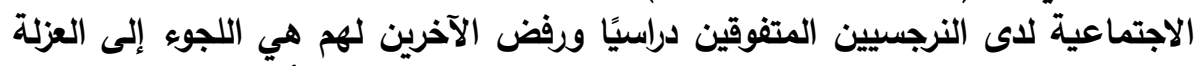

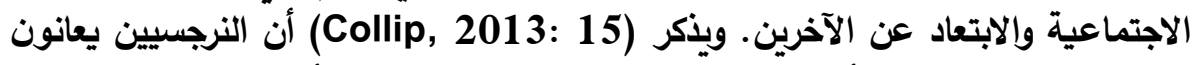

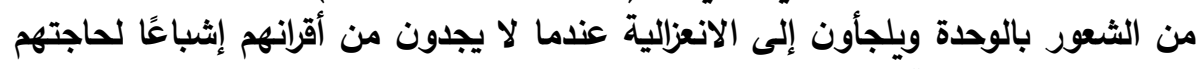

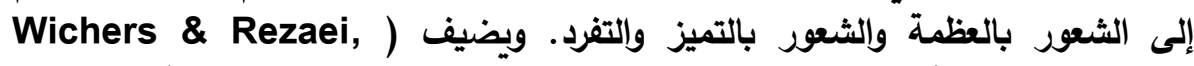

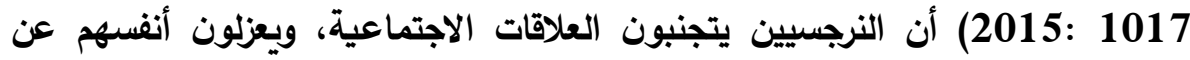

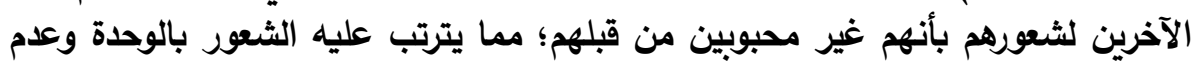
السعادة وردود الفعل الاكتئابية.

وعلى الرغم من أنه يكاد يكون هناك اتفاق بين الباحثين على العلاقة الارتباطية

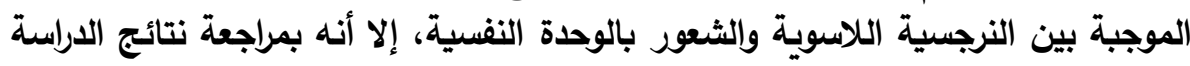

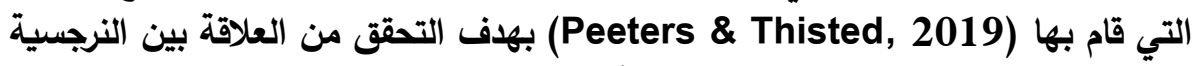

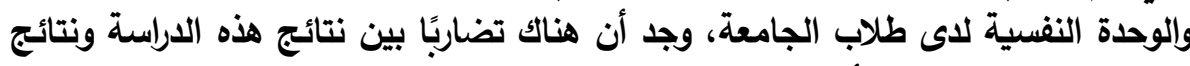

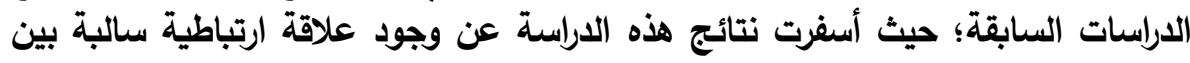

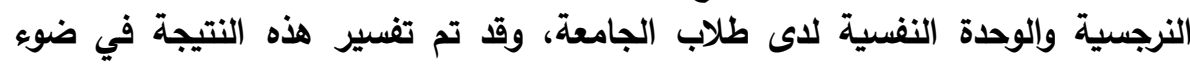

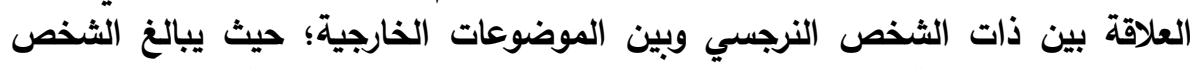

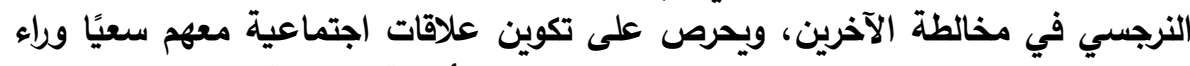
الاستفادة منهم وإثباعًا لرغباته وحاجته إلى الثعلى ويحرد على بالأهمية والعظمة. 
الوحدة النفسية وفقًا لمستوى النرجسية لاى المتفوقين دراسيًا والعاديين من طلاب كلية التربية بجامعة...

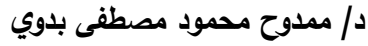

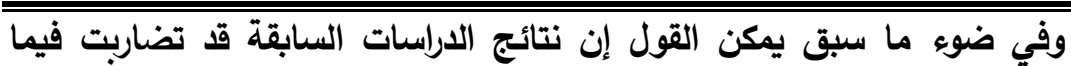
يتعلق بالعلاقة بين النرجسية والوحدة النفسية لاى طلاب الجامعة على النحو التالي:

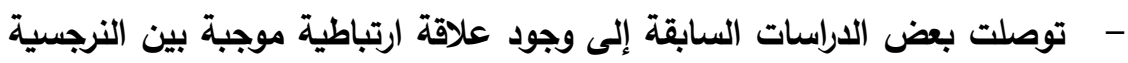

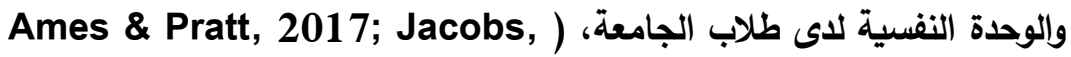

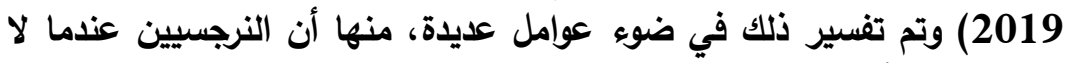

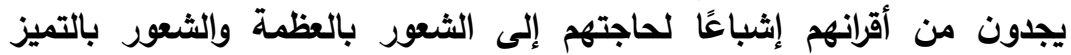

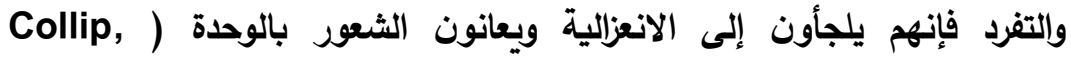

$$
\text { . } 2013
$$

- أسفرت نتائج دراسة (Peeters \& Thisted, 2019) عن وجود علاقة

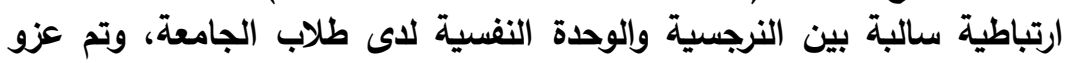

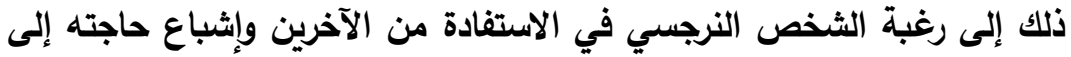

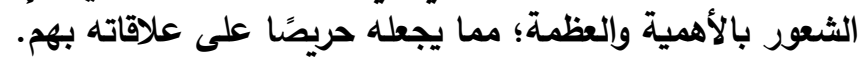

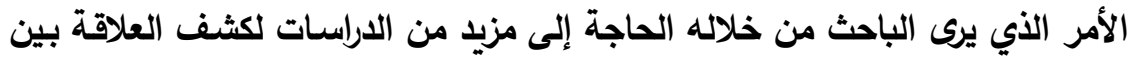
النرجسية والوحدة النفسية لاى طلاب الجامعة.

$$
\text { فروض البحث: }
$$

في ضوء الإطار النظري والدراسات السابقة تمت صياغة فروض البحث الحالي علي النحو

1- لا يوجد تفاعل دال إحصائيًا بين مستوى النرجسية (مرتفع / متوسط / منذفض) والأداء

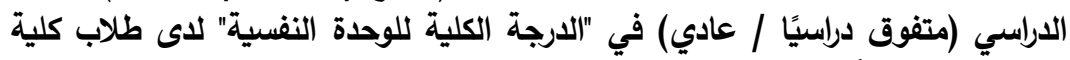
التربية بجامعة الأزهر. دالميكا 2-2 لا يوجد تفاعل دال إحصائيًا بين مستوى النرجسية (مرتفع / متوسط / منخفض) والألاء

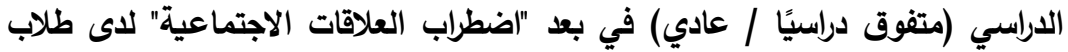
كلية التزبية بجامعة الأزهر. 3- لا يوجد تفاعل دال إحصائيًا بين مستوى النرجسية (مرتفع / متوسط / منذفض) والأداء

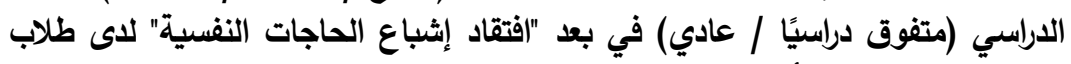
كلية التربية بجامعة الأزهر. 


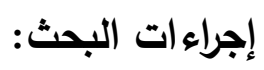

أولاً: المنهج:

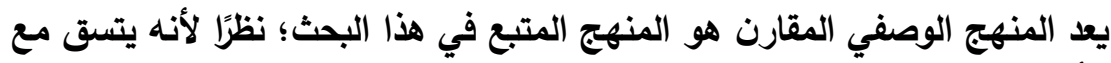

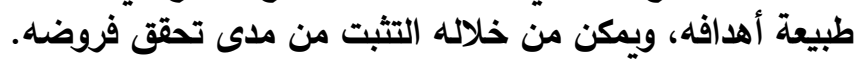

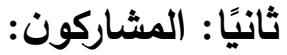

تكونت عينة البحث الأساسية في البداية من 400 طالبٍ من طلاب كلية التربية

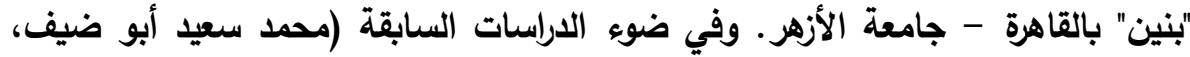

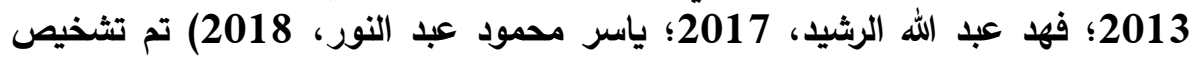

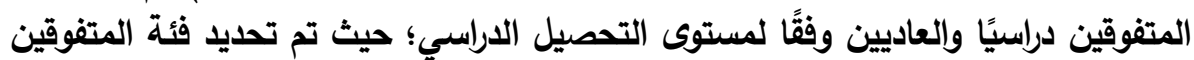

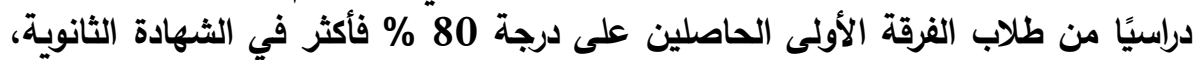

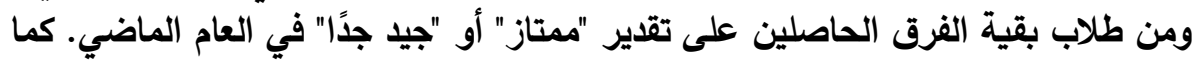

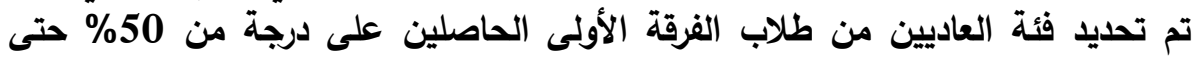

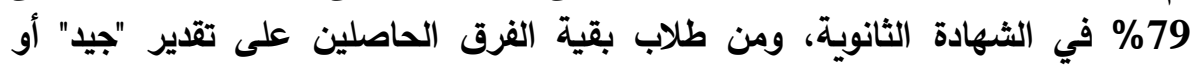

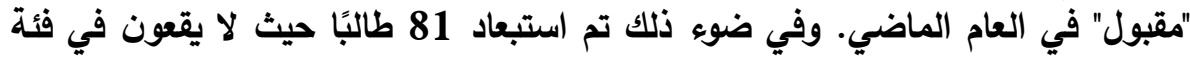

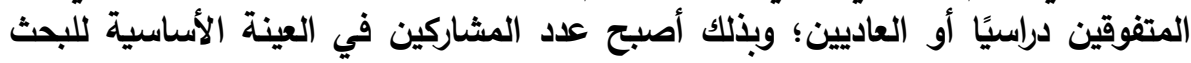

319 طالبًا (بمتوسط عمري قدره 20.39 عامًا، وانحراف معياري قدره

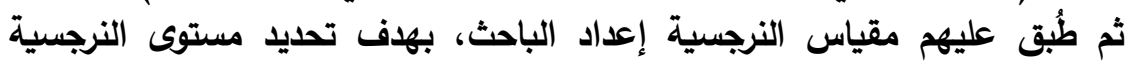

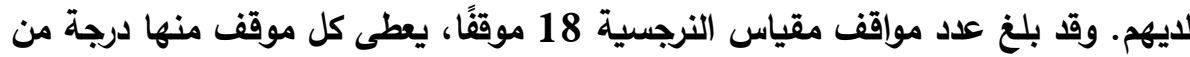

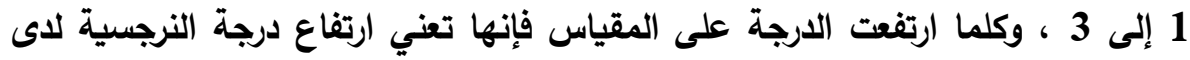

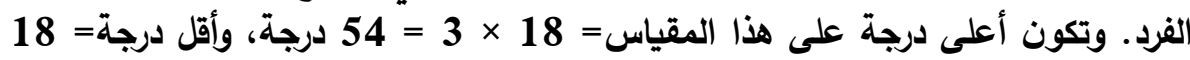

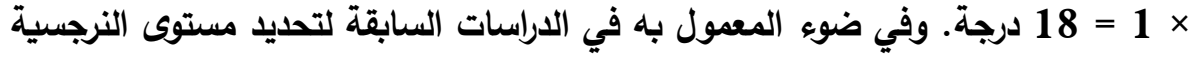

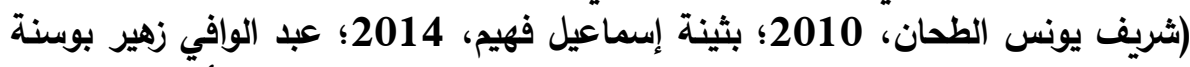

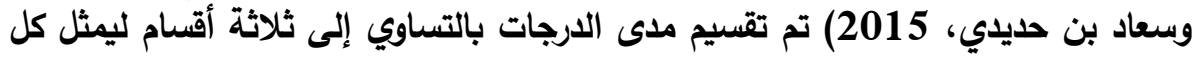

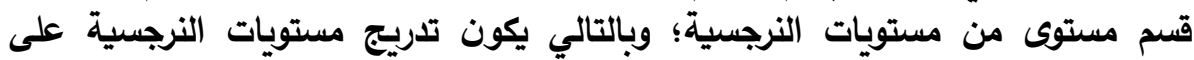
النحو التالي (مرتفع النرجسية: من 43 حتى 54 درجة، ومتوسط النرجسية: من 31 دات 31

$$
\text { حتى } 42 \text { درجة، ومنخفض النرجسية: من } 18 \text { حتى } 18 \text { حتى } 30 \text { درجة). }
$$

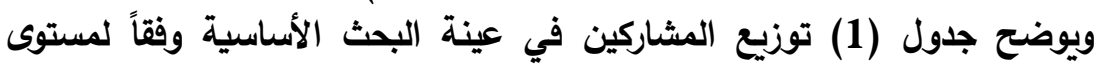
النرجسية (مرتفع / متوسط / منخفض)، والأداء الاراسي (متفوق دراسيًا / عادي). 
الوحدة النفسية وفقًا لمستوى النرجسية لاى المتفوقين دراسيًا والعاديين من طلاب كلية التربية بجامعة...

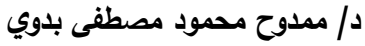

$$
\text { جدول (1) }
$$

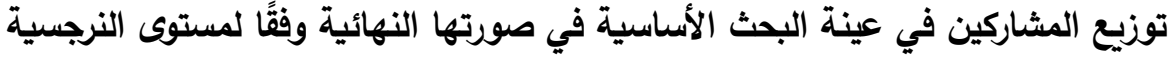

(مرتفع / متوسط / منخفض) والأداء الاراسي (متفوق / عادي) ن= 319

\begin{tabular}{|c|c|c|c|c|c|}
\hline \multicolumn{2}{|c|}{ منخفضو النرجسية } & \multicolumn{2}{|c|}{ متوسطو النرجسية } & \multicolumn{2}{|c|}{ مرتفعو النرجسية } \\
\hline عاديون & متفوقون دراسيا & عاديون & متفوقون دراسيا & عاديون & متفوقون دراسيا \\
\hline 47 & 42 & 78 & 52 & 39 & 61 \\
\hline
\end{tabular}

يتضح من جدول (1) أن إجمالي عينة مرتفعي النرجسية بلغ 100 طالب، بينما

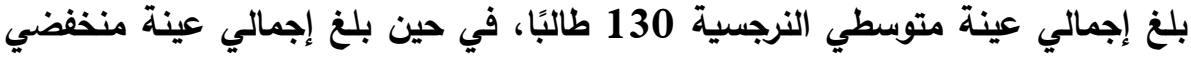

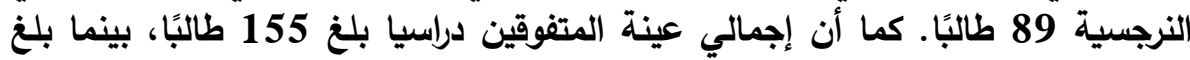
إجمالي عينة العاديين 164 طالبًا.

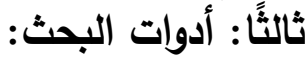

تطلب القيام بهذا البحث استخدام أداة لقياس الوحدة النفسية لاى طلاب كلية

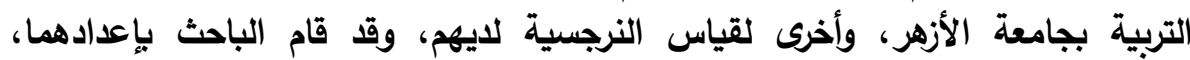

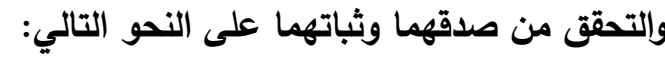
(1) مقياس الوحدة النفسية (إعداد الباحث):

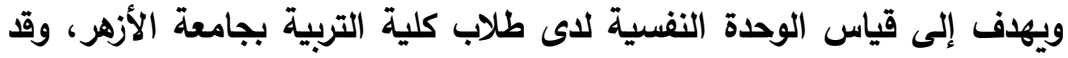

تطلب إعداد هذا المقياس القيام بالخطوات الآتية:

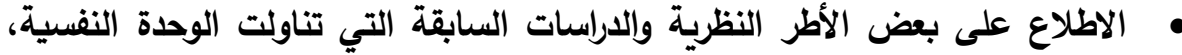

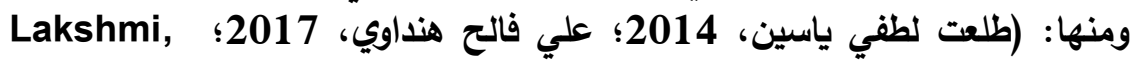
.$(2017$

الاطلاع على بعض الأدوات المستخدمة في قياس الوحدة النفسية، ومنها المقاييس

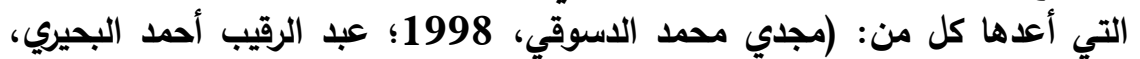

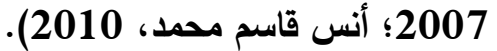

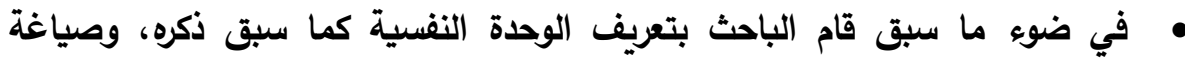

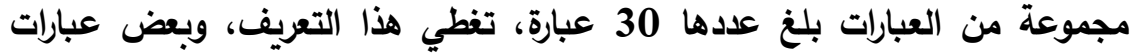

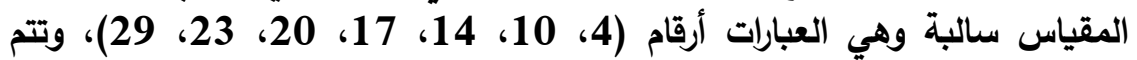

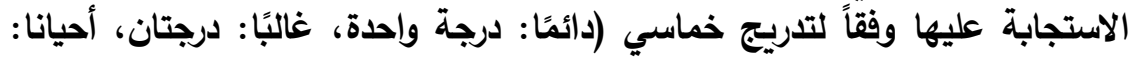

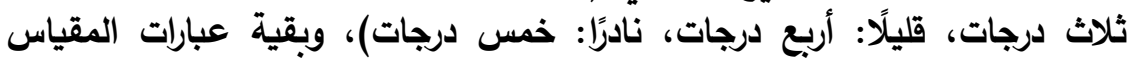

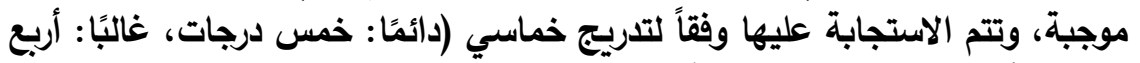

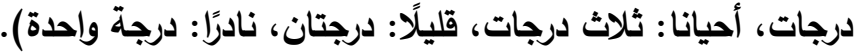


مجلة كلية التربية، جامعة الأزهر ، العدد: (185، الجزء الثالث) يناير لسنة 2020م

• • م حساب الخصائص السيكومتربة للمقياس كما يلي:

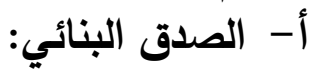

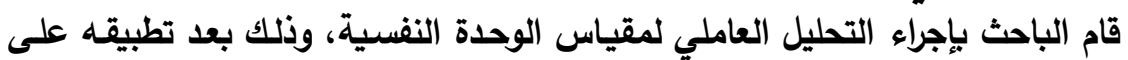

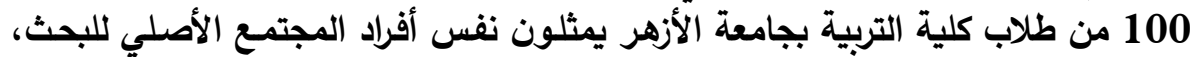

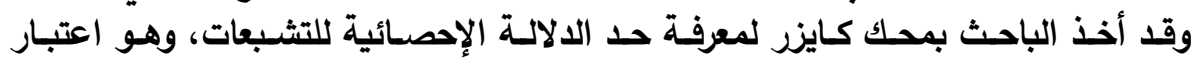

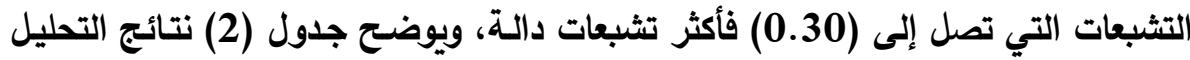
العاملي لعبارات مقياس الوحدة النفسية.

جدول (2)

نتائج التحليل العاملي لعبارات مقياس الوحدة النفسية (ن= 100)

\begin{tabular}{|c|c|c|c|c|c|c|c|}
\hline الشيوع & الثاني & الأول & & الشيوع & الثاني & الأول & \\
\hline 0.418 & *0.628 & 0.154 & 16 & 0.591 & *0.721 & 0.164 & 1 \\
\hline 0.525 & 0.178 & $* 0.702$ & 17 & 0.408 & *0.607 & 0.201 & 2 \\
\hline 0.430 & 0.222 & *0.617 & 18 & 0.452 & 0.119 & *0.662 & 3 \\
\hline 0.331 & *0.537 & 0.185 & 19 & 0.329 & $* 0.535$ & 0.207 & 4 \\
\hline 0.530 & $0.010-$ & $* 0.728$ & 20 & 0.613 & 0.148 & *0.769 & 5 \\
\hline 0.520 & *0.721 & $0.014-$ & 21 & 0.495 & 0.286 & *0.643 & 6 \\
\hline 0.049 & $0.090-$ & 0.202 & 22 & 0308 & $* 0.517$ & 0.203 & 7 \\
\hline 0.447 & *0.645 & 0.177 & 23 & 0.068 & 0.138 & 0.222 & 8 \\
\hline 0.397 & *0.609 & 0.161 & 24 & 0.492 & *0.673 & 0.197 & 9 \\
\hline 0.444 & 0.208 & *0633 & 25 & 0.636 & 0.115 & *0.798 & 10 \\
\hline 0.356 & *0.597 & $0.013-$ & 26 & 0.141 & 0.192 & 0.102 & 11 \\
\hline 0.644 & $0.044-$ & * 0.801 & 27 & 0.472 & $0.036-$ & *0.686 & 12 \\
\hline 0.102 & 0.158 & $0.278^{-}$ & 28 & 0.752 & 0.137 & * 0.856 & 13 \\
\hline 0.469 & *0.619 & $0.293-$ & 29 & 0.435 & *0.595 & 0.284 & 14 \\
\hline 0.538 & 0.129 & $* 0.722$ & 30 & 0.088 & 0.213 & 0.208 & 15 \\
\hline \multicolumn{4}{|c|}{ للعامل الثاني= 5.448} & \multicolumn{3}{|c|}{ للعامل الأول= 7.032} & الجذامنة \\
\hline \multicolumn{4}{|c|}{ للعامل الثاني= 18.16} & \multicolumn{3}{|c|}{ للعامل الأول= 23.44 } & التباين \% \\
\hline
\end{tabular}


الوحدة النفسية وفقًا لمستوى النرجسية لاى المتفوقين دراسيًا والعاديين من طلاب كلية التربية بجامعة...

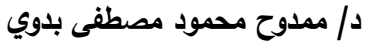

$$
\text { يتضح من جدول (2) ما يلي: }
$$

- - أن التحليل العاملي أسفر عن عاملين لمقياس الوحدة النفسية، بجذرين كامنين لهما على

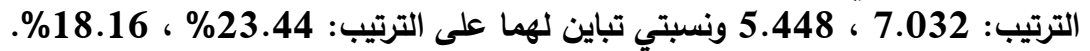

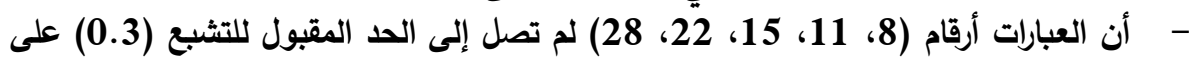

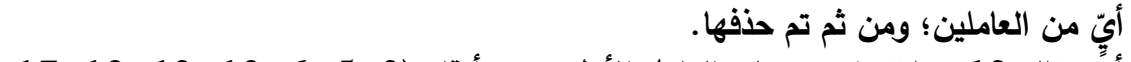

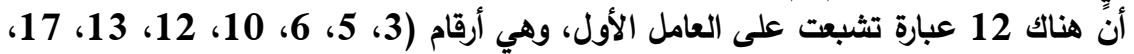

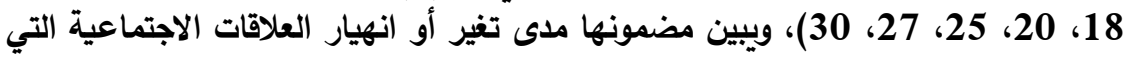

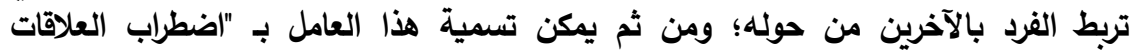

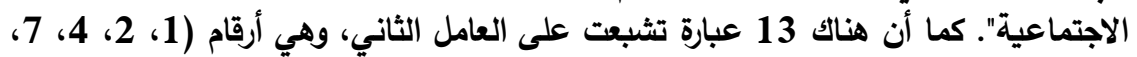

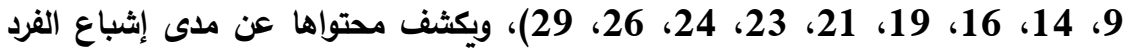

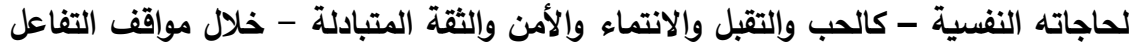

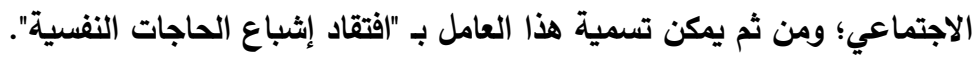

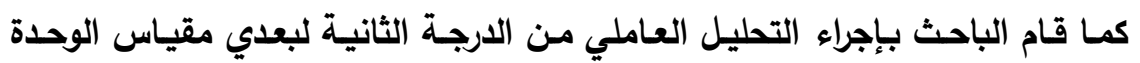
النفسية، ويلخص جدول (3) نتائج هذا التحليل العاملي. جدول (3) التحليل العاملي لبعدي مقياس الوحدة النفسية (ن= 100)

\begin{tabular}{|c|c|c|c|}
\hline الشيوع & العامل الثاني & العامل الأول & الأبعاد \\
\hline 0.806 & 0.216 & $* 0.871$ & اضطراب العلاقات الاجتماعية \\
\hline \multirow[t]{3}{*}{0.633} & 0.175 & $* * 0.795$ & افتقاد إثباع الحاجات النفسية \\
\hline & 0.0 .078 & 1.427 & الجذور الكامنة \\
\hline & $\% 3.9$ & $\% 71.35$ & نسبة التباين \\
\hline
\end{tabular}

يتضـح من جدول (3) أن التحليل العاملي أسفر عن عاملين بجذرين كامنين على

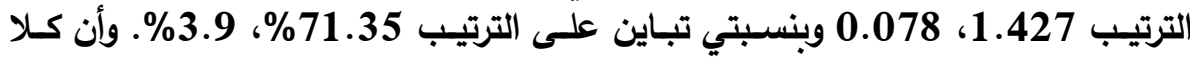

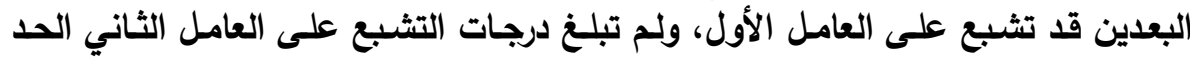

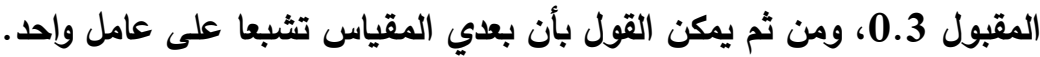
ب- - الاتساق الداخلي للمقياس: تم حساب معاملات الارتباط بين درجة كل عبارة والدرجة الكلية للبعد الذي تنتمي

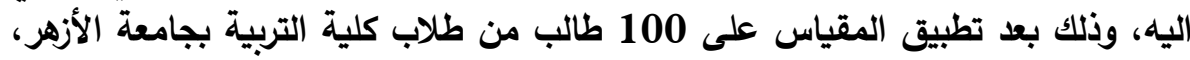


ويوضح جدول (4) معاملات الارتباط بين درجة كل عبارة والدرجة الكلية للبعد الذي تنتمي

جدول (4)

معاملات الارتباط بين العبارة والدرجة الكلية للبُعد الذي تنتمي إليه (ن= 100)

\begin{tabular}{|c|c|c|c|}
\hline \multicolumn{2}{|c|}{ افتقاد إثباع الحاجات النفسية } & \multicolumn{2}{|c|}{ اضطراب العلاقات الاجتماعية } \\
\hline معامل الارتباط & رقم العبارة & معامل الارتباط & رقم العبارة \\
\hline$* * 0.733$ & 1 & $* * 0.587$ & 3 \\
\hline$* * 0.618$ & 2 & $* * 0.724$ & 5 \\
\hline$* * 0.512$ & 4 & $* * 0.573$ & 6 \\
\hline$* * 0.503$ & 7 & $* * 0.743$ & 10 \\
\hline$* * 0.714$ & 9 & $* * 0.609$ & 12 \\
\hline$* * 0.573$ & 14 & $* * 0.819$ & 13 \\
\hline$* * 0.714$ & 16 & $* * 0.638$ & 17 \\
\hline$* * 0.532$ & 19 & $* * 0.518$ & 18 \\
\hline$* * .733$ & 21 & $* * 0.696$ & 20 \\
\hline$* * 0.691$ & 23 & $* * 0.546$ & 25 \\
\hline$* * 0.642$ & 24 & $* * 0.795$ & 27 \\
\hline$* * 0.594$ & 26 & $* * 0.662$ & 30 \\
\hline$* * 0.675$ & 29 & & \\
\hline
\end{tabular}

يتضح من جدول (4) أن معاملات الارتباط بين كل عبارة والارجة الكلية للبعد الذي تنتمي إليه دالة إحصائيًا عند مستوى ان معاملات 0.01.

كما تم حساب معاملات الارتباط بين بعدي مقياس الوحدة النفسية في علاقتهما

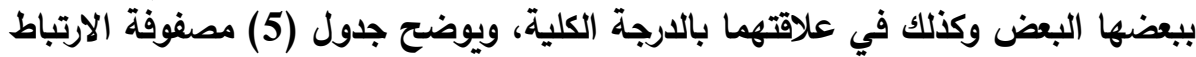
بين بعدي مقياس الوحدة النفسية والارجة الكلية للمقياس. 
الوحدة النفسية وفقًا لمستوى النرجسية لاى المتفوقين دراسيًا والعاديين من طلاب كلية التربية بجامعة...

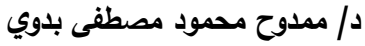

\section{جدول (5)}

مصفوفة الارتباط بين بعدي مقياس الوحدة النفسية والدرجة الكلية (ن = 100)

\begin{tabular}{|c|c|c|}
\hline |فتقاد إثباع الحاجات & اضطراب العلاقات الاجتماتة & أبعاد المقياس \\
\hline & $* * 0.676$ & افتقاد إثباع الحاجات النفسية \\
\hline$* * 0.796$ & $* * 0.811$ & الارجة الكلية \\
\hline
\end{tabular}

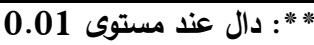

يتضح من جدول (5) أن قيم معاملات الارتباط بين بعدي مقياس الوحدة

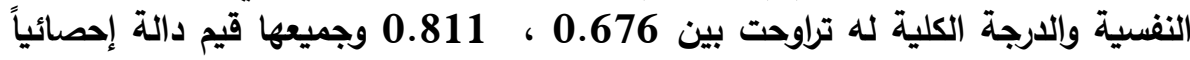
عند مستوى 0.01 ، وبذلك يكون قد تم التحقق من الاتساق الداخلي للمقياس.

ج- صدق المحك:

كما اعتمد الباحث أيضًا في حساب صدق المقياس على صدق المحك، حيث تم

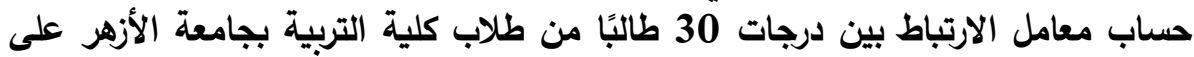

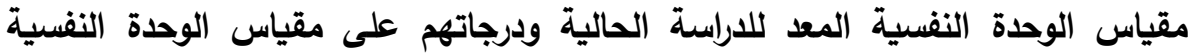

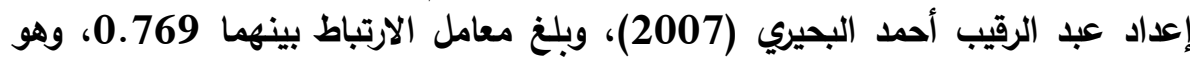
معامل ارتباط دال إحصائيًا عند مستوى 0.01؛ مما يشير إلى صدق المائ المقياس باستخدام

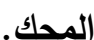

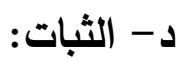

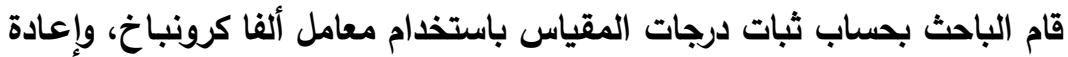

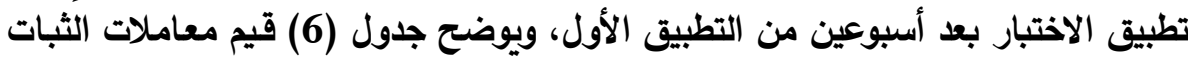
لبعدي مقياس الوحدة النفسية والدرجة الكلية للمقياس. 


\section{جدول (6)}

قيم معاملات الثبات باستخدام معامل ألفا كرونباخ، وإعادة تطبيق الاختبار لكلٍ من بعدي مقياس الوحدة النفسية والدرجة الكلية (ن = 100)

\begin{tabular}{|c|c|c|c|}
\hline الالدية & افتقاد إثباع الحاجات النفسية & اضطراب العلاقات الاجتماعية & المقياسر \\
\hline 0.809 & 0.674 & 0.728 & ألفا كرونباخ \\
\hline 0.792 & 0.665 & 0.715 & إعادة الاختبار \\
\hline
\end{tabular}

يتضح من جدول (6) أن قيم معاملات الثبات لبعدي المقياس والدرجة الكلية له

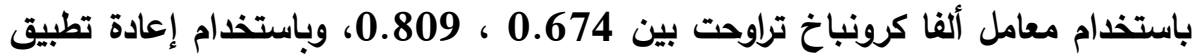

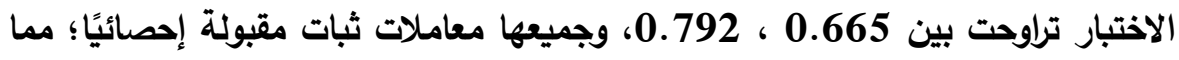
يدعو إلى الثقة في النتائج التي يمكن التوصل إليها عند استخدام المقياس.

يتبين مما سبق أن مقياس الوحدة النفسية في صورته النهائية يتكون من 25

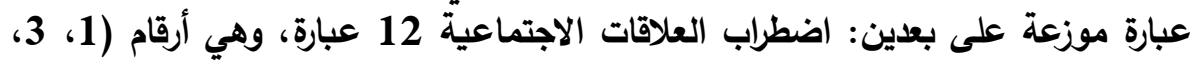

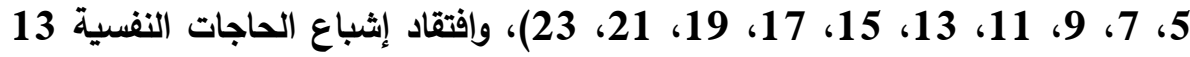

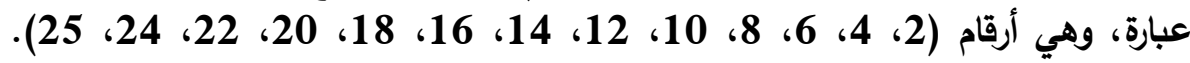

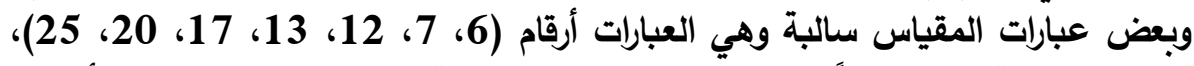

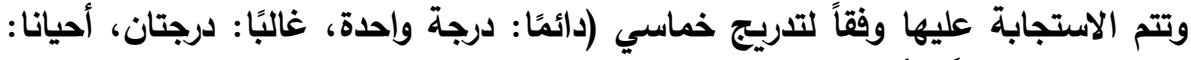

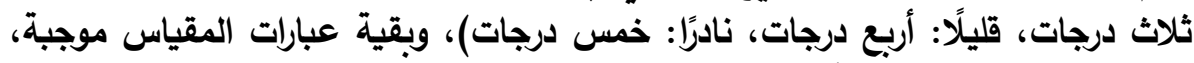

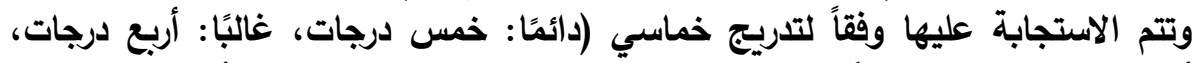

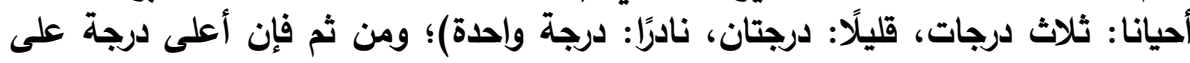

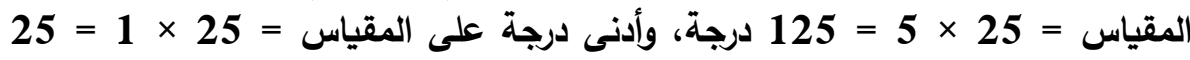
درجة، وبذلك أصبح المقياس جاهزًا للتطبيق في صورته

$$
\text { (2) مقياس النرجسية (إعداد الباحث): }
$$

ويهاف إلى قياس النرجسية لاى طلاب كلية التربية بجامعة الأزهر، وقد تطلب إعداد هذا المقياس القيام بالخطوات الآتية: 
الوحدة النفسية وفقًا لمستوى النرجسية لاى المتفوقين دراسيًا والعاديين من طلاب كلية التربية بجامعة...

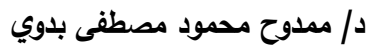

• الاطلاع على بعض الأطر النظرية والدارات السابقة التي تناولت النرجسية، ومنها: (بثينة

Kroenke \& Talepasand \& Rezaei, 2014 إسماعيل فهيم، 2014

(Spitzer, 2018

الاطلاع على بعض الأدوات المستخدمة في قياس النرجسية، ومنها المقاييس التي

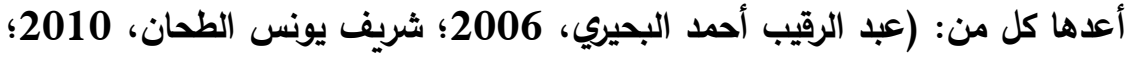

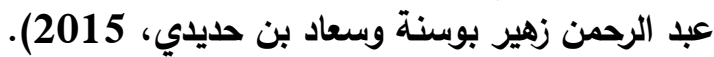

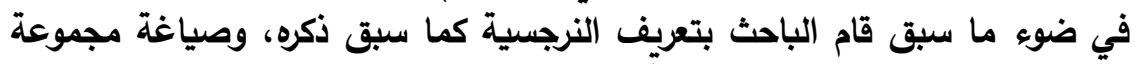

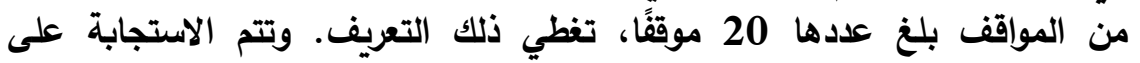

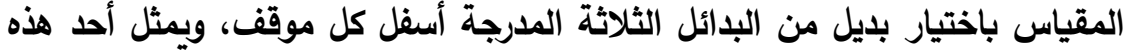

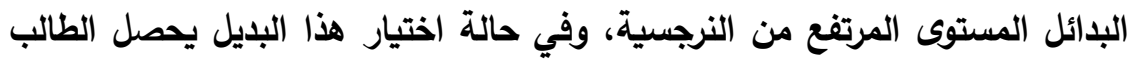

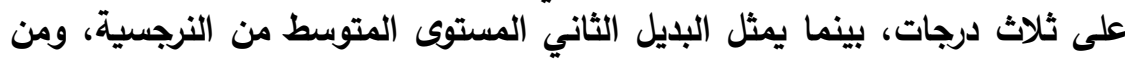

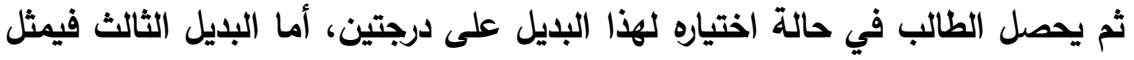

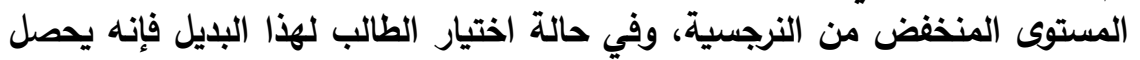

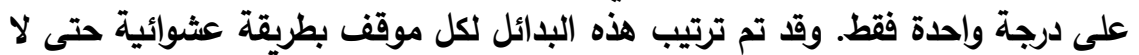
يفطن المشاركون إلى البديل الأمثل. تم حساب الخصائص السيكومترية للمقياس كما يلي: أ- الصدق البنائي:

قام الباحث بإجراء التحليل العاملي لمقياس النرجسية، وذلك بعد تطبيقه على 100

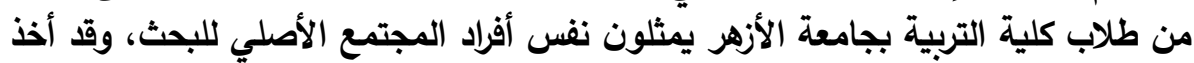

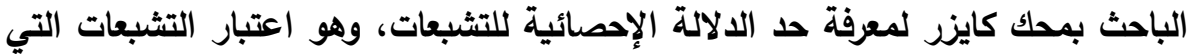

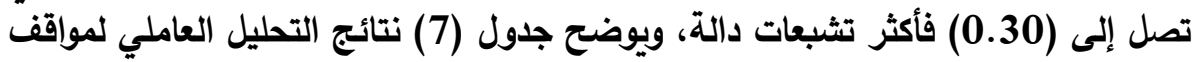

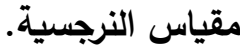


مجلة كلية التربية، جامعة الأزهر ، العدد: (185، الجزء الثالث) يناير لسنة 2020م

\section{جدول (7)}

نتائج التحليل العاملي لمواقف مقياس النرجسية (ن= 100)

\begin{tabular}{|c|c|c|c|c|c|}
\hline الثيوع & قيم التشبع بالعامل & المواقف & الثيوع & قيم التشبع بالعامل & المواقف \\
\hline 0.471 & *0.686 & 11 & 0.356 & *0.597 & $\overline{1}$ \\
\hline 0.210 & *0.458 & 12 & 0.307 & *0.554 & 2 \\
\hline 0.394 & *0.628 & 13 & 0.501 & *0.708 & 3 \\
\hline 0.386 & *0.621 & 14 & 0.353 & *0.594 & 4 \\
\hline 0.460 & *0.678 & 15 & 0.402 & *0.634 & 5 \\
\hline 0.521 & *0.722 & 16 & 0.047 & 0.217 & 6 \\
\hline 0.382 & *0.618 & 17 & 0.473 & *0.688 & 7 \\
\hline 0.329 & *0.574 & 18 & 0.493 & *0.702 & 8 \\
\hline 0.052 & 0.228 & 19 & 0.260 & *0.510 & 9 \\
\hline 0.324 & *0.569 & 20 & 0.527 & *0.726 & 10 \\
\hline \multicolumn{5}{|c|}{7.248} & الجذر الكامن \\
\hline \multicolumn{5}{|c|}{36.24} & التباين \% \\
\hline
\end{tabular}

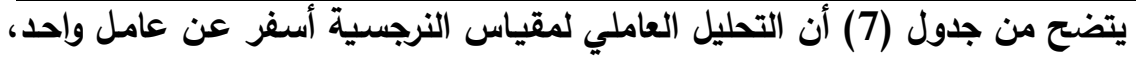

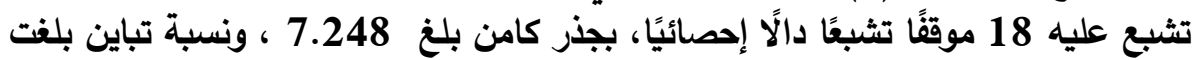

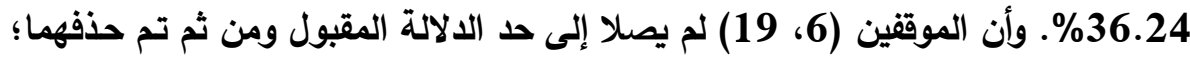
وبذلك أصبحت مواقف المقياس بعد إجراء التحليل العاملي 18 موقفًا. ب- الاتساق الداخلي للمقياس: تم حساب معاملات الارتباط بين درجة كل موقف والدرجة الكلية لمقياس النرجسية،

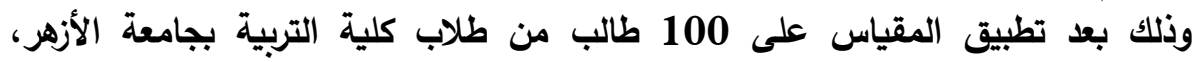
ويوضح جدول (8) معاملات الارتباط بين درجة كل موقف والدرجة الكلية للمقياس. 
الوحدة النفسية وفقًا لمستوى النرجسية لاى المتفوقين دراسيًا والعاديين من طلاب كلية التربية بجامعة...

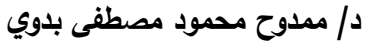

$$
\text { جدول (8) }
$$

معاملات الارتباط بين درجة كل موقف والدرجة الكلية لمقياس النرجسية (ن= 100)

\begin{tabular}{|c|c|c|c|}
\hline معامل الارتباط & رقم الموقف & معامل الارتباط & رقم الموقف \\
\hline$* * 0.602$ & 11 & $* * 0.615$ & 1 \\
\hline *** 0.705 & 12 & $* * 0.718$ & 2 \\
\hline$* \% 0.532$ & 13 & $* * 0.656$ & 3 \\
\hline$* * 0.661$ & 14 & ***0.634 & 4 \\
\hline$* * 0.623$ & 15 & ***0.587 & 5 \\
\hline$* * 0.584$ & 16 & $* * 0.693$ & 7 \\
\hline$* * 0.675$ & 17 & **0.714 & 8 \\
\hline$* * 0.696$ & 18 & ***0.599 & 9 \\
\hline ***0.581 & 20 & $* * 0.636$ & 10 \\
\hline
\end{tabular}

يتضح من جدول (8) أن معاملات الارتباط بين كل موقف والارجة الكلية

للمقياس دالة إحصائيًا عذد مستوى (8) أن معاملات

$$
\text { ج- صدق المحك: }
$$

كما اعتمد الباحث ايضًا في حساب صدق المقياس على صدق المحك، حيث تم تملئ

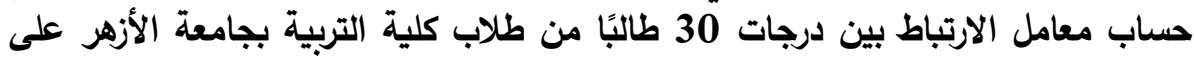

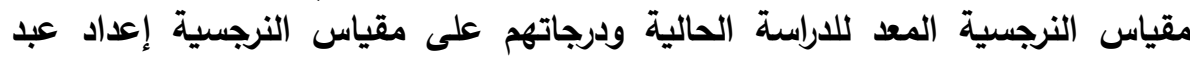

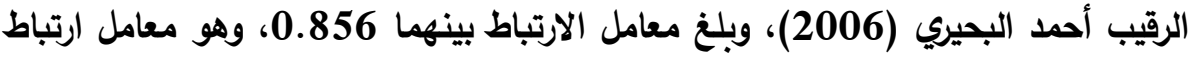
دال إحصائيًا عند مستوى 0.01؛ مما يثير إلى صدق المقياس باستخام المحك.

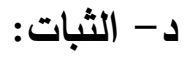

قام الباحث بحسـاب معامـل الثبات لمقيساس النرجسية باستخدام معامل ألفـا

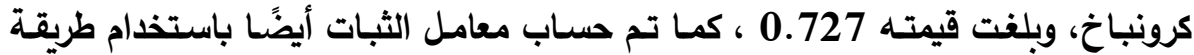

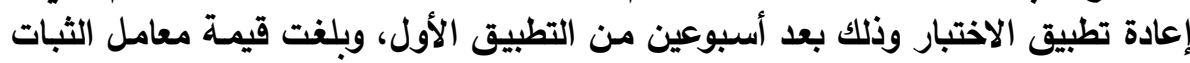


وفقًا لهذه الطريقة 0.709، وهي قيم ثبات مقبولـة إحصائيًا؛ مما يدعو إلى الثقة في إلتِ النتائج التي يمكن التوصل إليها عند استخدام المقياس.

يتبين مما سبق أن مقياس النرجسية في صورته النهائية يتكون من 18 موقفاً إناء

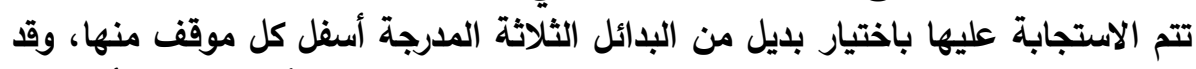

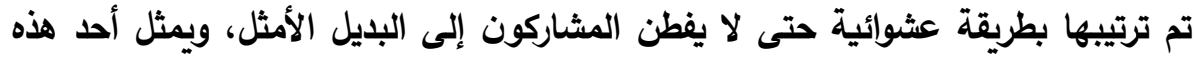

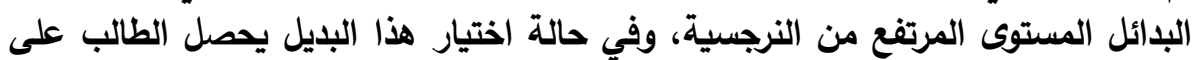

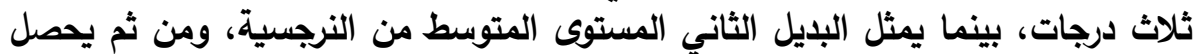

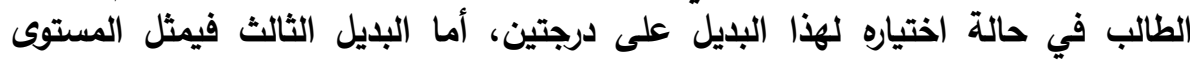

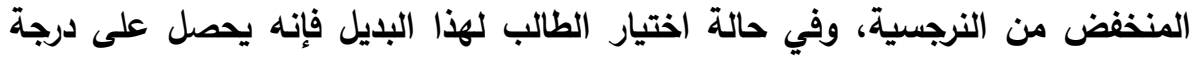

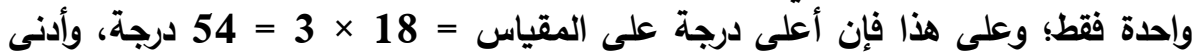

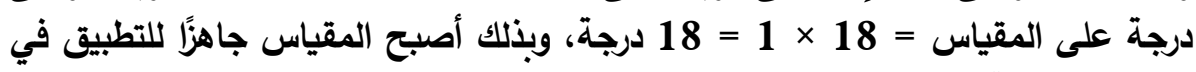

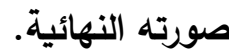
رابعًا: المعالجات الإحصائية: المهاية:

للتحقق من فروض الدراسة تم استخدام الأساليب الإحصائية التالية: تحليل

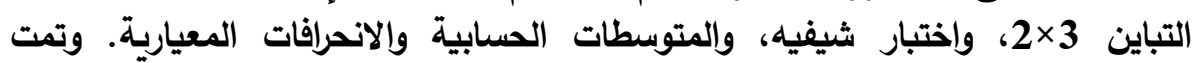
معالجة البيانات باستخدام الحاسب الآلي (برنامج والمتئهات نتائج البحث: أولًا: نتائج الفرض الأول ومناقشتها: ينص الفرض الأول على أنه "لا يوجد تفاعل دال إحصائيًا بين مستوى النرجسية

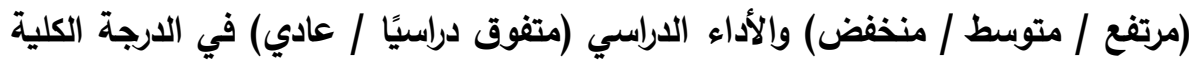

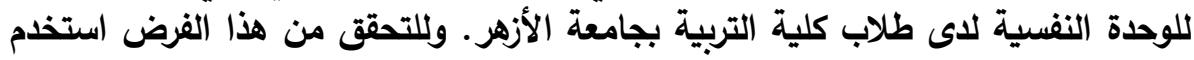

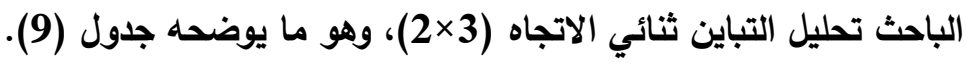


الوحدة النفسية وفقًا لمستوى النرجسية لدى المتفوقين دراسيًا والعاديين من طلاب كلية التربية بجامعة...

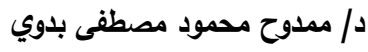

\section{جدول (9)}

نتائج تحليل التباين ثنائي الاتجاه 3×2 لتحديد التفاعل بين متغيري مستوى النرجسية

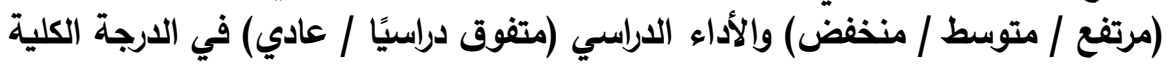

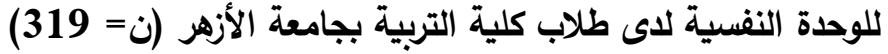

\begin{tabular}{|c|c|c|c|c|c|}
\hline مستوى & قيمة "ف" & متوسط & الدرجية & المربعات & مصدر التباين \\
\hline 0,01 & 2653.860 & 93487.112 & 2 & 186974.224 & (مرتفع/متوسط/منخفض) النرجسية \\
\hline 0,01 & 53.469 & 1883.540 & 1 & 1883.540 & (متفوق دراسيًا/عادي) \\
\hline \multirow[t]{3}{*}{0,01} & 117.273 & 4131.154 & 2 & 8262.307 & 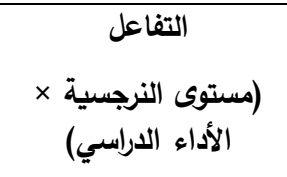 \\
\hline & & 35.227 & 313 & 11026.001 & الخطأ \\
\hline & & & 318 & 1696497.000 & المجموع الكلي \\
\hline
\end{tabular}

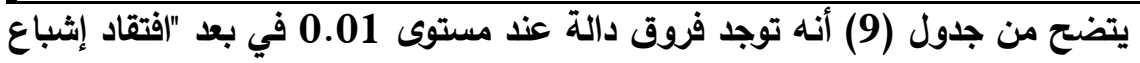

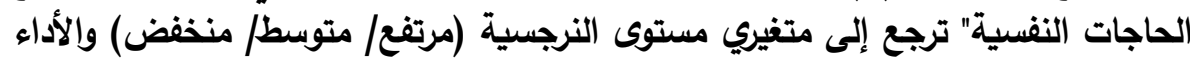

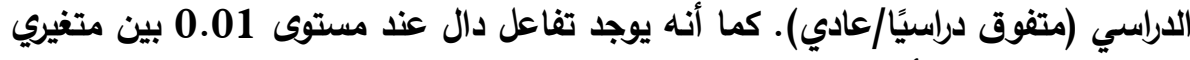
مستوى النرجسية والأداء الدراسي في كي الارجة الكلية للوحدة النفسية.

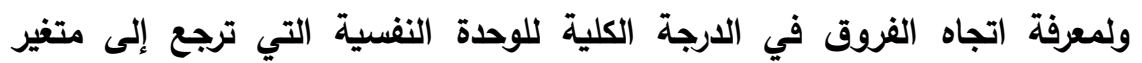

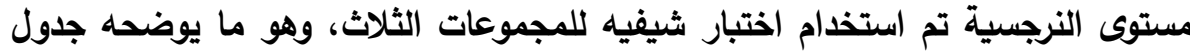


مجلة كلية التربية، جامعة الأزهر ، العدد: (185، الجزء الثالث) يناير لسنة 2020م

\section{جدول (10) - (10)}

نتائج اختبار شيفيه لمعرفة اتجاه الفروق في الدرجة الكلية للوحدة النفسية/التي ترجع إلى النى

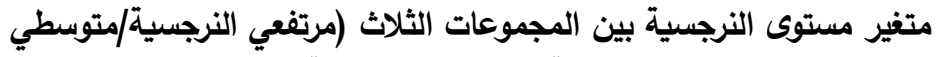
النرجسية/منخفضي النرجسية)

\begin{tabular}{|c|c|c|c|c|}
\hline منخفضو & متوسطو النرجسية & المتوسطات & العدد & المجموعات \\
\hline$* 62.44$ & *40.45 & 101.65 & 100 & مرتفعو النرجسية \\
\hline$* 22.00$ & - & 39.60 & 130 & متوسطو النرجسية \\
\hline - & - & 60.14 & 89 & منخفضو النرجسية \\
\hline
\end{tabular}

يتضح من جدول (10) وجود فروق دالة بين المجموعات الثلاث (مرتفعي

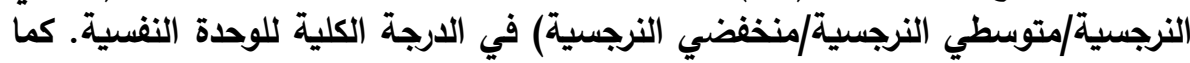

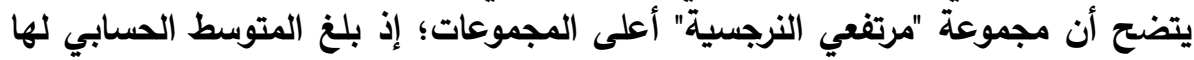

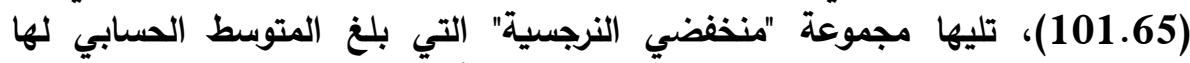
(60.14)، بينما كانت مجموعة متوسطي النرجسية أقل المجموعات في الارجة الكلية

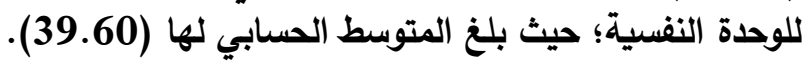

ولمعرفة اتجاه الفروق في الارجة الكلية للوحدة النفسية التي ترجع إلى متغير الأداء

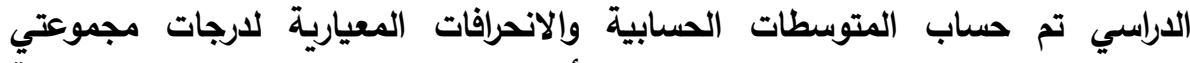

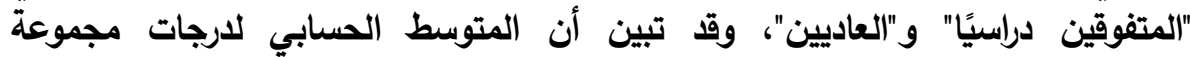

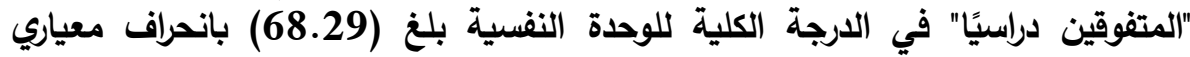

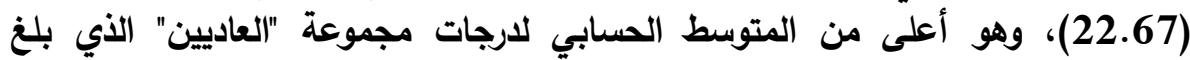

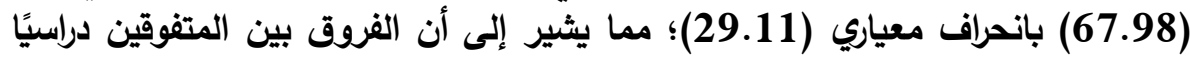
والعاديين في الارجة الكلية للوحدة النفسية في اتجاه المتفوقين دراسيًا.

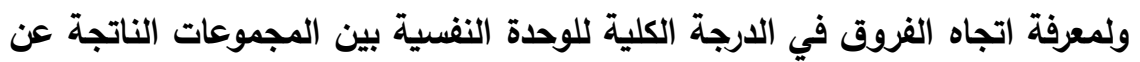
التفاعل بين مستوى النرجسية (مرتفع/ متوسط/ منخفض) والأداء الدراسي (متفوق الدئه

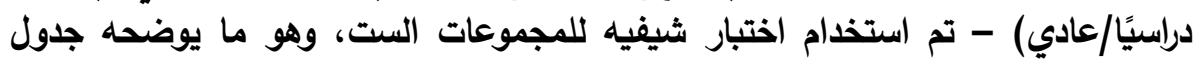


الوحدة النفسية وفقًا لمستوى النرجسية لدى المتفوقين دراسيًا والعاديين من طلاب كلية التربية بجامعة...

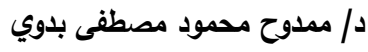

\section{جدول (11)}

نتائج اختبار شيفيه لمعرفة اتجاه الفروق في الارجة الكلية للوحدة النفسية بين المجموعات

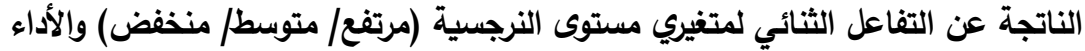
الاراسي (متفوق دراسيًا/عادي)

\begin{tabular}{|c|c|c|c|c|c|c|c|}
\hline \multirow[t]{5}{*}{ | متفخفضو } & | عاديون & متوسطو & عرتفعو & متفورقفون & المتوسطات & العدد & المجموعات \\
\hline & & & & - & 103.41 & 61 & متفوقفون دالنرجسيةًا \\
\hline & & & - & 3.512 & 99.90 & 39 & مرتفعو النرجسية \\
\hline & & - & *61.090 & *64.602 & 39.29 & 52 & متفوقونو النرجسية \\
\hline & - & 0.487 & $* 60.631$ & $* 64.115$ & 38.81 & 78 & متوسطو النرجسية \\
\hline- & $* 23.703$ & *32.954 & $* 28.136$ & *31.648 & 71.76 & 42 & منففضضو النرجسية \\
\hline *9.251 & $* 23.216$ & $* 32.467$ & *37.387 & *40.899 & 62.51 & 47 & منخفضو النرجسية \\
\hline
\end{tabular}

0.01 دال عند مستوى 0.

يتضح من جدول (11) وجود فروق دالة عند مستوى 0.01 بين المجموعات

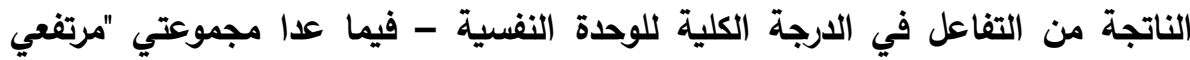

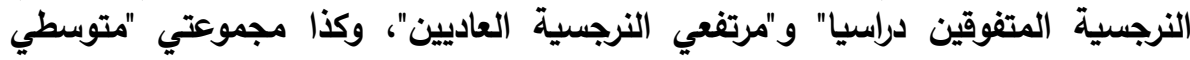

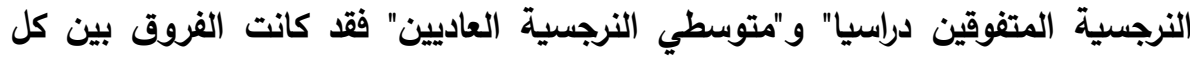

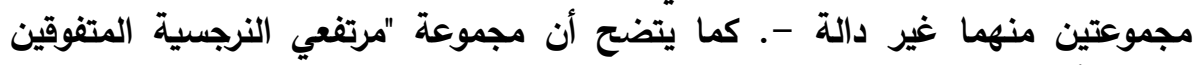

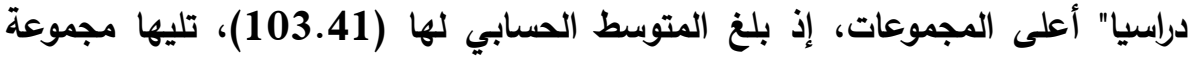

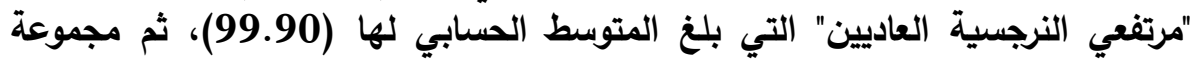

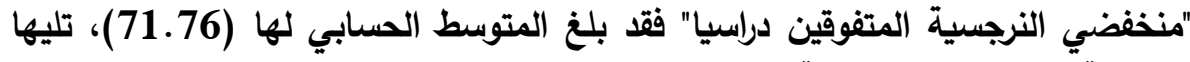

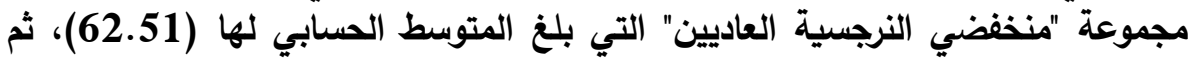




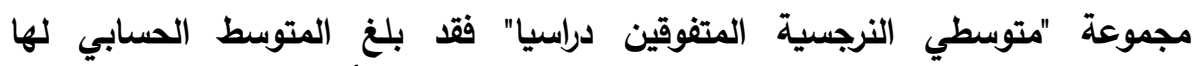
(39.29)، بينما كانت مجموعة "متوسطي النرجسية العاديين" أقل المجموعات في الدرجة الدئة

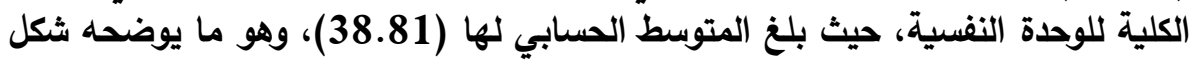
(1) (1) (1)

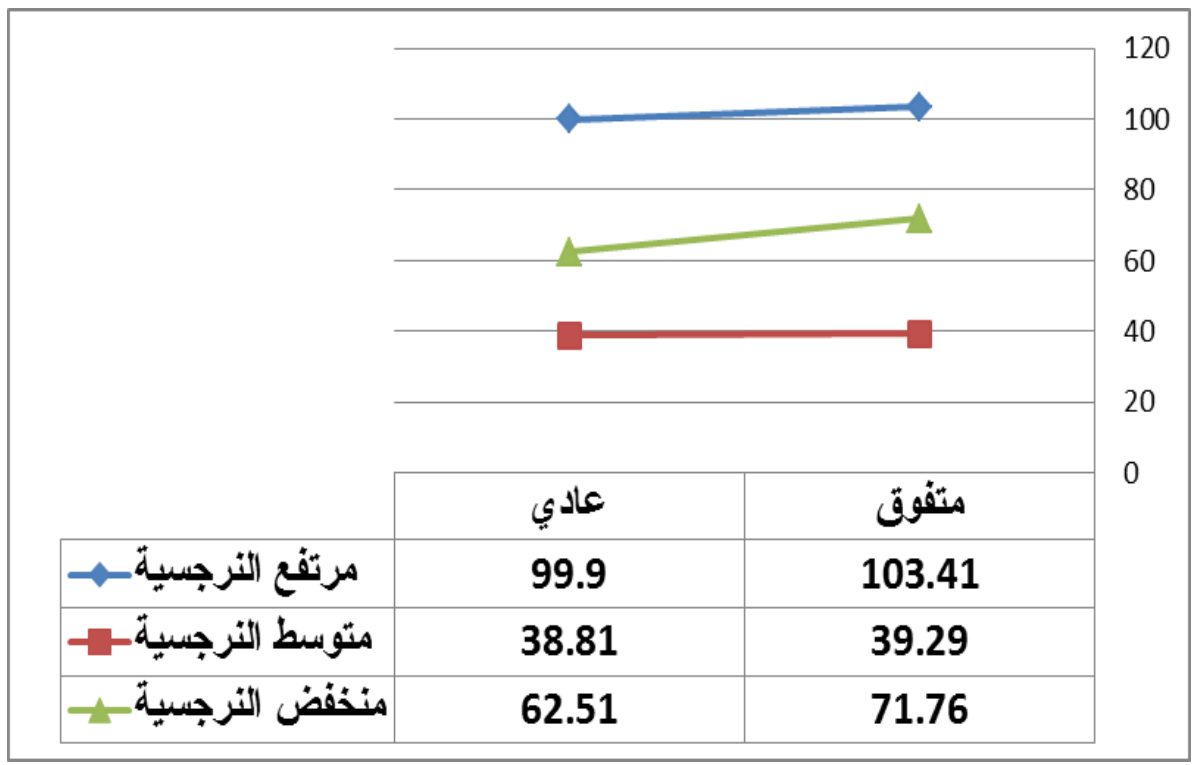

شكل (1) رسم بياني للفروق في الدرجة الكلية للوحدة النفسية بين المجموعات الناتجة عن التفاعل بين متفيري مستوى النرجسية والأداء الدراسي مناقشة وتفسير نتائج الفرض الأول:

تبين من نتائج هذا الفرض وجود فروق في الارجة الكلية للوحدة النفسية وفقًا

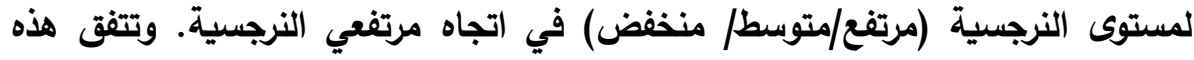

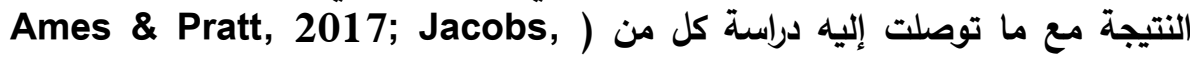
2019) من وجود علاقة موجبة بين النرجسية والوحدة النفسية لاى طلاب الجامعة دامئ.

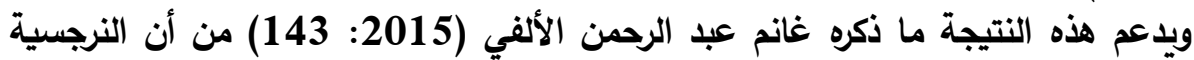

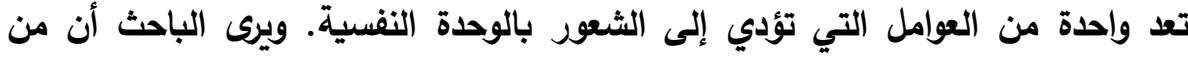

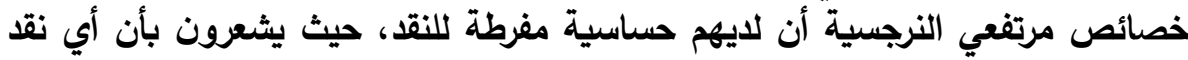

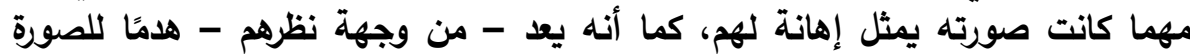

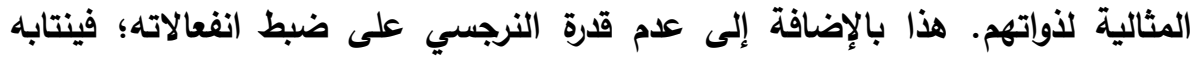

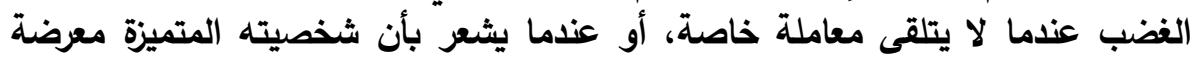




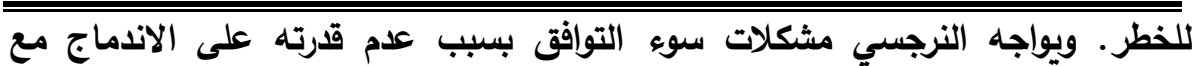

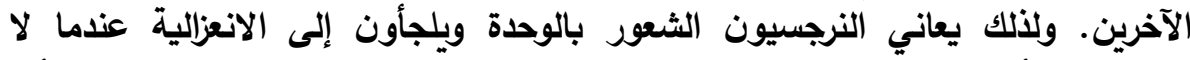

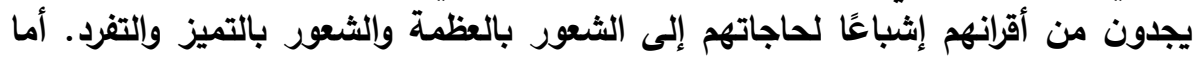

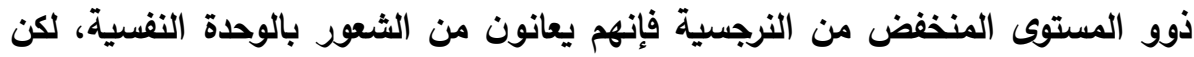

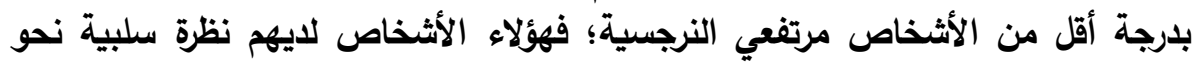

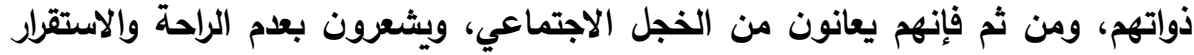

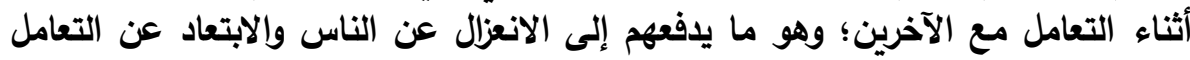

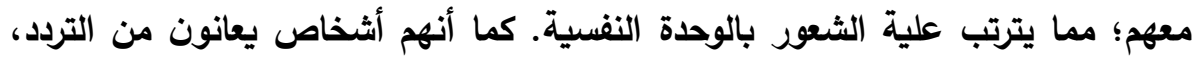

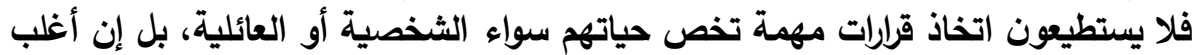

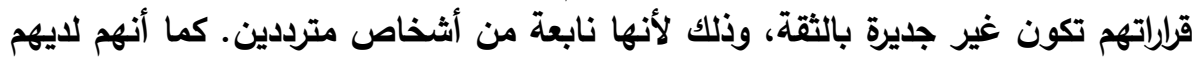

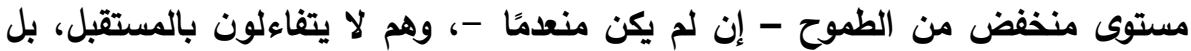

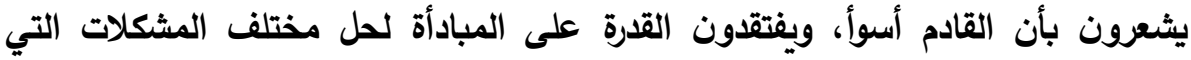

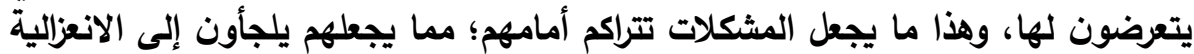

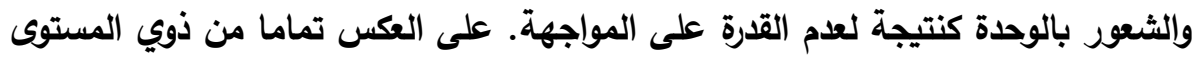

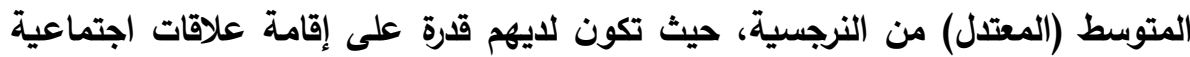

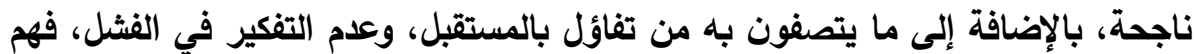

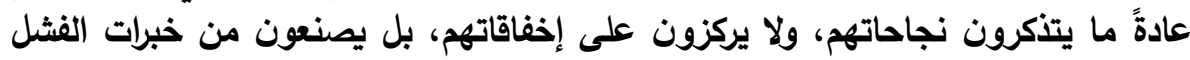

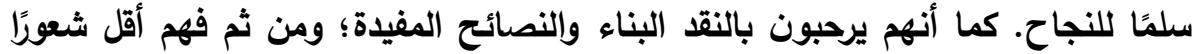

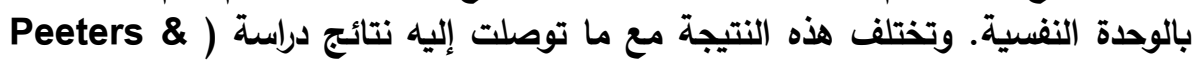
(Thisted, 2019

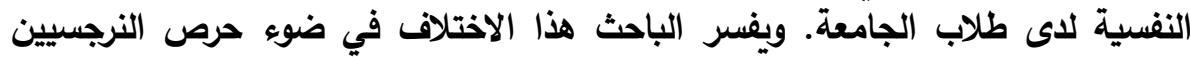

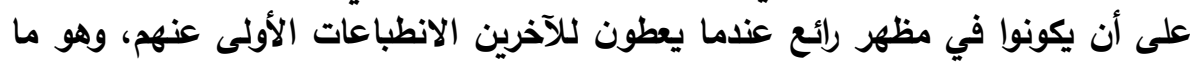

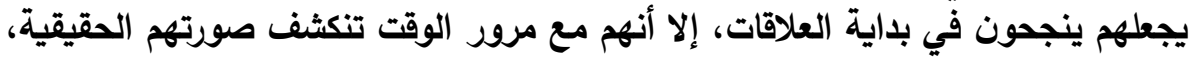

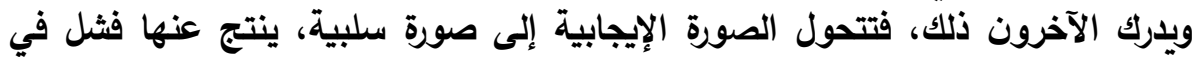

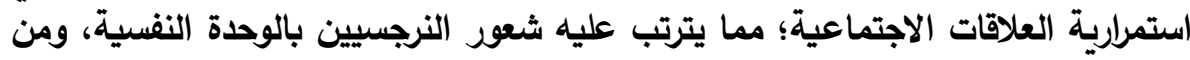

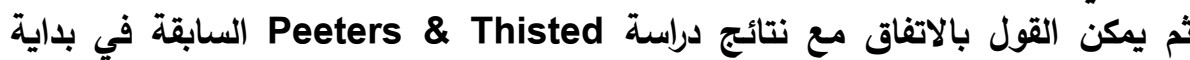

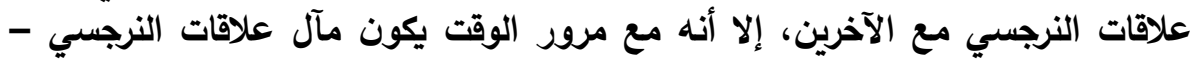
غالبًا - الفشل، الذي يترتب عليه الشعور بالوحدة النفسية.

كما تبين من نتائج هذا الفرض وجود فروق في الدائين الدارجة الكلية للوحدة النفسية

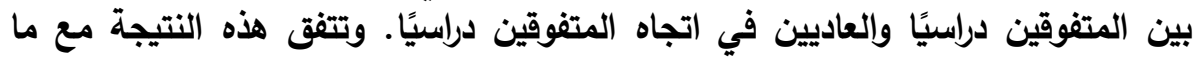

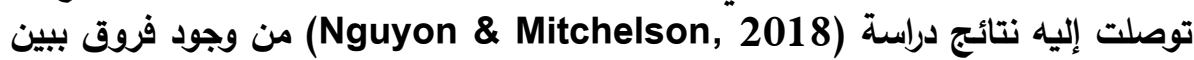


المتفوقين دراسيًا والعاديين في الوحد النفسية في اتجاه المتفوقين دراسيًا. كما أسفرت نتائج دراسة (Mobley; Trippi \& Ashby, 2010) عن أن نسبة الثعور بالوحدة

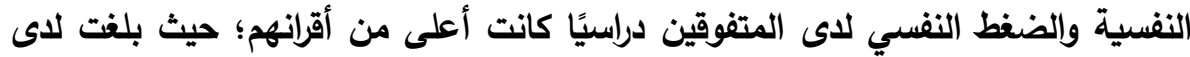

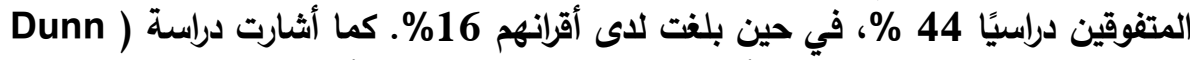
\& Wayment, 2016 إلى أن الوحدة النفسية تعد من أهم التحديات التي تواجه

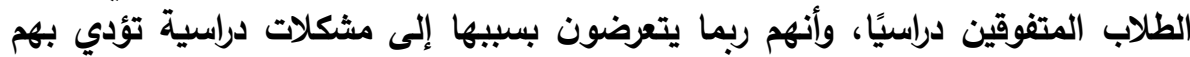

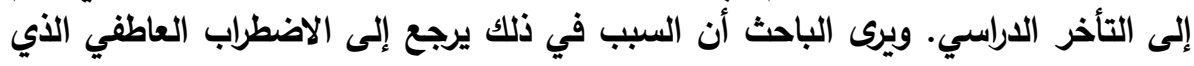

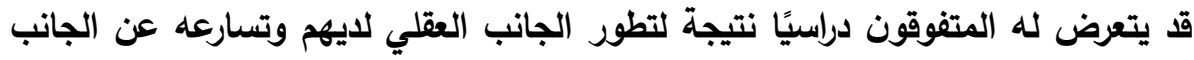

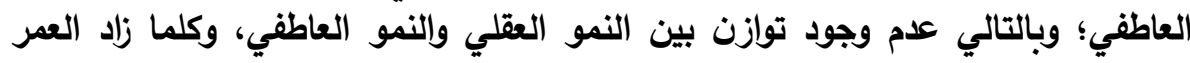

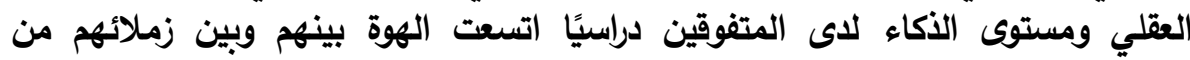

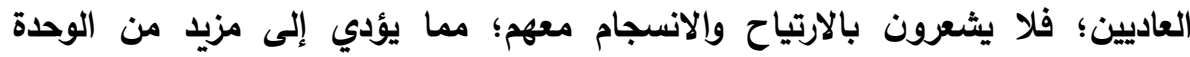

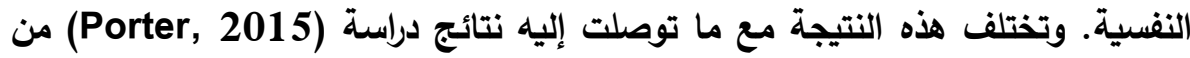

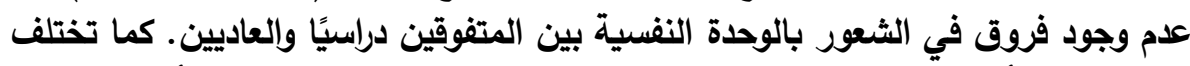

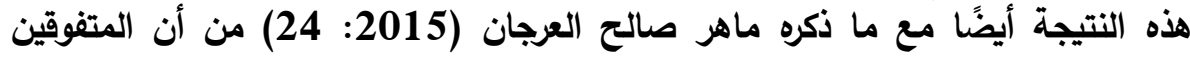

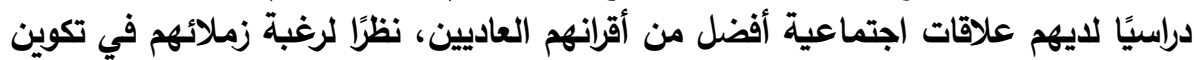

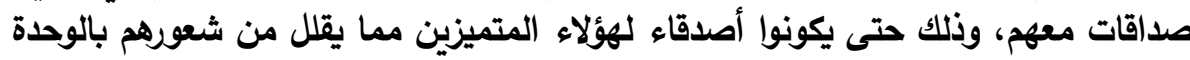

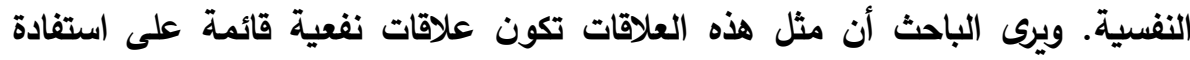

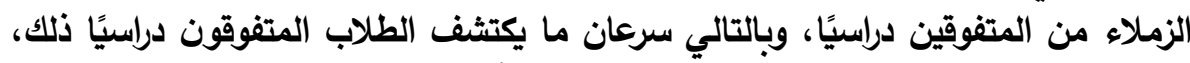

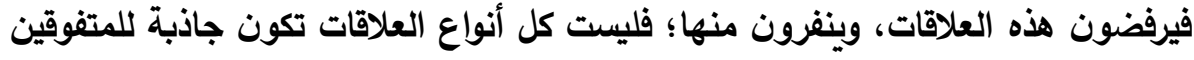

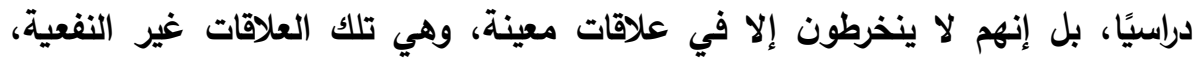
خاصة عندما تكون مع من في مستواهم العقلي والإراسي.

كذلك تبين من نتائج هذا الفرض وجود أثر للتفاعل بين مستوى النرجسية

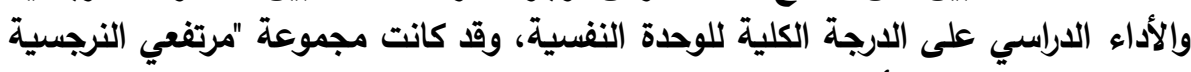

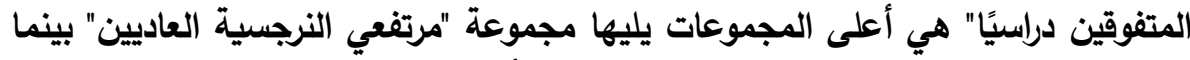

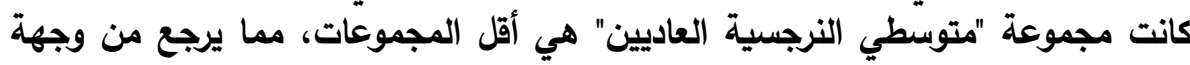

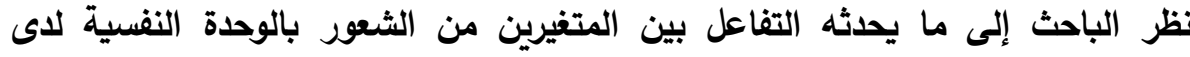

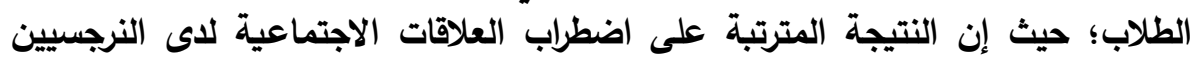

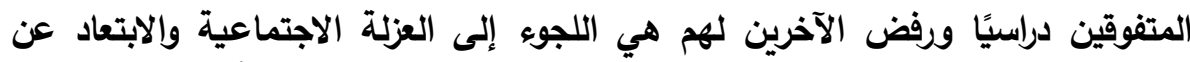

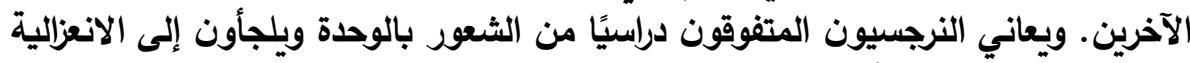

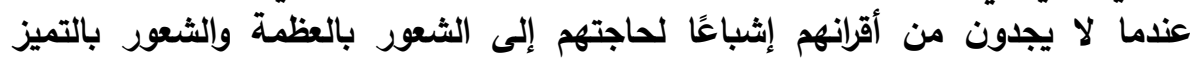
والتفرد. كما تثير النتائج أيضًا إلى أن متغير النرجسية أكثر أهمية من متغير الأداء 
الوحدة النفسية وفقًا لمستوى النرجسية لاى المتفوقين دراسيًا والعاديين من طلاب كلية التربية بجامعة...

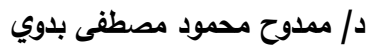

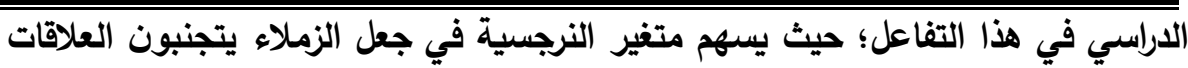

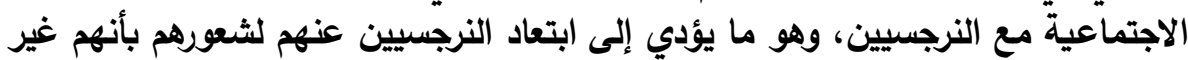
محبوبين من قبلهم؛ الأمر يترتب عليه شعورهم بالوحدة النفسية.

ثانيًا: نتائج الفرض الثاني ومناقشتها:

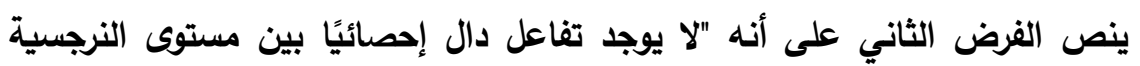

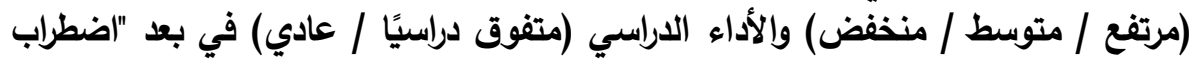

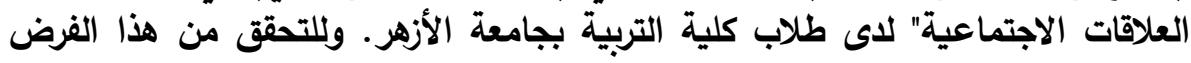

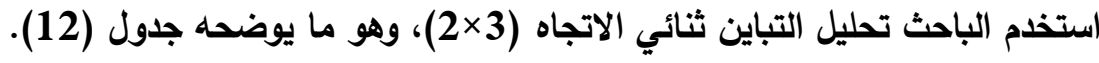

جدول (12)

نتائج تحليل التباين ثنائي الاتجاه 3×2 لتحديد التفاعل بين متغيري مستوى النرجسية

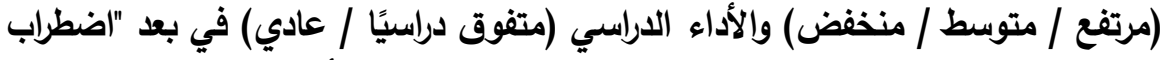

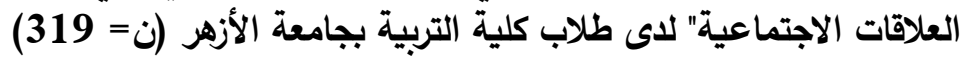

\begin{tabular}{|c|c|c|c|c|c|}
\hline مستوى الدلائ & قيمة "ف" & المربعات & الدرجات & مجموع المربعات & مصدر التباين \\
\hline 0,01 & $\begin{array}{c}1653.11 \\
7\end{array}$ & 22984.771 & 2 & 45969.541 & (مرتفع/متوسط/منخفض) مسترجية \\
\hline 0,01 & 55.826 & 776.198 & 1 & 776.198 & $\begin{array}{c}\text { (الأداء الاراسيسي } \\
\text { (متفوق دراسيًاعادي) }\end{array}$ \\
\hline \multirow[t]{3}{*}{0,01} & 85.130 & 1183.638 & 2 & 2367.275 & 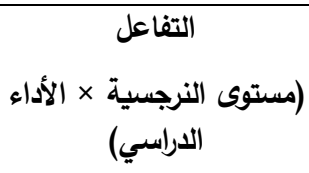 \\
\hline & & 13.904 & 313 & 4351.921 & الخطأ \\
\hline & & & 318 & 435784.000 & المجموع الكلي \\
\hline
\end{tabular}

يتضح من جدول (12) أنه توجد فروق دالة عند مستوى 0.01 في بعد "(ضطراب الإني

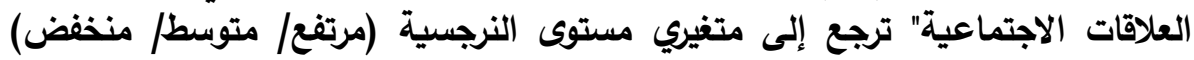

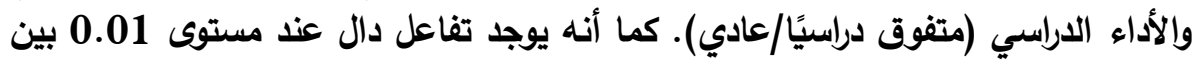

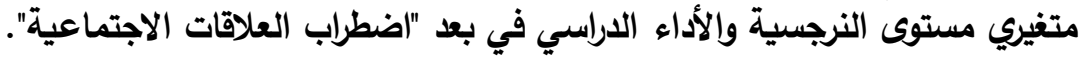


ولمعرفة اتجاه الفروق في بعد "اضطراب العلاقات الاجتماعية" التي ترجع إلى متغير

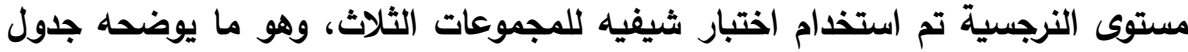

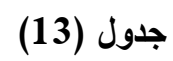

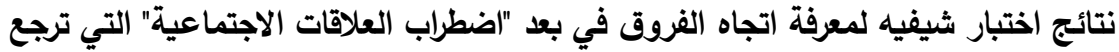

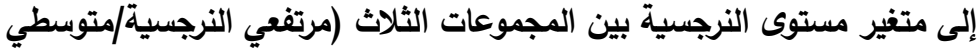
النرجسية/منخفضي النرجسية)

\begin{tabular}{|c|c|c|c|c|}
\hline النزخسضية & متوسطو النرجسية & المتوسطات & العدد & المجموعات \\
\hline *31.55 & *17.10 & 50.21 & 100 & مرتفعو النرجسية \\
\hline *14.44 & - & 18.77 & 130 & متوسطو النرجسية \\
\hline - & - & 32.39 & 89 & منخفضو النرجسية \\
\hline
\end{tabular}

يتضح من جدول (13) وجود فروق دالة بين المجموعات الثلاث (مرتفعي

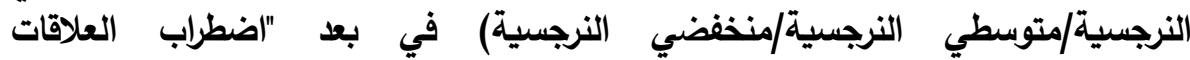

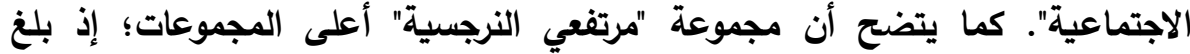

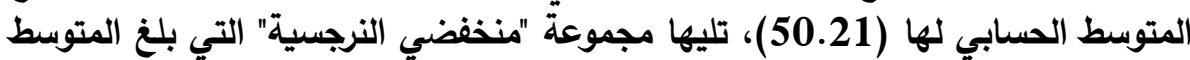

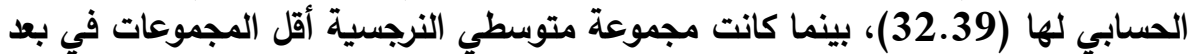

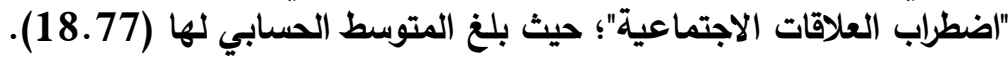

ولمعرفة اتجاه الفروق في بعد "اضطراب العلاقات الاجتماعية" التي ترجع إلى متفير

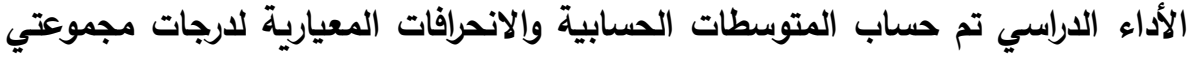

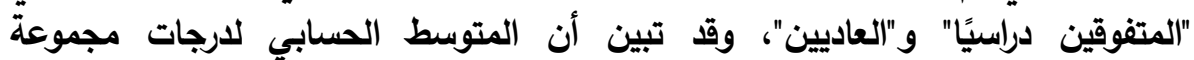

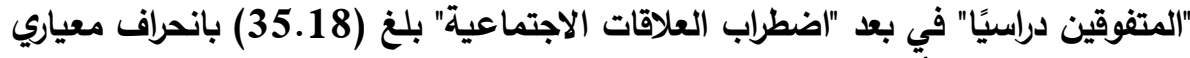

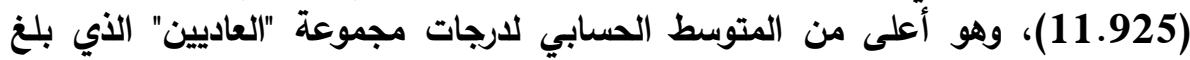

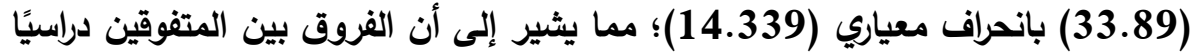
والعاديين في بعد "اضطراب العلاقات الاجتماعية" في اتجاه المتفوقين دراسيًا. 
الوحدة النفسية وفقًا لمستوى النرجسية لدى المتفوقين دراسيًا والعاديين من طلاب كلية التربية بجامعة...

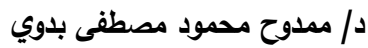

ولمعرفة اتجاه الفروق في بعد "اضطراب العلاقات الاجتماعية" بين المجموعات

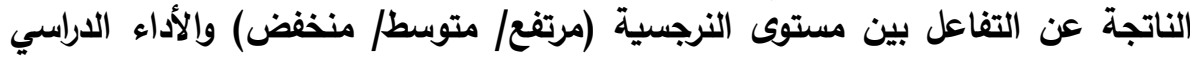

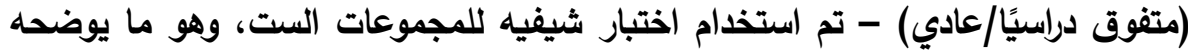
جدول (14).

جدول (14) - (14)

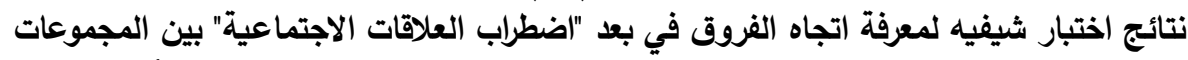

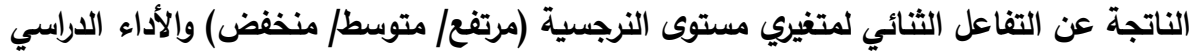
(متفوق دراسيًا/عادي) (ريفي

\begin{tabular}{|c|c|c|c|c|c|c|c|}
\hline منففضضو & مترسطية & متفوسيطة & عادريونية & متفرتوقيسة & |لمتوسطات & العدد & المجموعات \\
\hline & & & & - & 50.66 & 61 & مترتفسية \\
\hline & & & - & 0.887 & 49.77 & 39 & عادريونية \\
\hline & & - & *31.064 & *32.040 & 18.71 & 52 & متفوسطية \\
\hline & - & 0.090 & $* 31.064$ & $* 31.951$ & 18.63 & 78 & عادروسية \\
\hline- & $* 15.704$ & $* 19.575$ & $* 11.579$ & $* 12.465$ & 38.19 & 42 & منفففية \\
\hline *3.871 & $* 15.614$ & * 19.485 & $* 15.450$ & $* 16.337$ & 34.32 & 47 & النرجسية \\
\hline
\end{tabular}

0.01 * دال عند مستوى 
يتضح من جدول (14) وجود فروق دالة عند مستوى 0.01 بين المجموعات

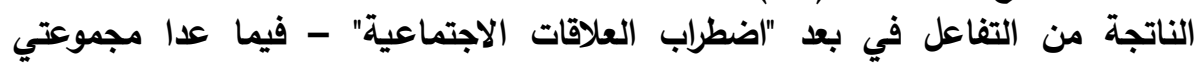

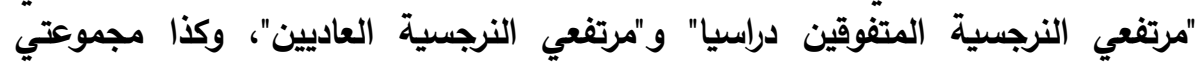

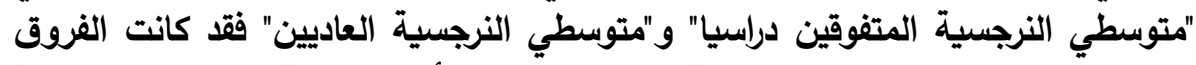

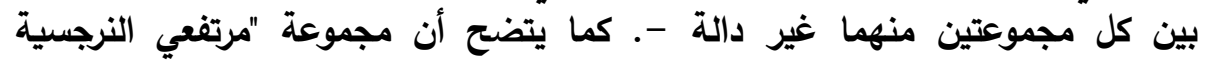

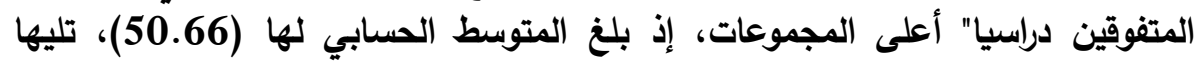

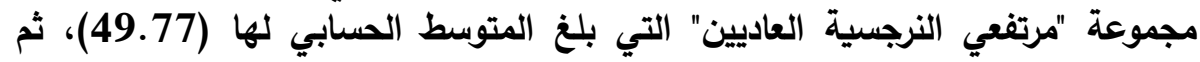

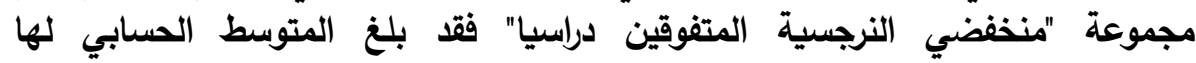

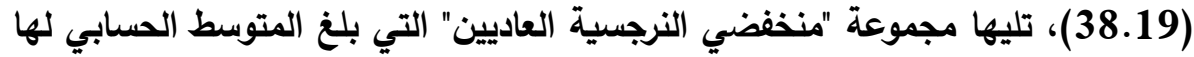

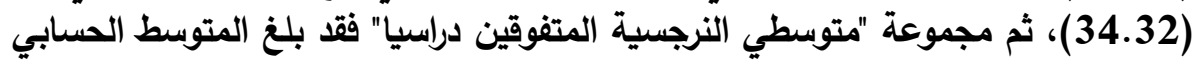

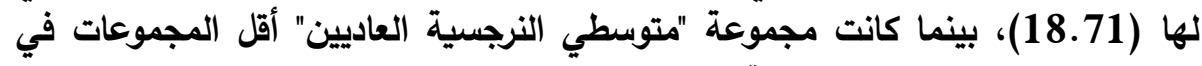

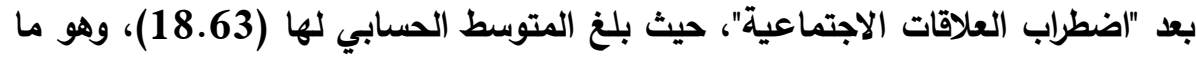

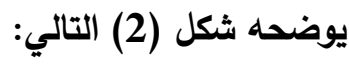

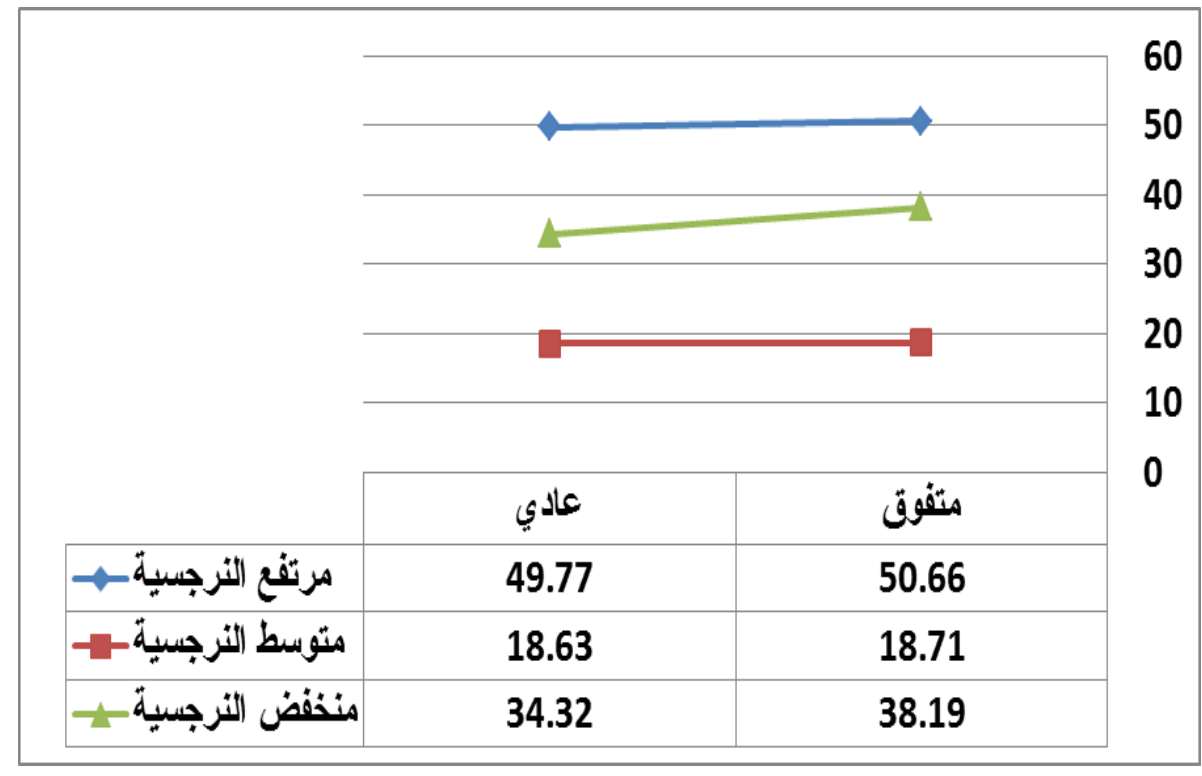

شكل (2) رسم بياني للفروق في بعد "اضطراب العلاقات الاجتماعية" بين المجموعات الناتجة عن التفاعل بين متفيري مستوى النرجسية والأداء الدراسي 


$$
\text { مناقثة وتفسير نتائج الفرض الثاني: }
$$

تبين من نتائج هذا الفرض وجود فروق في بعد "اضطراب العلاقات الاجتماعية"

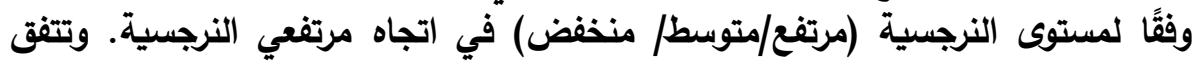

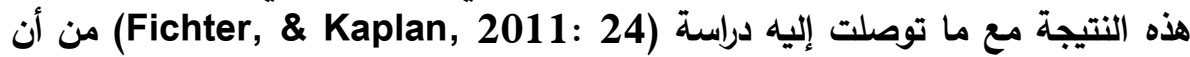

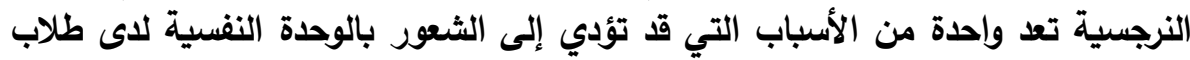

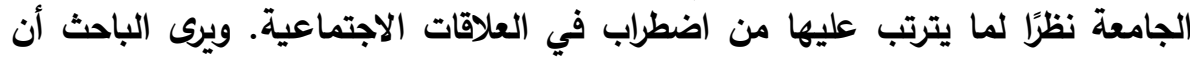

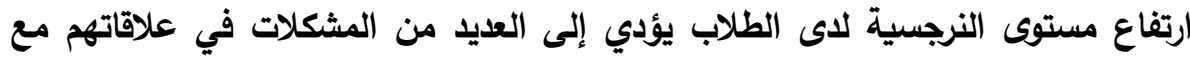

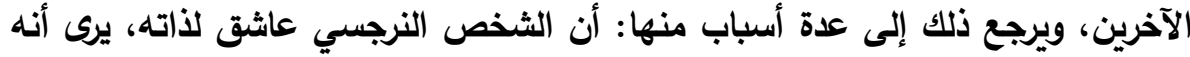

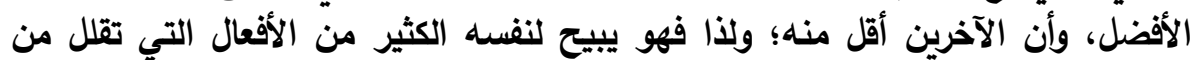

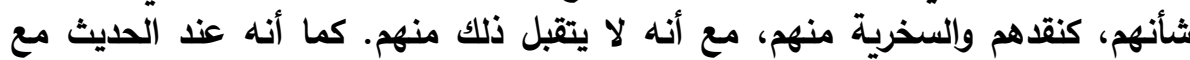

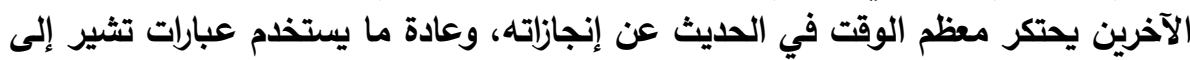

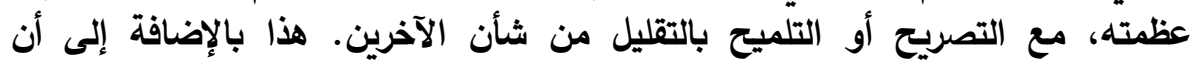

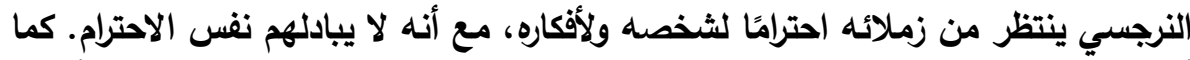

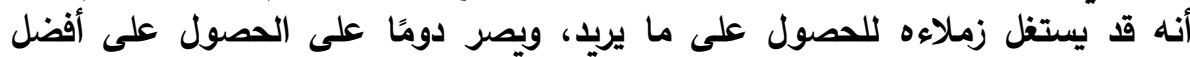

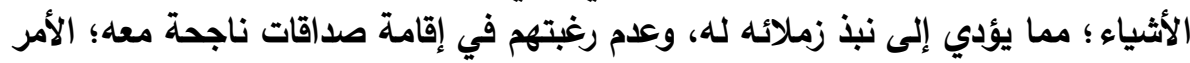

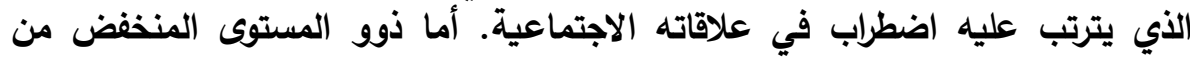

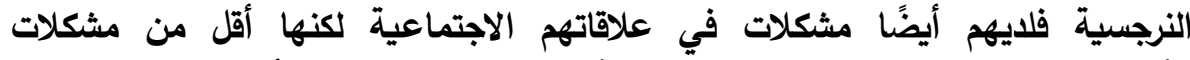

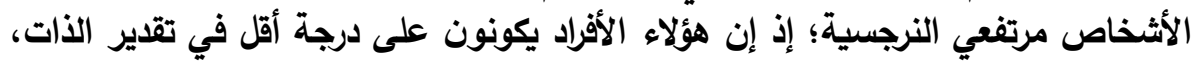

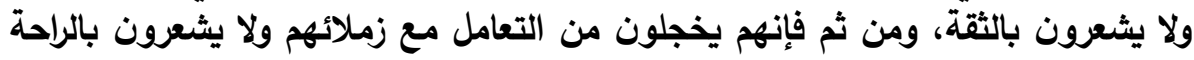

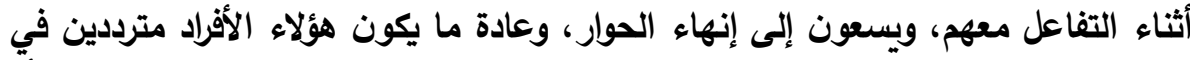

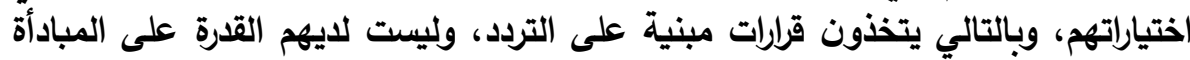

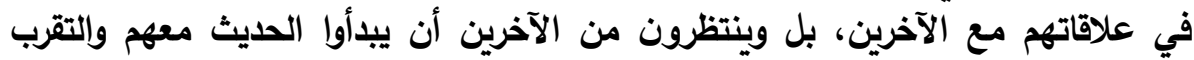

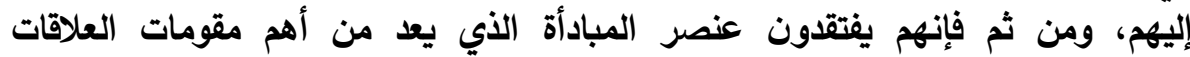

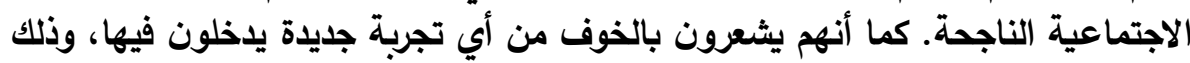

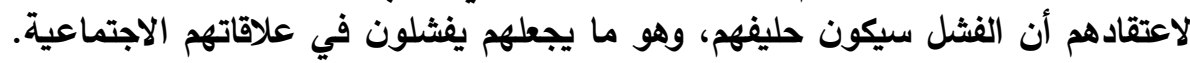

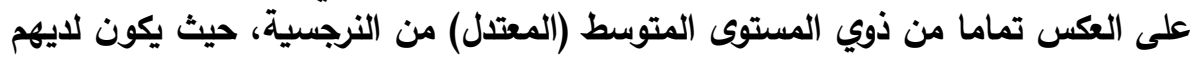

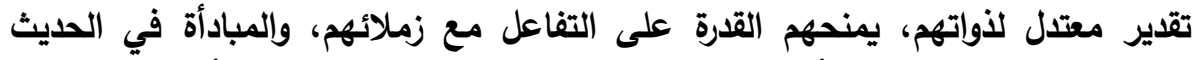

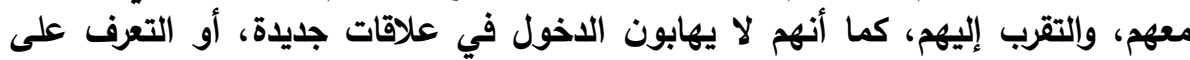

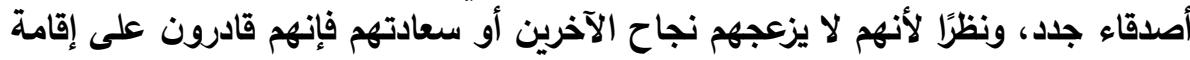

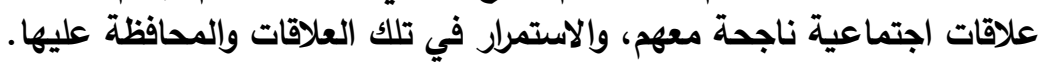


كما تبين من نتائج هذا الفرض وجود فروق في بعد "اضطراب العلاقات

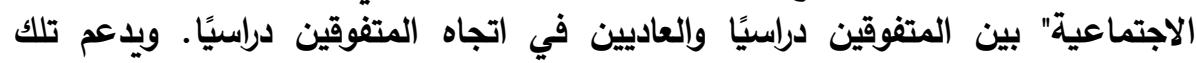
النتيجة ما ذكرته صفية سعد الاجتئ النيال (1999:

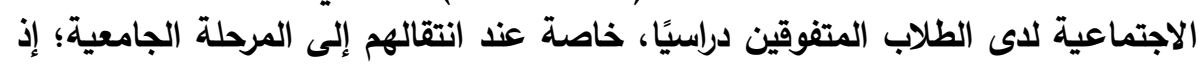

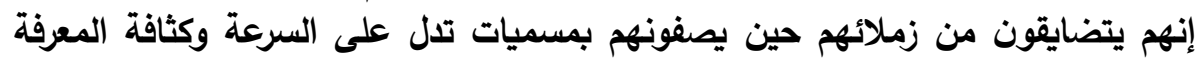

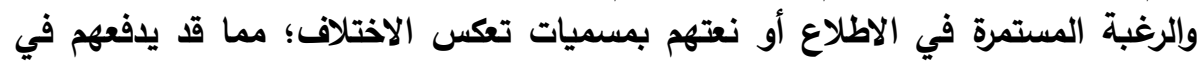

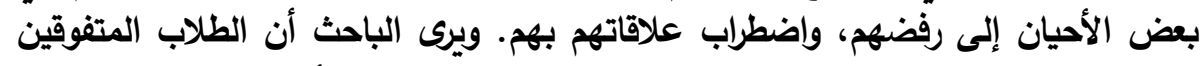

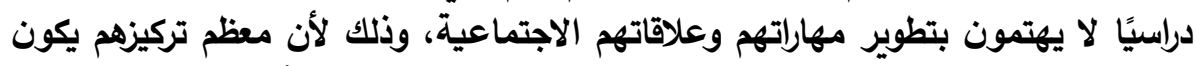

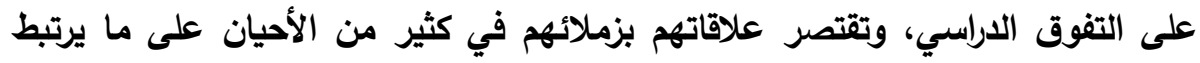

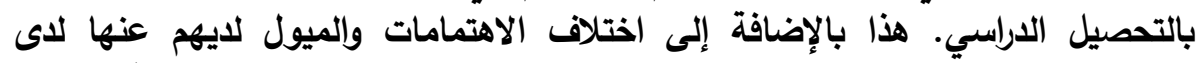

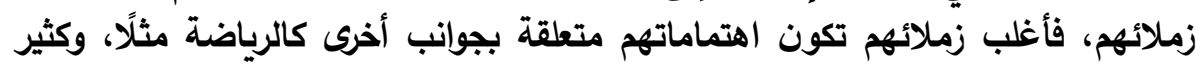

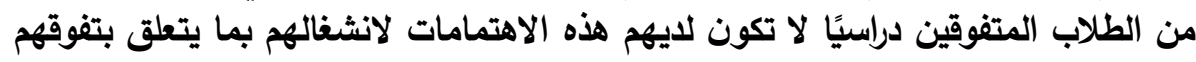

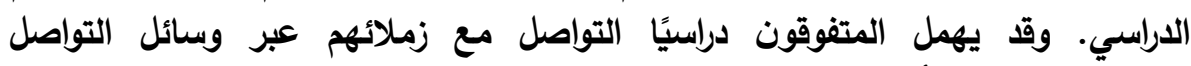

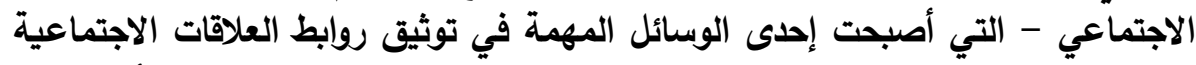

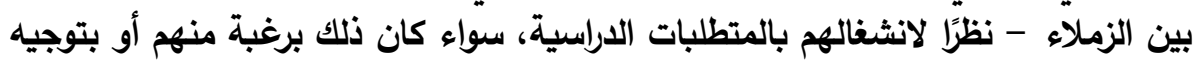

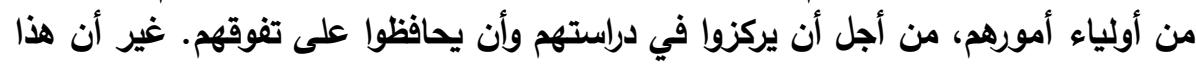

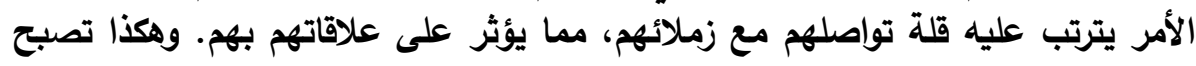

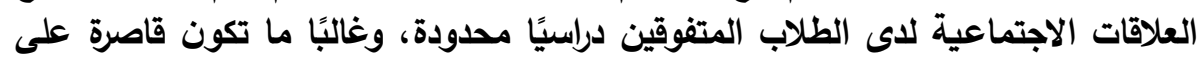
من هم في نفس مستواهم العقلي أو الاراسي.

كذلك تبين من نتائج هذا الفرض وجود أثر للتفاعل بين مستوى النرجسية

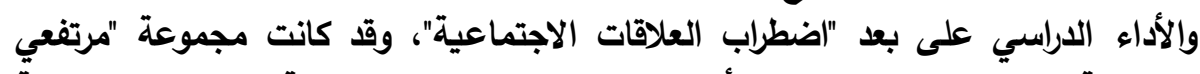

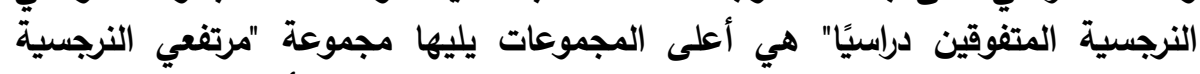

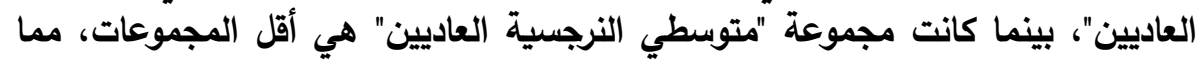

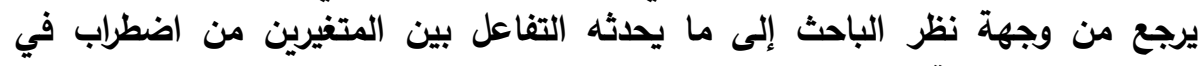

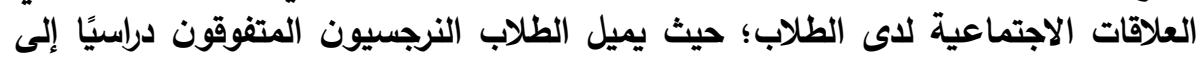

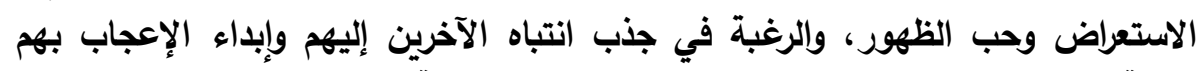

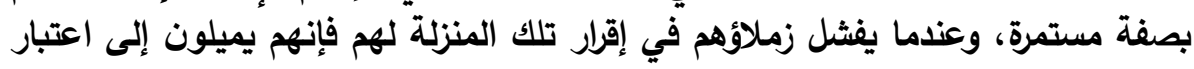

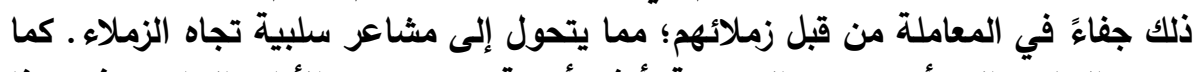

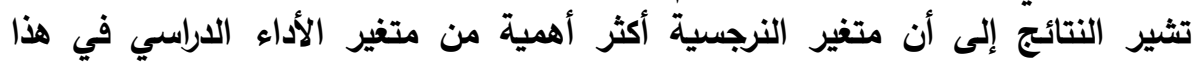
التفاعل؛ حيث يسهم متغير النرجسية - بدرجة كبيرة - في استغرلق الفير الفرد في الهتماماته 
الوحدة النفسية وفقًا لمستوى النرجسية لاى المتفوقين دراسيًا والعاديين من طلاب كلية التربية بجامعة...

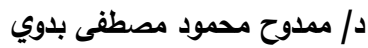

الثخصية، مما يثظه عن علاقاته بزملائه؛ الأمر الذي يؤدي إلى اضطراب علاقاته الاجتماعية.

ثالثًا: نتائج الفرض الثاءئث

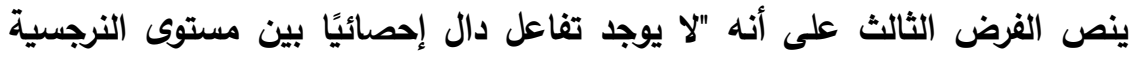

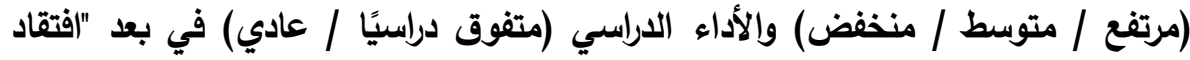

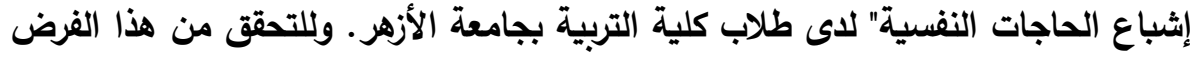

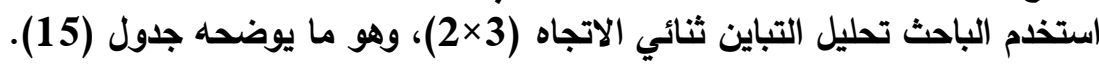

جدول (15)

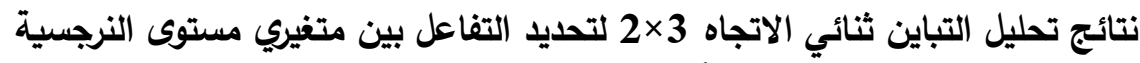

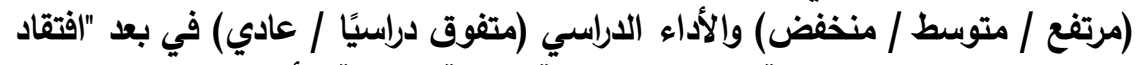

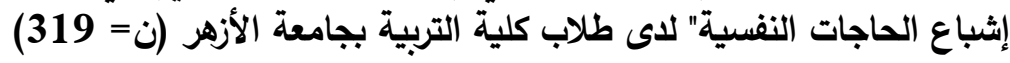

\begin{tabular}{|c|c|c|c|c|c|}
\hline مستوى & قيمة "ف" & المربعات & لدرجات & مجموع المربعات & مصدر التباين \\
\hline 0,01 & 1474.517 & 24503.935 & 2 & 49007.871 & (مرتفع/متوسط/منخفض النرجسية) \\
\hline 0,01 & 14.531 & 241.474 & 1 & 241.474 & 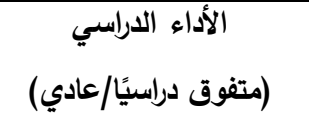 \\
\hline \multirow[t]{3}{*}{0,01} & 54.311 & 902.555 & 2 & 1805.110 & 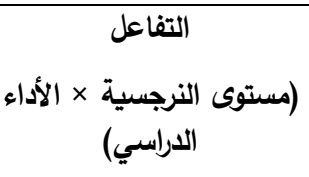 \\
\hline & & 16.618 & 313 & 5201.520 & الخطأ \\
\hline & & & 318 & 418443.000 & المجموع الكلي \\
\hline
\end{tabular}

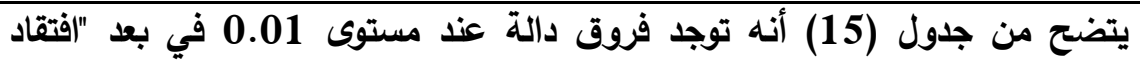

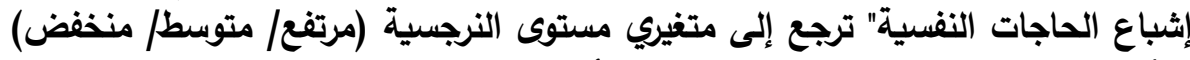

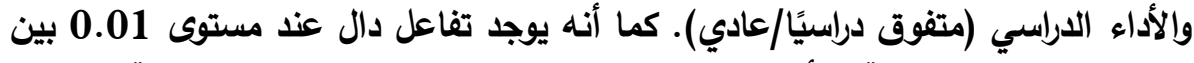

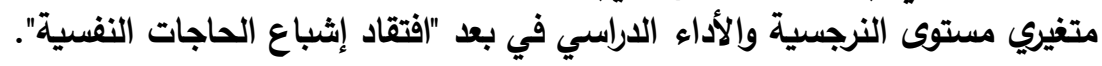


ولمعرفة اتجاه الفروق في بعد "|فتقاد إثباع الحاجات النفسية" التي ترجع إلى متغير

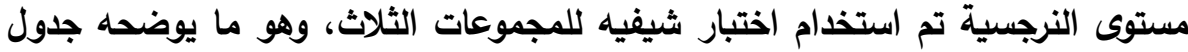

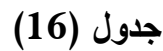

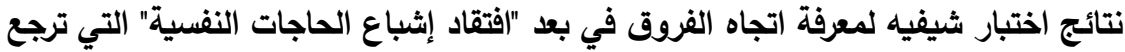

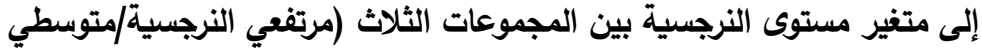

النرجسية/منخفضي النرجسية)

\begin{tabular}{|c|c|c|c|c|}
\hline النرجسية & متوسطو النرجسية & المتوسطات & العدد & المجموعات \\
\hline$* 30.90$ & $* 23.35$ & 51.44 & 100 & مرتفعو النرجسية \\
\hline$* 7.55$ & - & 20.84 & 130 & متوسطو النرجسية \\
\hline - & - & 27.76 & 89 & منخفضو النرجسية \\
\hline
\end{tabular}

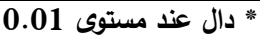

يتضح من جدول (16) وجود فروق دالة بين المجموعات الثلاث (مرتفعي

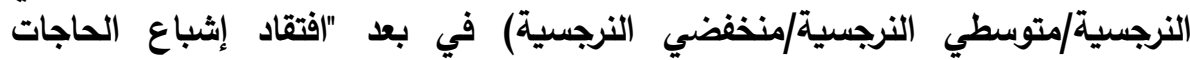

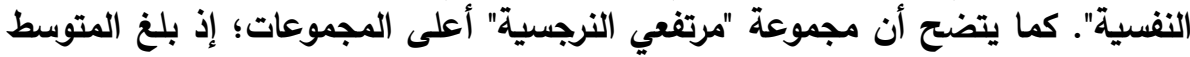

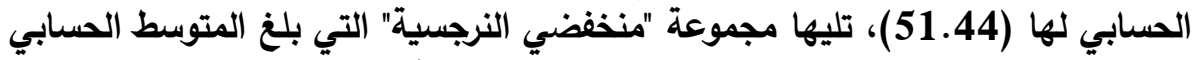

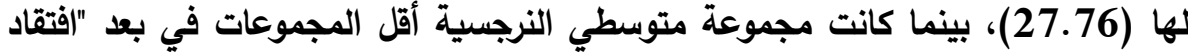

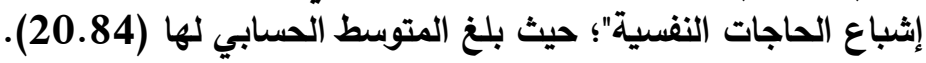

ولمعرفة اتجاه الفروق في بعد "|فتقاد إثباع الحاجات النفسية" التي ترجع إلى متفير

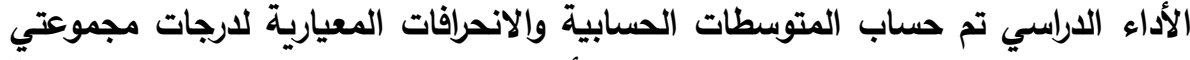

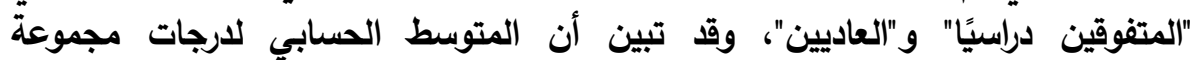

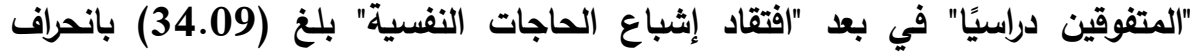

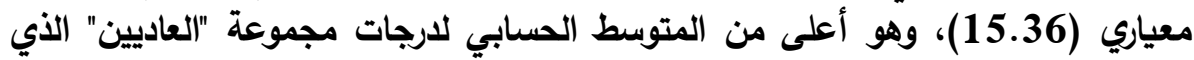

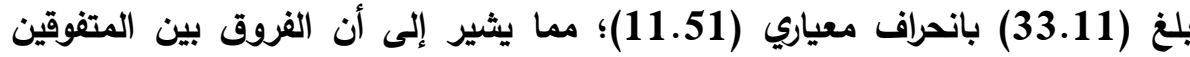

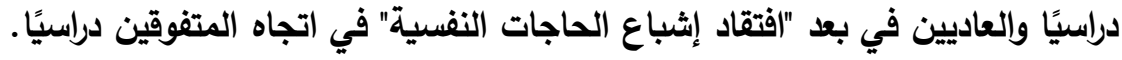


الوحدة النفسية وفقًا لمستوى النرجسية لدى المتفوقين دراسيًا والعاديين من طلاب كلية التربية بجامعة...

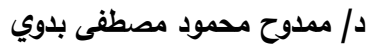

ولمعرفة اتجاه الفروق في بعد "(فتقاد إثباع الحاجات النفسية" بين المجموعات

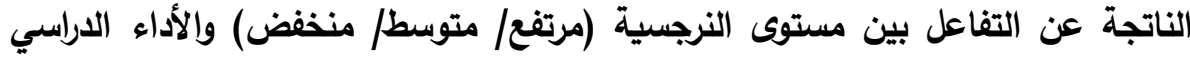

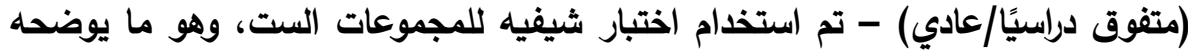
جدول (17).

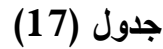

نتائج اختبار شيفيه لمعرفة اتجاه الفروق في بعد "(فتقاد إثباع الحاجات النفسية" بين

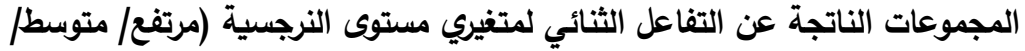
منذفض) والأداء الدراسي (متفوق دراسيًا اعادي)

\begin{tabular}{|c|c|c|c|c|c|c|c|}
\hline منففضضو & متوسطو & متفوسوسية & عادريونة & متفرتفية & المتوسطا & | العدد & المجموعات \\
\hline & & & & - & 52.75 & 61 & متفوقيونية \\
\hline & & & - & 2.626 & 50.13 & 39 & عاديون \\
\hline & & - & $* 29.551$ & *32.177 & 20.74 & 52 & متفوسطية \\
\hline & - & 0.167 & $* 29.385$ & *32.011 & 20.58 & 78 & مترسطية \\
\hline- & *7.615 & *12.995 & *16.557 & * 19.183 & 33.57 & 42 & منففضية \\
\hline *5.380 & *7.448 & *12.828 & *21.937 & * 24.563 & 28.19 & 47 & عادريونة \\
\hline
\end{tabular}

0.01 * دال عند مستوى 
يتضح من جدول (17) وجود فروق دالة عند مستوى 0.01 بين المجموعات

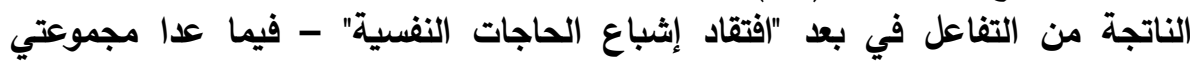

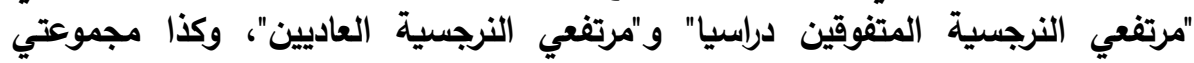

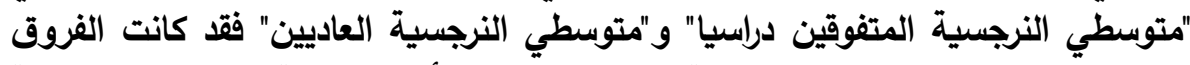

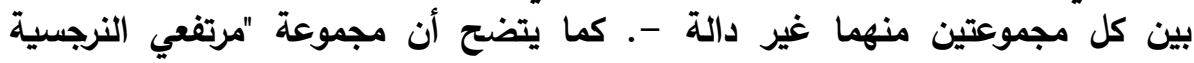

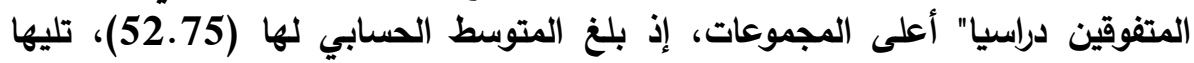

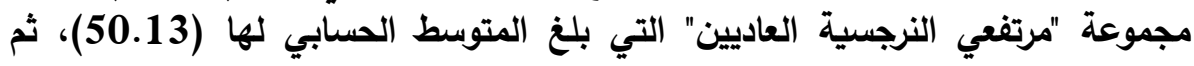

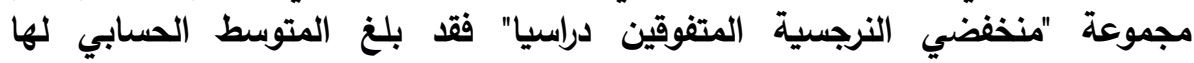

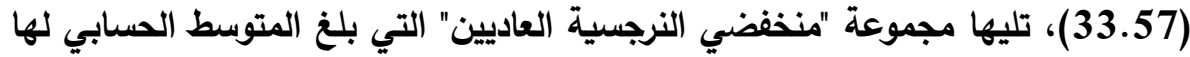

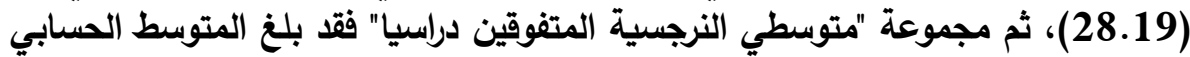

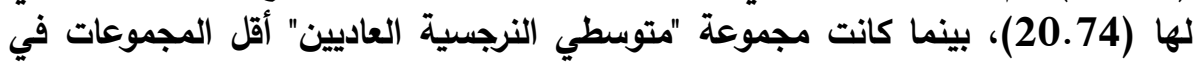

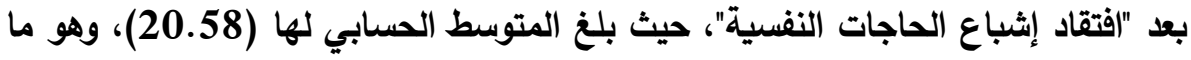

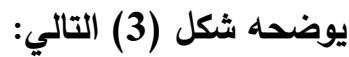

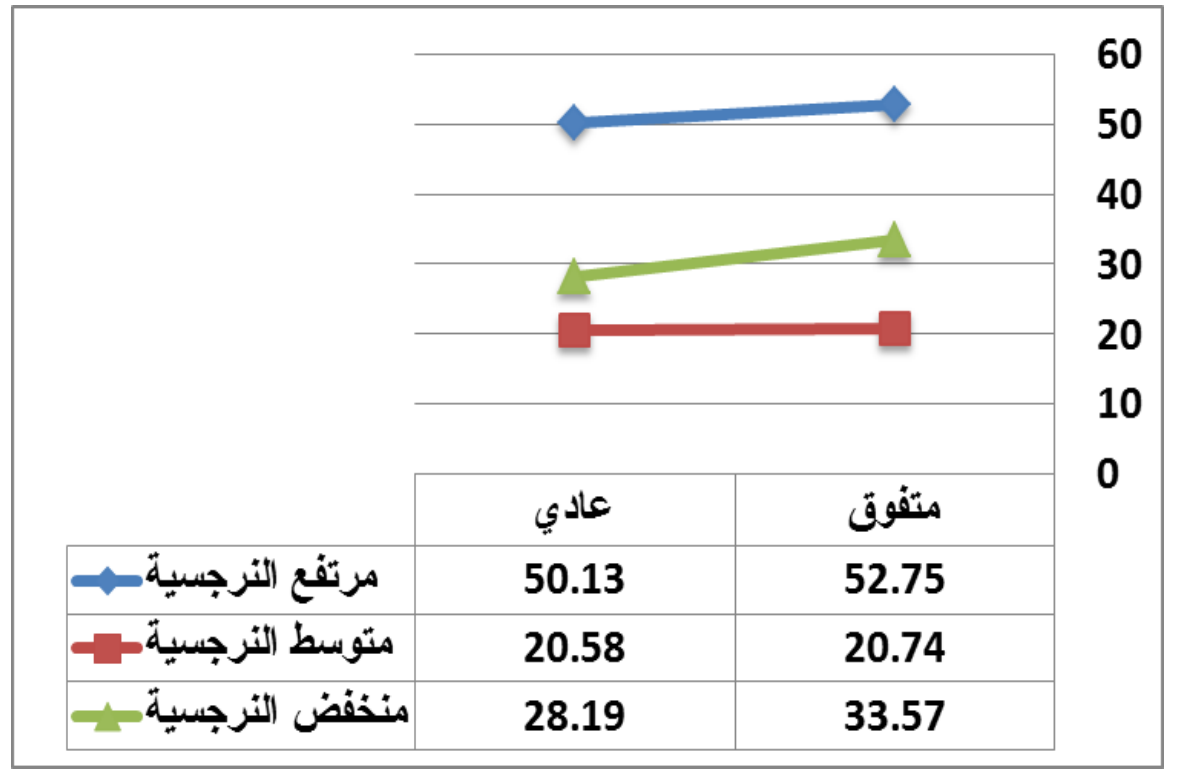

شكل (3) رسم بياني للفروق في بعد "(فتقاد إثباع الحاجات النفسية" بين المجموعات الناتجة عن التفاعل بين متغيري مستوى النرجسية والأداء الدراسي 


\section{مناقثة وتفسير نتائج الفرض الثالث:}

تبين من نتائج هذا الفرض وجود فروق في بعد "افتئقاد إشباع الحاجات النفسية"

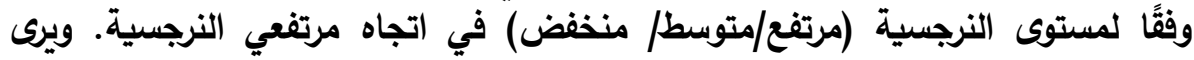

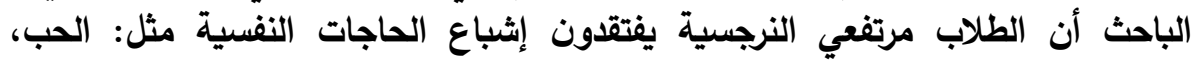

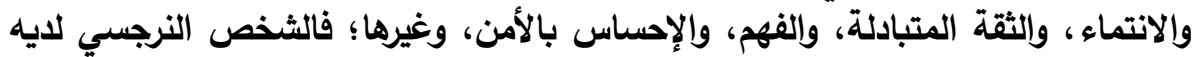

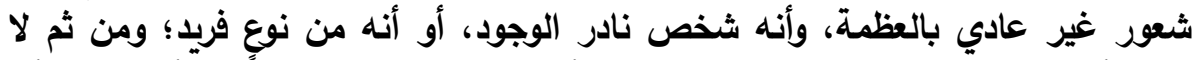

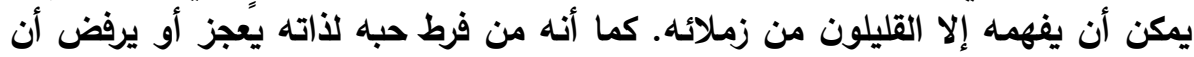

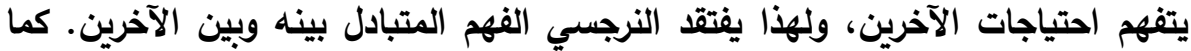

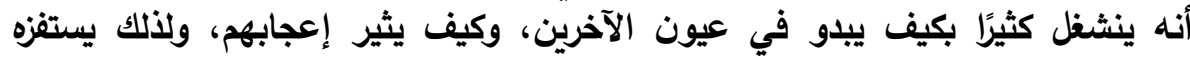

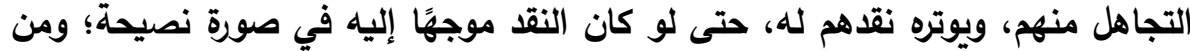

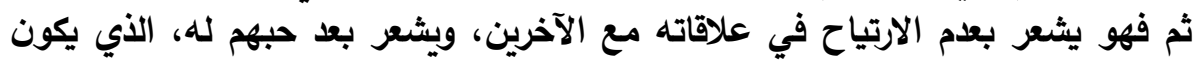

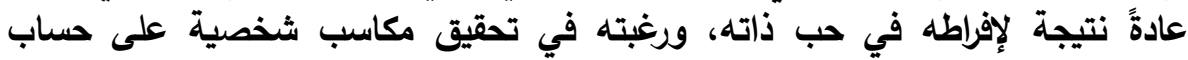

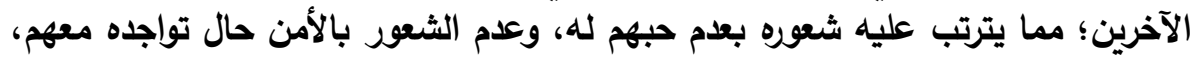

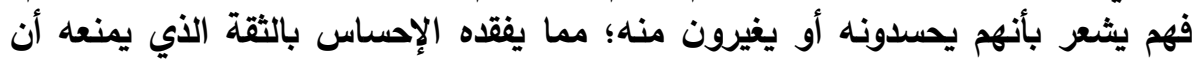

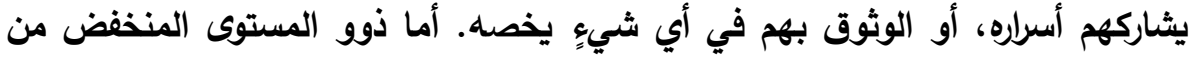

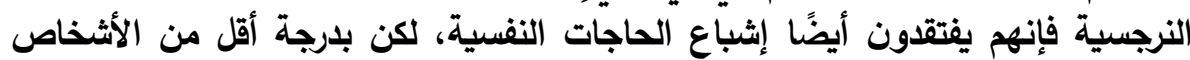

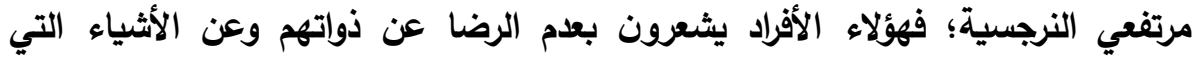

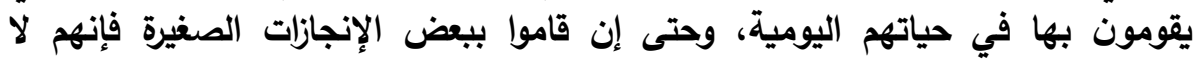

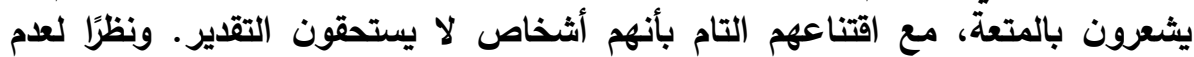

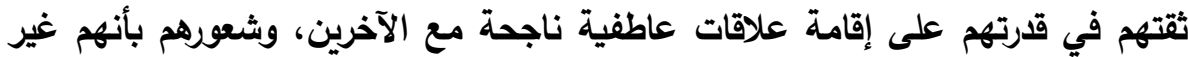

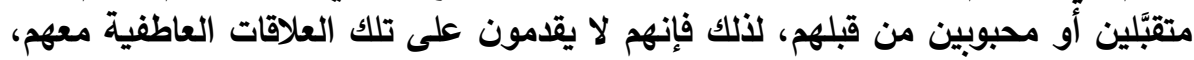

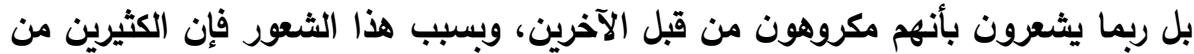

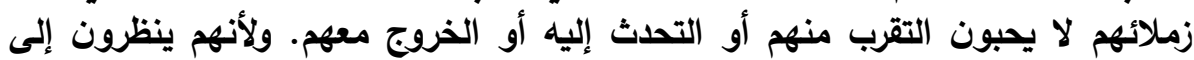

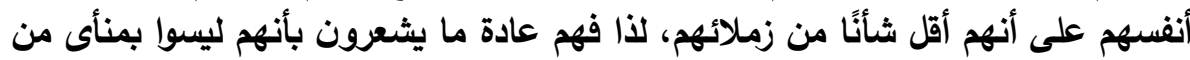

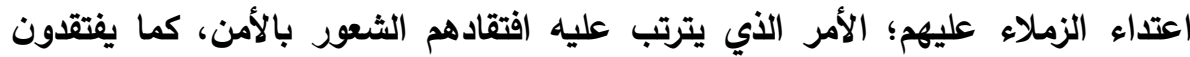

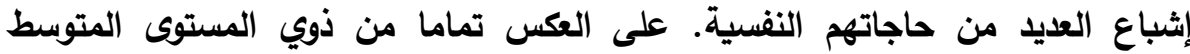

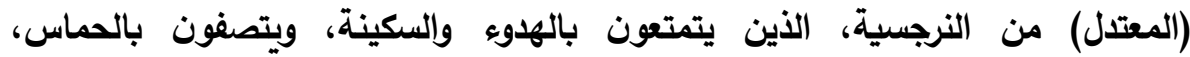

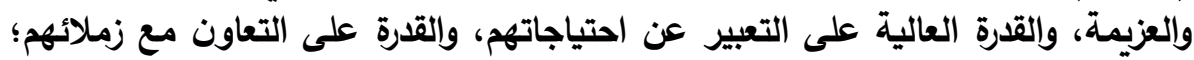

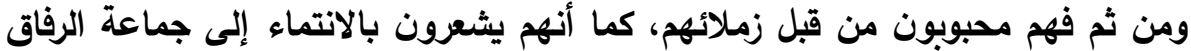

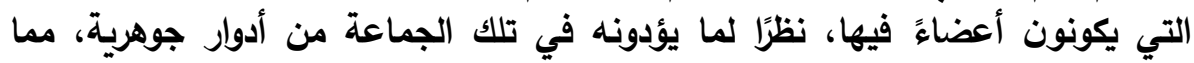


يجعهم يثعرون بالأمن وهم بين أصدقائهم؛ ومن ثم يعد المستوى المعتدل لايهر من النرجسية عاملًا لإشباع حاجاتهم النفسية.

كما تبين من نتائج هذا الفرض وجود فروق في بعد "|فتقاد إثباع الحاجات

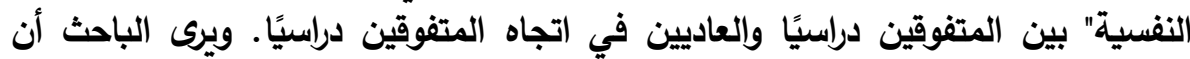

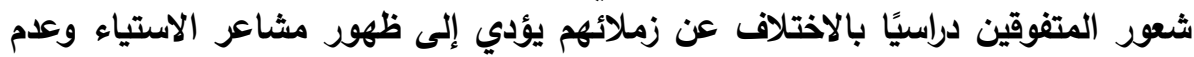

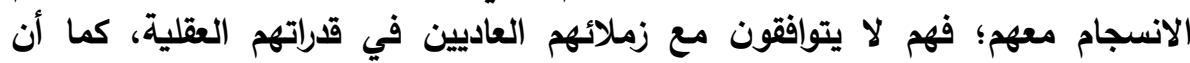

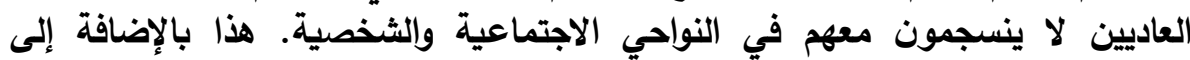

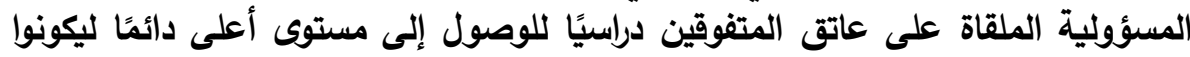

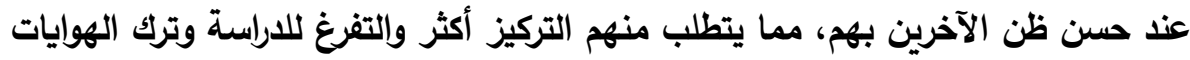

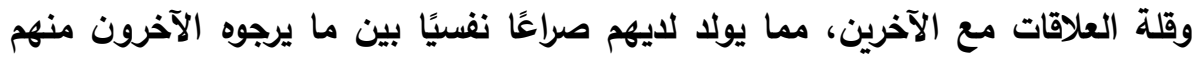

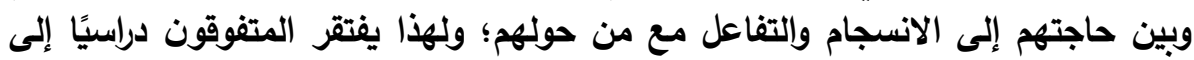
إشباع العديد من الحاجات النفسية.

كذلك تبين من نتائج هذا الفرض وجود أثر للتفاعل بين مستوى النرجسية

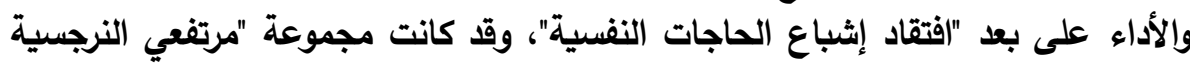

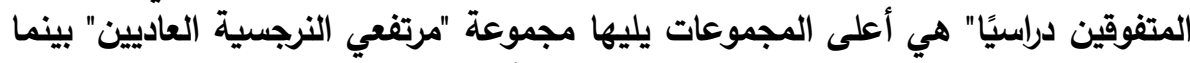

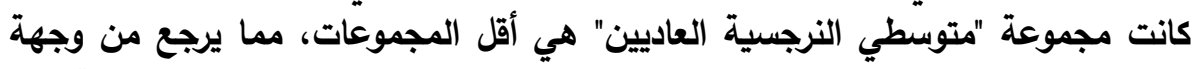

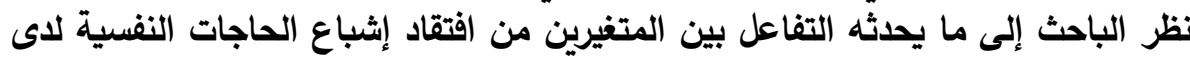

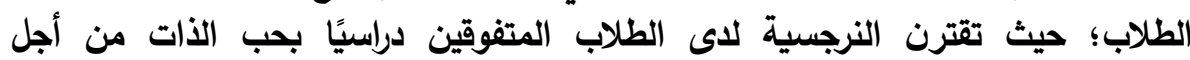

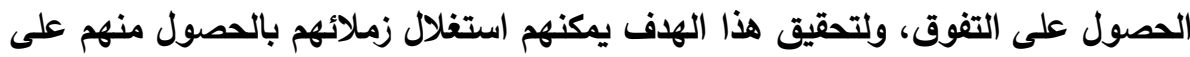

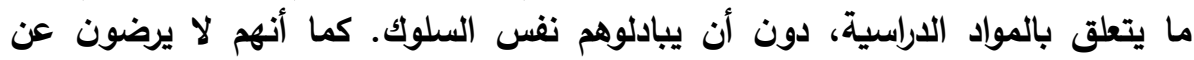

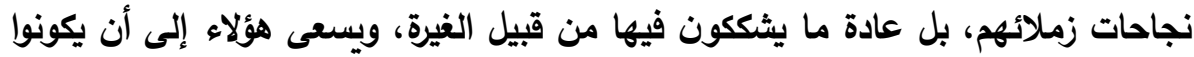

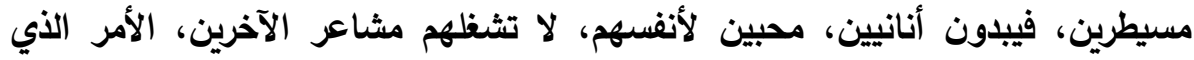

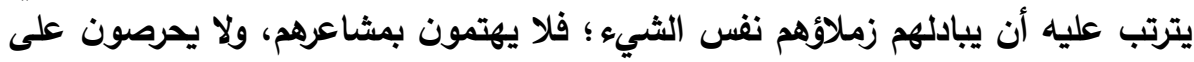

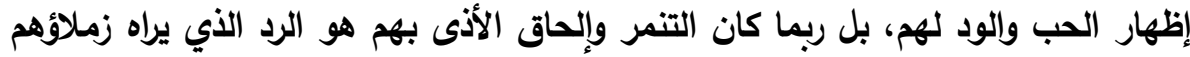

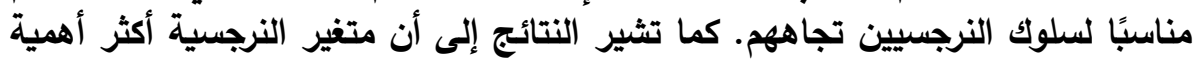

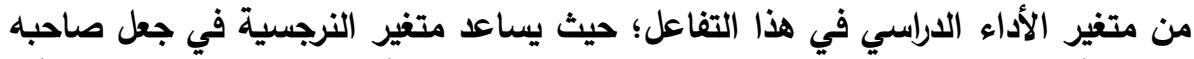

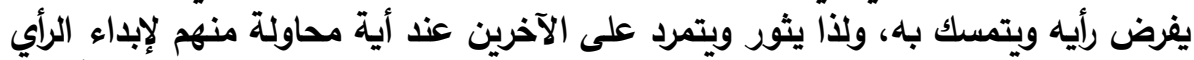

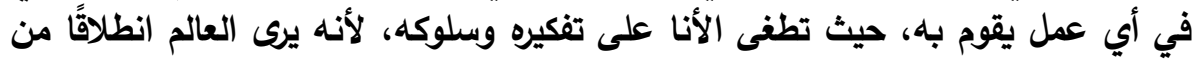

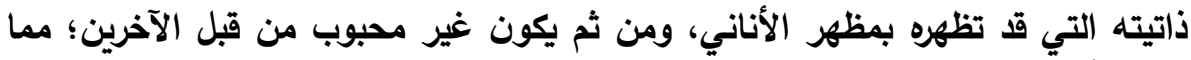

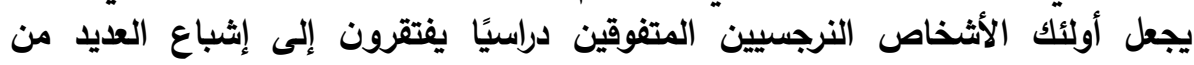

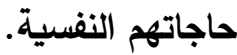




$$
\text { توصيات البحث: }
$$

في ضوء ما أسفر عنه البحث من نتائج يقدم الباحث التوصيات التالية:

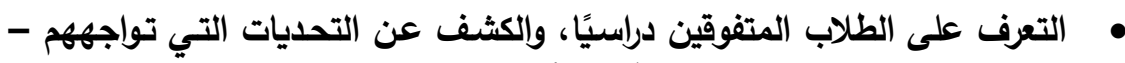

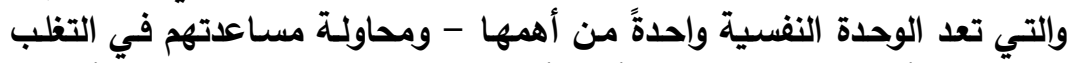

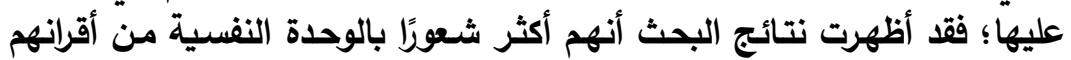

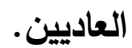

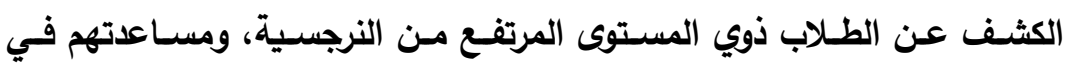

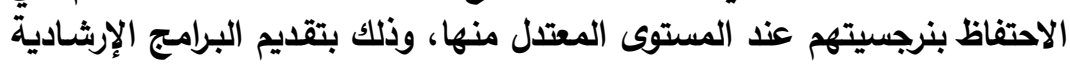

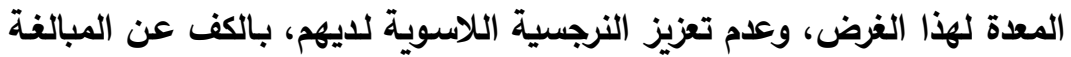

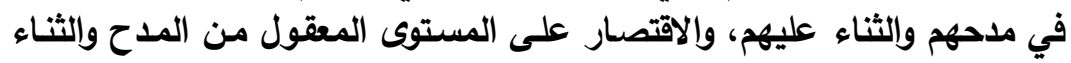

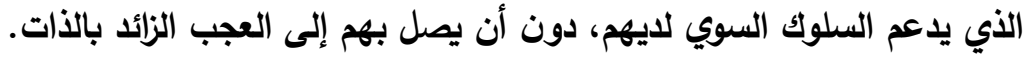

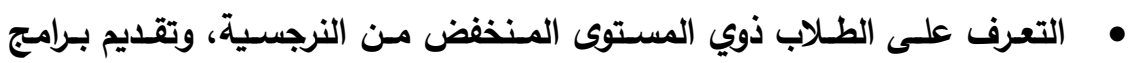

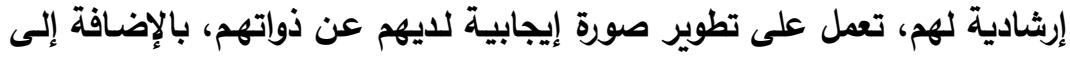

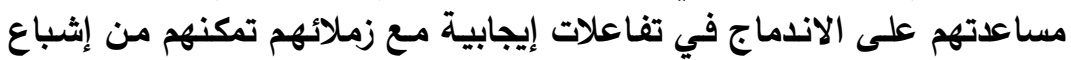
حاجاتهم إلى الحب والصداقة والثاتئة والثقة المتبادلة وغيرها.

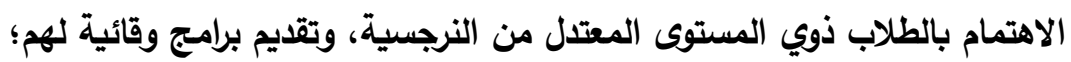

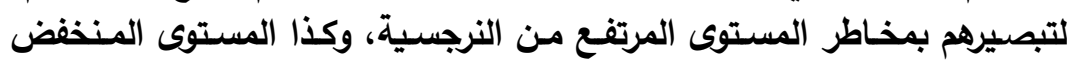

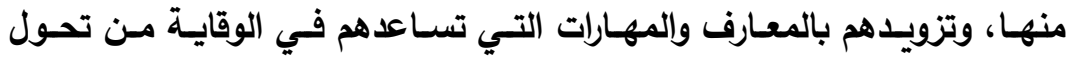

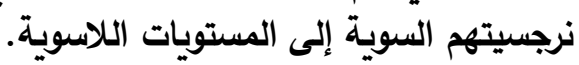

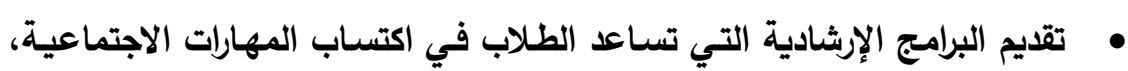

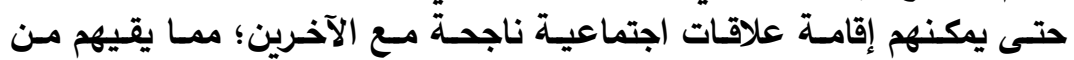
الثعور بالوحدة النفسية.

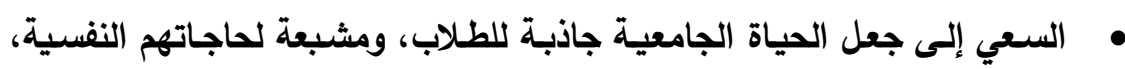
كالحاجِّة إلى الأمن، والحاجة إلى الانتماء ، وغيرها. 
مجلة كلية التربية، جامعة الأزهر ، العدد: (185، الجزء الثالث) يناير لسنة 2020م

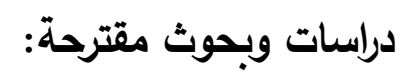

أثارت نتائج البحث الحالي بعض الموضوعات البحثية التي تحتاج إلي مزيد من

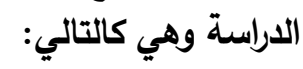

• الوحدة النفسية وعلاقتها بالعوامل الخمس الكبرى للشخصية لاى طلاب الجامعة.

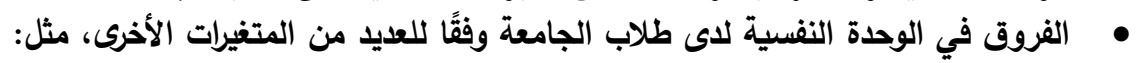
أساليب المعاملة الوالدية، والخلفية الثقافية، وغيرها.

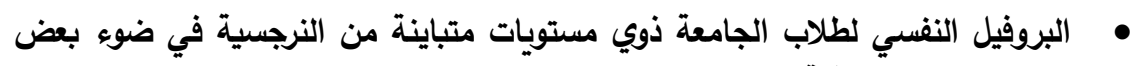
المتفيرات الايموجرافية. هراسة لبعض المتفيرات النفسية المرتبطة بالنرجسية لاى المتفوقين دراسيًا من طلاب كلية التربية بجامعة الأزهر . • برنامج إرشادي لخفض بادية الثعور بالوحدة النفسية لاى المتفوقين دراسيًا من طلاب كلية التربية بجامعة الأزهر. • تعديل النرجسية اللاسوية وأثره على الوحدة النفسية لاى المتفوقين دراسيًا من طلاب كلية التربية بجامعة الأزهر. • عسين بعض المهارات الاجتماعية وأثره على الوحدة النفسية لأى المتفوقين دراسيًا من طلاب كلية التربية بجامعة الأزهر . 


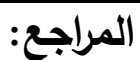

آمال إبراهيم الفقي، سلوى محمد الهوساوي. (2015). النرجسية وعلاقتها بقلق

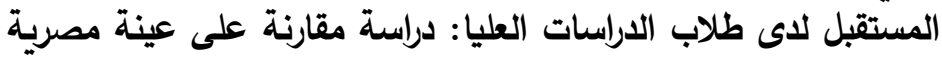
وسعودية. مجلة دراسات تربوية ونفسية، كلية التربية، جامعة الزقازيق،

$$
\text { 100-33 } 33 \text { (106 }
$$

آمال عبد القادرة جودة. (2012). النرجسية وعلاقتها بالعصابية لاى عينة من طلبة العابة جامعة الأقصى. مجلة الجامعة الإسلامية للاراسات التربوية والنفسية النية،

$$
\text { غزة، 20(20)، 540-580. }
$$

أبراهام ماسلو. (2001). التحفيز والشخصية. ترجمة عبد المنعم الزيادي، دمثق: دار الفكر.

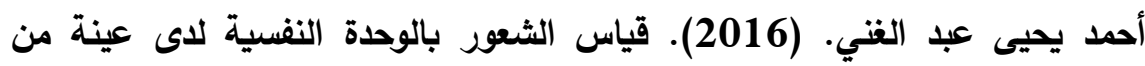

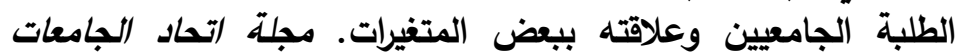

$$
\text { العربية للتربية وعلم النفس، الأردن، 14 (3)، 43-92. }
$$

البرت أليس. (1999). شعور أفضل نفسية أفضل حياة أفضل. ترجمة محمد عثمان نجاتي، القاهرة: مكتبة النهضة المصرية.

الفريد آدلر (2003). الطبيعة البشرية. ترجمة محمود محفوظ، عمان: دار عالم الثقافة للنشر والتوزيع.

أمل إبراهيم الخالدي، كاظم علي الدفاعي. (2017). الثخصية النرجسية وعلاقتها

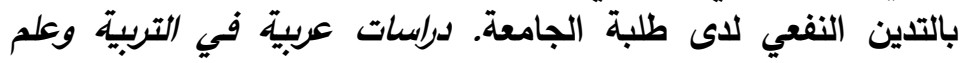

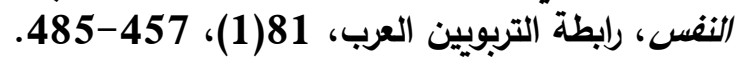

أنس محمد قاسم. (2010). الثعور بالوحدة النفسية لاى الثباب في مرحلة التعليم الجامعي. مجلة العلوم النفسية، مركز الاراسات التزبوية النغية والأبحاث

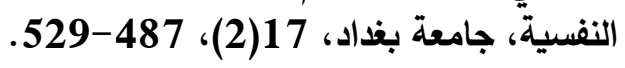

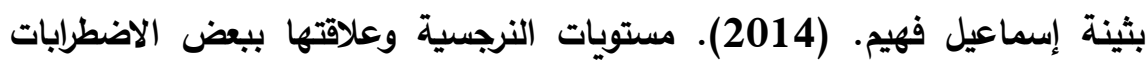
النفسية لاى المرأة العاملة. مجلة العلوم التربيوية والثنفسية، المركز

$$
\text { القومي للبحوث، الأردن، 19(3)، 94 -94-136. }
$$

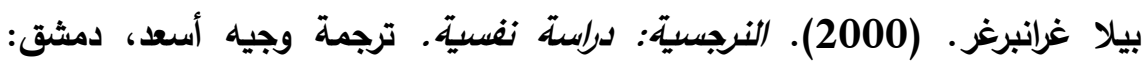
منشورات وزارة الثقافة. 
مجلة كلية التربية، جامعة الأزهر ، العدد: (185، الجزء الثالث) يناير لسنة 2020م

حسين علي فايد. (2004). علم النفس المرضي. القاهرة: مؤسسة حورس الدولية للنشر والتوزيع.

حسين محمد الثماس. (2015). نظريات الشخصية. لبنان: دار الثرق العربي

سيجموند فرويد. (1989). الأنا والثهو. ترجمة ليلى سليمان، القاهرة: دار الراية

للنشر والتوزيع.

سيجموند فرويد. (دت). ما فوق مبلأ اللذة. ترجمة إسحاق رمزي، ط5، القاهرة: دار

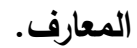

سيد أحمد عجاج. (2016). الفروق بين طلاب الجامعة في الثعور بالرفض

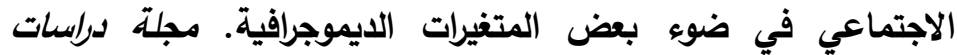

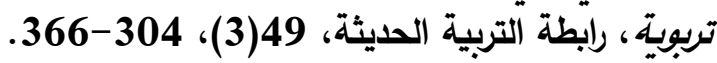

شريف يونس الطحان. (2010). مستوى النرجسية لاى الطلاب الثعراء وعلاقته

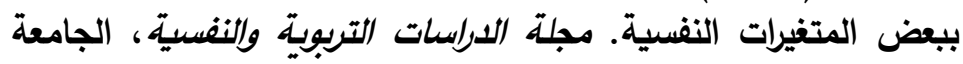

الهاشمية، الأردن، 4(2)، 372-415.

صفية سعد النيال. (1999). التفوق الدراسي: التعديات وسبل المواجهة. الأردن: دار

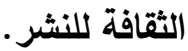

صلاح حسن إسماعيل. (2009). الثخصية النرجسية: خبرات العاضي وإلحاضر ومخاوف المستقبل. بيروت: دار الكتب العلمية.

طلعت لطفي ياسين. (2014). الوحدة النفسية وعلاقتها ببعض المتغيرات النفسية

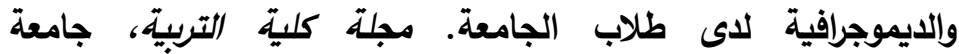

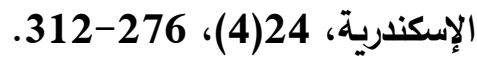

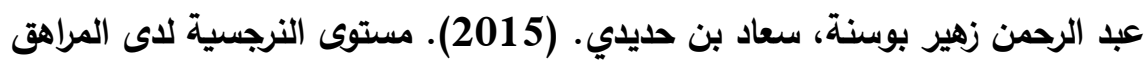
الجزائري المتمدرس: دراسة ميدانية عل عينة من تلاميذ السنة الثانية

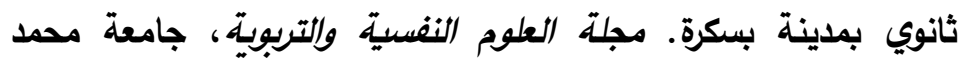

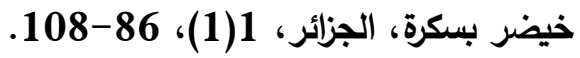

عبد الرقيب أحمد البحيري. (2006). اختبار الشخصية النرجسية. القاهرة: مكتبة النهضة المصرية. 
الوحدة النفسية وفقًا لمستوى النرجسية لاى المتفوقين دراسيًا والعاديين من طلاب كلية التربية بجامعة...

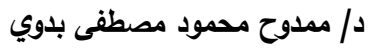

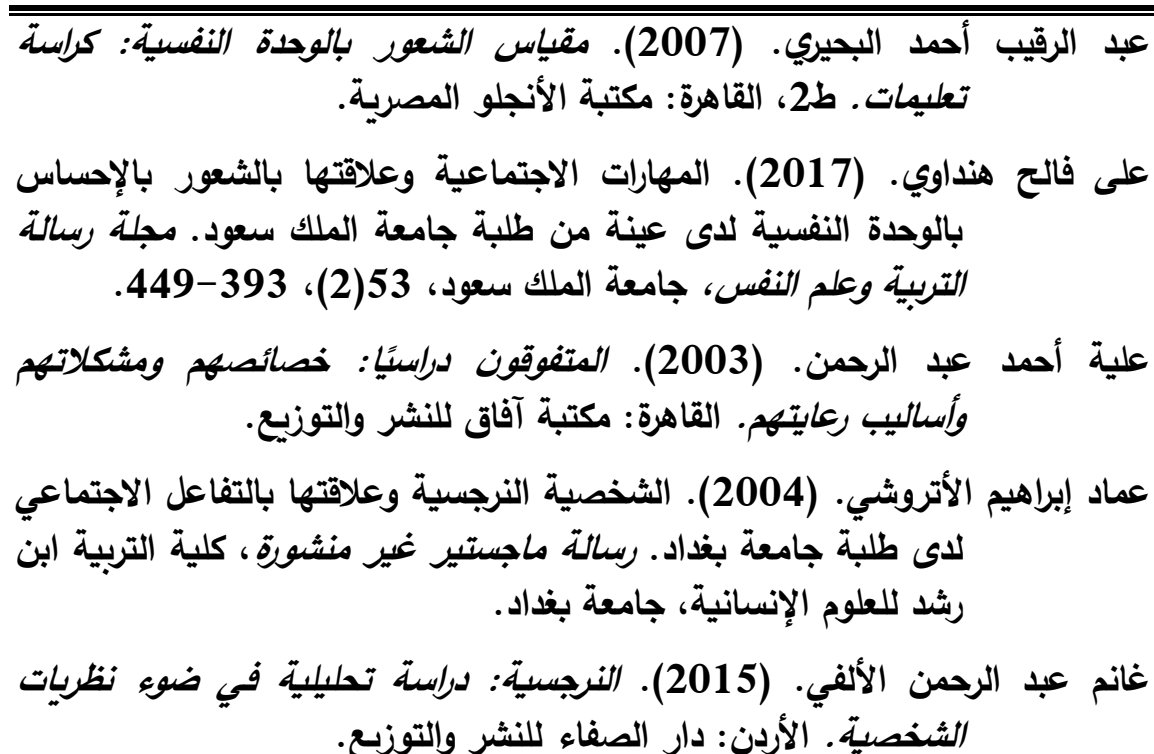

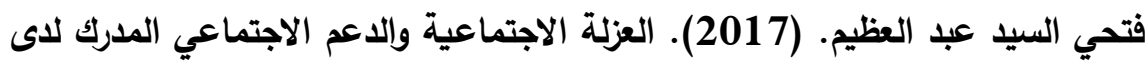

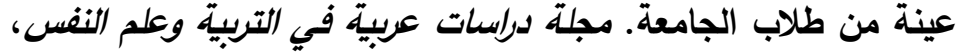

$$
\text { رابطة التربويين العرب، 81(1)، 120-177-120. }
$$

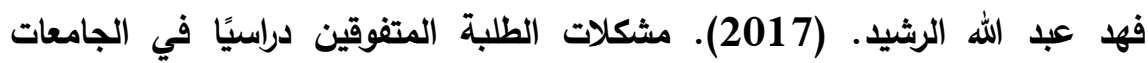

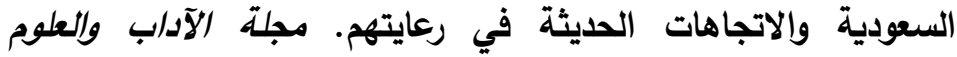
الإنسانية، جامعة الملك عبد العزيز، 23 (4)، 309-347.

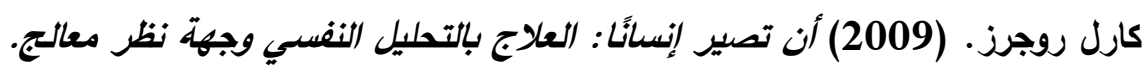
ترجمة أسامة القفاش، القاهرة: دار الحكمة.

ماهر صالح العرجان. (2015). الفائقون دراسيًا والمبدعون: الآمال والتطلعات. عمان: دار الفكر للنشر.

مجدي محمد الاسوقي. (1998). مقياس الشعور بالوحدة النفسية. القاهةة : مكتبة الأنجلو الدصرية.

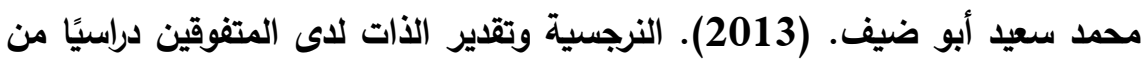

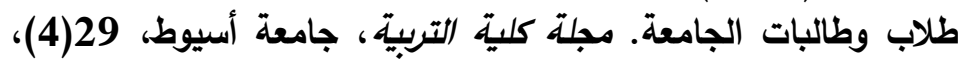


مصطفى محمد فهمي. (2011). الاغتراب النفسي: التشخيص والععلاج. عمان: مركز الفرسان للنشر والتوزيع.

محمد الفاتح أبو النصر . (2010). بعض الأعراض الاكتئابية لاى الثباب الجامعة

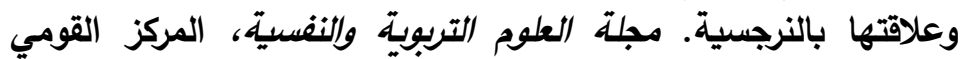
للبحوث بغزة، 22(4)، 378-415.

هبة السيد العربي. (2019). أنماط الثخصية النرجسية وعلاقتها بالتفوق العقلي

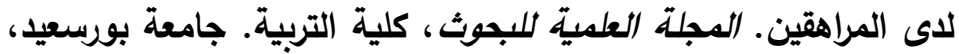

.732-699، (2)25

هشام عبد الرحمن الخولي. (2011). الصحة النفسية نحو حياة أفضل. بنها: دار المصطفى للطباعة والنشر.

هثام محمود غلاب. (2014). النرجسية وعلاقتها بالعدائية لاى طلاب الجامعة.

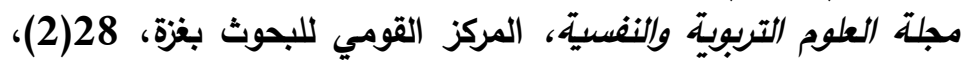

.211-163

ياسر محمود عبد النور. (2018). النرجسية وعلاقتها بالنزعة إلى الكمالية اللاسوية

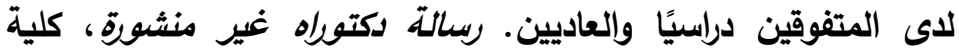

التربية، جامعة المنيا.

Ames, M \& Pratt, M.(2017). Relation between two type of narcissism and loneliness among British college students. Journal of Social Psychology, 76(3), 213-229.

Besser, A. (2010). Loneliness: Its correlates and associations with health risk behaviours among universitv students in 25 countries. Psvchonomic Bulletin \& Annual Review, 23(2), 95-111.

Bettencourt, A; Talley, A \& Benjamin, A. (2006). Personality and aggressiv behavior under provoking and neutral condition: Ameta-analytic review. Psychological Bulletin, 123(5), 751-777.

Bushman, B; Bonacci, A \& Baumeister, R. (2003). Narcissism, sexual refusal and aggression: Testing a narcissistic reactance model of sexual coercion. Journal of Personality and Social Psychology, 84(5), 1027-1040. 
الوحدة النفسية وفقًا لمستوى النرجسية لاى المتفوقين دراسيًا والعاديين من طلاب كلية التربية بجامعة...

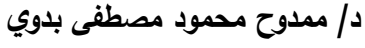

Cacioppo, J. (2017). Telling narcissists about their narcissism: Effects of providing feedback on emotional reactivity and psychological symptoms. Educational Psychologist, 56(3), 331-356.

Charlebois, K. (2018). Who are lonely? Loneliness in different age groups (18-81 years old), using two measures of loneliness. The Journal of Special Education, 53(4), 5179.

Collip D. (2013). Aggressivity, narcissism, and social relationship disorder among university students. Journal of Educational Research, 28(3), 4-19.

Danese, A \& Caspi, A. (1999). Narcissism and intrinsic motivation: The role of goal congruence. New York: Plenum Press.

Derosa, T. (2008). Evaluation of the factors affecting loneliness and hopelessness among university students in Turkey. Turkish Journal of Rehabilitation, 34, 511-540.

Dunn,G. \& Wayment, H. (2016). Loneliness: As a problem among high achievers students. Journal of Learning Disabilities, 61(2), 113-138.

Ferguson, A. \& Rodway, M. (2012). Loneliness, common mental disorders and suicidal behavior: Results from a general survey of university students. Journal of Experimental Psychology, 49 (5), 156-181.

Fichter, M \& Kaplan, A. (2011). Who are the narcissists? Investigate the relationship between narcissism, aggression, self-perception, and loneliness. Journal of Cross-Cultural Psychology, 43(2) 21-44.

Girgin, G. (2011). Anxiety and maladaptive narcissism symptoms among high achievers students in three educational settings. International Journal of Psychology, 105(2), 84-109.

Goldstein, S. (2017). How to recognize a narcissist?. New Jersey: Prentice- Hall.

Hawkley, L.(2011). Multidimensional narcissism and success or failure in social roles. ( $2^{\text {nd }}$ ed), Boston: Allyn \& Bacon.

Jacobs, N. (2019). The influence of pathological narcissism on loneliness and emotional responses to negative events: The roles of visibility and concern about humiliation among college students. Journal of Applied Sciences Research, 32(3), 411-432. 
Junger, C. (2011). Assessing hypersensitive narcissism: A reexamination of Murray's narcissism scale. Journal Advances in Psychology, 14(2), 1-17.

Kenneth, G. \& Eric, A. (2015). A cross-cultural study into loneliness amongst university students. International Journal of Educational Research, 5(2), 19-33.

Kroenke, K \& Spitzer, R. (2018). Narcissism characteristics of high achievers students. Journal of Personality and Psychology, 87(4), 709-733.

Ladd, G \& Ettekal, I. (2016). Narcissism and creative thinking: A survey of Sydney University students. Educational Psychology Review, 28(1), 183-196.

Ladouceur, R. \& Freeston, M. (2016). Loneliness and abnormal behavior among university students. Journal of Psychopathology, 72(3), 17-36.

Lakshmi, P. (2017). Loneliness at universities: Determinants of emotional and social loneliness among students. Educational Psychologist, 56(5), 325-339.

Mansi, J. \& Paulomi, S. (2016). The relationship between social adjustment and loneliness among university students. International Journal of Educational Research, 6(3), 6785.

Mobley, M; Trippi, J \& Ashby, J. (2010). Loneliness and psychological distress among high-achieving university students. Journal Advances in Psychology, 13(3) 46-62.

Nguyon, $\mathbf{N} \&$ Mitchelson, R. (2018). Academic achievement, social support and loneliness among college students. Journal of Personality and Psychology, 87(2), 804-831.

Nicolaisen, F. (2014) Narcissism, Perfectionism and Self-Esteem: Relationships with Talent for University Students. General Psychology, 58(3),17-41.

Nielsen, L \& Due, P. (2010). Parents and their narcissistic children. New York: Routledge.

Peeters, F \& Thisted. R (2019). Self-knowledge and narcissism among Iranian university students: Relationships with empathy and loneliness. Psychiatric Disorders, 102(4), 885-911. 
الوحدة النفسية وفقًا لمستوى النرجسية لاى المتفوقين دراسيًا والعاديين من طلاب كلية التربية بجامعة...

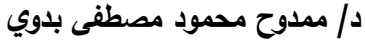

Pitkala, S. (2019). The intergenerational transmission of narcissism: Parents psychological control as intervening variable. Journal of Applied Sciences Research, 32(2), 178-206.

Porter, D. (2015). The relationship between loneliness and academic achievement for university students. International Journal of Educational Research, 5(3), 328-343.

Robins, H; Beesley, D. \& Mendozan, J. (2015). loneliness and psychosomatic symptoms: a study for Monash University students. Journal of Psychopathology, 71(4), 482-498.

Roll, T. \& Arthur, N. (2019). Study problems, lack of social skills, and loneliness among university students. Journal of Personality and Psychology, 88(2), 509-528.

Savikko, N. (2015). Relation of narcissism and self-Estee to conduct problems amongst university students. Educational Psychology Review, 27(5), 454-472.

Sherry, S; Collins, L \& Flynn, Y. (2015). Loneliness, self-esteem, and life satisfaction as predictors of internet addiction: A cross-sectional study among Korean university students. General Psychology, 59(1), 23-47.

Stephan, L. (2016). Sounds like a narcissist: Behavioral manifestations of narcissism in high-achieving university students. Educational Psychologist, 55(2), 289-306.

Talepasand, S \& Rezaei, A. (2014). Narcissism and academic achievement for university students. Journal of Existential Psychology \& Psychotherapy, 13(2), 29-41.

Thiery, N \& Derom, K. (2015). The mistakes of parents in education their children. ( $2^{\text {nd }}$ ed), San Diego: Academic Press.

White, K. \& Lehman, D. (2013). Social and emotional loneliness and self-reported difficulty initiating and maintaining sleep (dims) in a sample of Norwegian university students. Journal of Educational Research, 28(5), 570-588.

Wichers, M \& Rezaei, A. (2015). Narcissism and its relationship to social acceptance and rejection for high school students. Journal of Psychopathology, 71(2), 1012-1026. 
Wintre M. (2013). Facets of the self in grandiose and vulnerable narcissism, implicit self-esteem and explicit self-esteem. Journal of Existential Psychology \& Psychotherapy, 12(4), 521-539.

Zigler, E \& Goldstein, D. (2011). Loneliness among students at universities: The experience of emotional and social isolation. Journal of Cross-Cultural Psychology, 43(4), 640-667. 